DEFECTS IN METAL CRYSTALS

\author{
Progress Report \\ for the period May 1, 1980 to April 30, 1981
}

David N. Seidman

Cornell University Ithaca, New York 14853

Thered This bonk was prepared as an account of work sponsoncy thereot, nor any of their tminloysees, mokos any Neither the United States Government nor any agency thereol, nor any completeness, or usefulness of any information, apparatus, product. or process disclosed, or represents that its use would not infringe privately owned rights. Reference herein to any specitic commercial product, process, or service by trade name, trademark, manufacturer, or otherwise, Uoes not necessarily constitute or imply its endorsement, recommendation, or tavoring by the Unthes States Government or any agency thereof. The views and opinions of authors expressy

January 1981

Prepared for

THE U.S. DEPARTMENT OF ENERGY UHDER CONTRACT NO. DE-ACO2-76ER03158 


\section{DISCLAIMER}

This report was prepared as an account of work sponsored by an agency of the United States Government. Neither the United States Government nor any agency Thereof, nor any of their employees, makes any warranty, express or implied, or assumes any legal liability or responsibility for the accuracy, completeness, or usefulness of any information, apparatus, product, or process disclosed, or represents that its use would not infringe privately owned rights. Reference herein to any specific commercial product, process, or service by trade name, trademark, manufacturer, or otherwise does not necessarily constitute or imply its endorsement, recommendation, or favoring by the United States Government or any agency thereof. The views and opinions of authors expressed herein do not necessarily state or reflect those of the United States Government or any agency thereof. 


\section{DISCLAIMER}

Portions of this document may be illegible in electronic image products. Images are produced from the best available original document. 


\title{
DEFECTS IN METAL CRYSTALS
}

David N. Seidman

Cornell University

Ithaca, New York 14853

\begin{abstract}
During the past year a strong endeavor was made to redirect the efforts of the research group to determine atomic mechanism(s) for the formation of metal silicides, among other problems, produced as a result of: (a) ion or electron irradiation of metal-silicon sandwiches; and $(b)$ the ion irradiation of subsaturated binary alloys containing silicon. The formation of metal silicides produced as a result of irradiating thin metal-silicon sandwiches has many problems . in common with the radiation induced precipitation (RIP) of metal.silicides from subsaturated binary alloys. Thus, the study of both of these problems simultaneously complement and supplement one another. In addition, an appreciable component of the research is aimed at understanding the atomic mechanisms responsible for radiation-induced segregation and RIP in a wide range of fastneutron irradiated refractory metals and alloys. In these same neutron irradiated specimens a search is being made for the species that are responsible for the nucleation of voids. In particular, the voids are being examined, by the atomprobe field-ion microscope technique, for the interstitial impurities helium, carbon, nitrogen and oxygen. Evidence was obtained for the presence of carbon in a void of a fast neutron-irradiated molybdenum (titanium) alloy. Toward the goal of understanding the atomic mechanism(s) of the formation of metal silicides in ion or electron-irradiated metal-silicon sandwiches we are: (a) determining the optimal conditions for imaging, via field-ion microscopy, intrinsic silicon whiskers; and (b) growing whiskers of silicon to given high dopant levels, by the vapor-liquid-solid technique, to examine the effect(s) of the dopant level on the stability and quality of the FIM images. Heavy. use was made of the high resolution field-ion microscope, the atom-probe field-ion microscope for analytical chemistry on an angstrom scale, and a $60 \mathrm{keV}$ ion accelerator system.
\end{abstract}

Progress was made in the following areas:

A. A Study of the Chemistry of the \{1ll\} GaP Planes by Atom-Probe Field-Ion Microscopy (Dr. M. Yamamoto and Dr. S. Nakamurá)

1. Introduction

2. Experimental Details and Procedure

3. Results

4. Discussion 
B. The Determination of the Composition of Ordered $\mathrm{Pt}_{3} \mathrm{Co}$ by Atom-Probe Field-Ion Microscopy (Dr. M. Yamamoto)

1. Introduction

2. Experimental Details and Procedure

3. Results

4. Discussion

C. An Atom-Probe Field-Ion Microscope Study of the Stoichiometry of Ordered $\mathrm{Ni}_{4}$ Mo (Dr. M. Yamamoto)

1. Introduction

2. Experimental Details and Procedures

3. Results

4. Discussion

D. Direct Experimental Determination of the Particle Reflestinn Sovfficicnt of Low-Energy ${ }^{3}$ He and ${ }^{4}$ He Atoms from the (110) Plane of Tungsten (.T. Amano)

1. Introduction

2. Experimental Background and Procedure

3. Theory

4. Results and Discussion

E. Segregation of Solute Atoms to Voids in Fast-Neutron Irradiated Refractory Metals and Alloys (D. Seidman and H. Morikawa)

1. Introduction

2. A Drief Revilew or our Previous Work in this Area

3. An Example of Evidence for the Segregation of Carbon to a Void

4. Discussion

5. Current Renrareh Activilles and objectives

F. Growth of Silicon and III-V Compound Semiconducting Whiskers for the Study of Metal-semiconductor and Insulator-Semiconductor Interfaces (J.C. Barbour, B. Reding and B. Moser)

1. Introduction

2. Background

2.1. Nucleation

2.2. D13location Theory

2.3. Vapor-Liquid-Solid (VLS) Theory

2.4. Requirements for a Vapor-Liquid-Solid Growth Mechanism

2.5. Explanation of Shorteomings in Dislocation Theory

3. Experimental Work

3.1. Work in Progress

3.2. Design Considerations

3.3. Equipment

3.4. Substrate and Gold Preparation 
4. Scope of Activities

G. Field-Ion Microscope Imaging of Silicon (B. Moser, J.C. Barbour and B. Reding)

1. Introduction

2. Specimen Preparation

3. Experimental Techniques and Results

4. Discussion

H. Direct Observation of the Primary State of Damage in Ion-Irradiated Platinum and Tungsten (D. Pramanik)

1. Overali Summary

2. Nonlinear Effects in Irradiated Tungsten

3. Depleted Zones

3.1. $20 \mathrm{keV}$ Ion Irradiations

3.2. Results for $40 \mathrm{keV}$ Dimers

3.3. Comparison of monomer and dimer irradiations

I. Seminars and Meetings

Key Phrases and Words: Chemistry of the \{1ll\} planes of GaP on an atomic scale; determination of the chemistry of ordered $\mathrm{Pt}_{3} \mathrm{Co}$ on angstrom scale; the stoichiometry of $\mathrm{Ni}_{4}$ Mo on an atomic scale; particle reflection coefficients of 100 to $1500 \mathrm{eV}^{3} \mathrm{He}$ and 4 He atoms from the (110) plane of tungsten; segregation of solute atoms to voids in fast-neutron-irradiated refractory metals and alloys; heterogeneous nucleation of voids at interstitial impurity atoms; vapor-liquid-solid growth of doped silicon and III-V compound semiconducting whiskers; metal-semiconductor and insulatorsemiconductor interfaces; field-ion microscopy of silicon; primary state of damage of ion-irradiated platinum and tungsten; depleted zones; nonlinear effects in the production of alsplacement cascades produced by heavy dimers; metal or silicides; field-ion microscopy; atom-probe field-ion microscopy. 


\section{INTRODUCTION}

During the past year several projects were completed and significant progress was made in other areas. In addition, a major effort was initiated to redirect the research program towards problems related to the chemistry of metal-semiconductor interfaces on the angstrom scale, the effects of particle irradiation on the formation of metal silicides and radiation induced segregation effects in neutron irradiated metals and alloys. These new research programs will be discussed in detail in the research renewal proposal. A brief account of the work is given in section II. The following personnel were involved:

Professor D.N. Seidman, Principal Investigator

Dr. M. Current, Research Associate (left June 1980 to take a position as a staff scientist, Signetics Corporation, Sunnyrale, California).

Dr. G. Kimmel, Postdoctoral Associate (left August 1980 to return to his position with the Israel Nuclear Research Centre, Dimona, Israel).

Dr. A. Macrander, Postdoctoral Associate (left July 1980 to take a position as a staff scientist, Bell Laboratories, Murray Hil.l, New Jersey).

Dr. H. Morikawa, Postdoctoral Associate (joined October 1980). Dr. M. Yamamoto, Postdoctoral Associate (left May 1980 to return to his position at Osaka University, Osaka, Japan).

J.C. Barbour, Research Assistant (joined June 1980).

S.-H. Chen, Research Assistant (joined August 1980).

B. Moser, Research Assistant (joined September 1979).

D. Pramanik, Research Assistant (completed Ph.D. degree and left

Sept ember 1980 to join Signetics Corporation, Sunnyvale, California).

J. Givot, Half-time film scanner (joined January 1980).

R. Whitmarsh, Technician (joined January 1968)

D. Mancini, Undergraduate Assistant (joined June 1980).

B. Reding, Undergraduate Assistant (joined June 1980). 
II. EXPERIMENTAL WORK

A. A STUDY OF THE CHEMISTRY OF THE \{111\} GaP PLANES BY ATOM-PROBE FIELD-ION MICROSCOPY (Dr. M. Yamamoto, Dr. S. Nakamura ${ }^{*}$ )

\section{INTRODUCTION}

Atom-probe field-ion microscope (FIM) -- hereinafter called an atom probe -analyses were performed on specimens of the compound semiconductor GaP. The purposes of the investigation were to show the step-like field-evaporation behavior -- corresponding to each atomic layer of the $\{111\}$ planes -- and to determine the chemistry of each plane of atoms. These types of information are of great potential value for the study of a wide range of physical problems involving compound semiconductors. Our studies showed that the chemistry of each \{1II\} plane could indeed be determined and that small deviations from stoichiometry within a given plane were also measurable. The overall stoichiometry of GaP was found to be related to the background gas hydrogen and the number of ions field-evaporated per pulse. The observations were explained in terms of possible field-evaporation mechanisms involving the main background gas in the FIM -- hydrogen.

2. EXPERIMENTAL DETAILS AND PROCEDURE

The GaP specimen was prepared by chemically polishing a whisker which had been grown by the technique described by Ohno et al. (I) Next the specimen was imaged in our atom-probe $(2,3)$ and developed to an end form in pure $\mathrm{H}_{2}$ gas ( $\mathrm{N}_{10}{ }^{-6}$ Torr gauge pressure) at $78 \mathrm{~K}$ to obtain a clear image. It was then analyzed at $2300 \mathrm{~K}$ simply because the field evaporation process was easier at this temperature. The background pressure during the analysis was $4 \times 10^{-9}$ Torr; this pressure was mainly due to hydrogen. With this partial pressure of hydrogen in the background the pulse field-evaporation of GaP, during analysis, was easy. The planes examined were the $\{111\}$ planes. The pulse fraction ( $f$ ) was 0.15 ; the quantity $f$ was given by the ratio of the pulse voltage $\left(v_{\text {pulse }}\right)$ to the steady-state voltage $\left(\mathrm{V}_{\mathrm{dc}}\right)$. The pulse frequency was constant at $60 \mathrm{~Hz}$. The procedure used to determine the distribution of $\mathrm{Ga}$ and $\mathrm{P}$ atoms as a function of depth was similar to the one described previously in a study of implanted ${ }^{3} \mathrm{He}$ and ${ }^{4} \mathrm{He}$ in tungsten. $(4,5)$

3. RESULTS

The mass spectrum of the GaP specimen -- in the $\{111\}$ planes -- consisted of essentially $\mathrm{P}^{+1}$ and $\mathrm{Ga}^{+1}$ ions and complexes of these ions, for the case when the quantity $\mathrm{N}_{\text {ion }} / \mathbb{N}_{\text {pulse }}$ was 0.01 ; where $\mathrm{N}_{\text {ion }}$ was the total number of ions detected for a given number of pulses ( $N_{\text {pulse }}$ ). The spectrum for $\mathrm{N}_{\text {ion }} / \mathrm{N}_{\text {pulse }}>0.02$ was considerably more complicated and we have discussed it in a more extensive paper. ( 6 )

Short term visitor (unpaid) from the University of Osaka, Osaka, Japan. 
Figure 1: The pulse field-evaporation behavior of the (III) plane, giving the cumulative number of $\mathrm{Ga}$ plus $\mathrm{P}$ atoms versus the cumulative number of field-evaporation pulses. The pulse frequency was constant at $60 \mathrm{~Hz}$. 


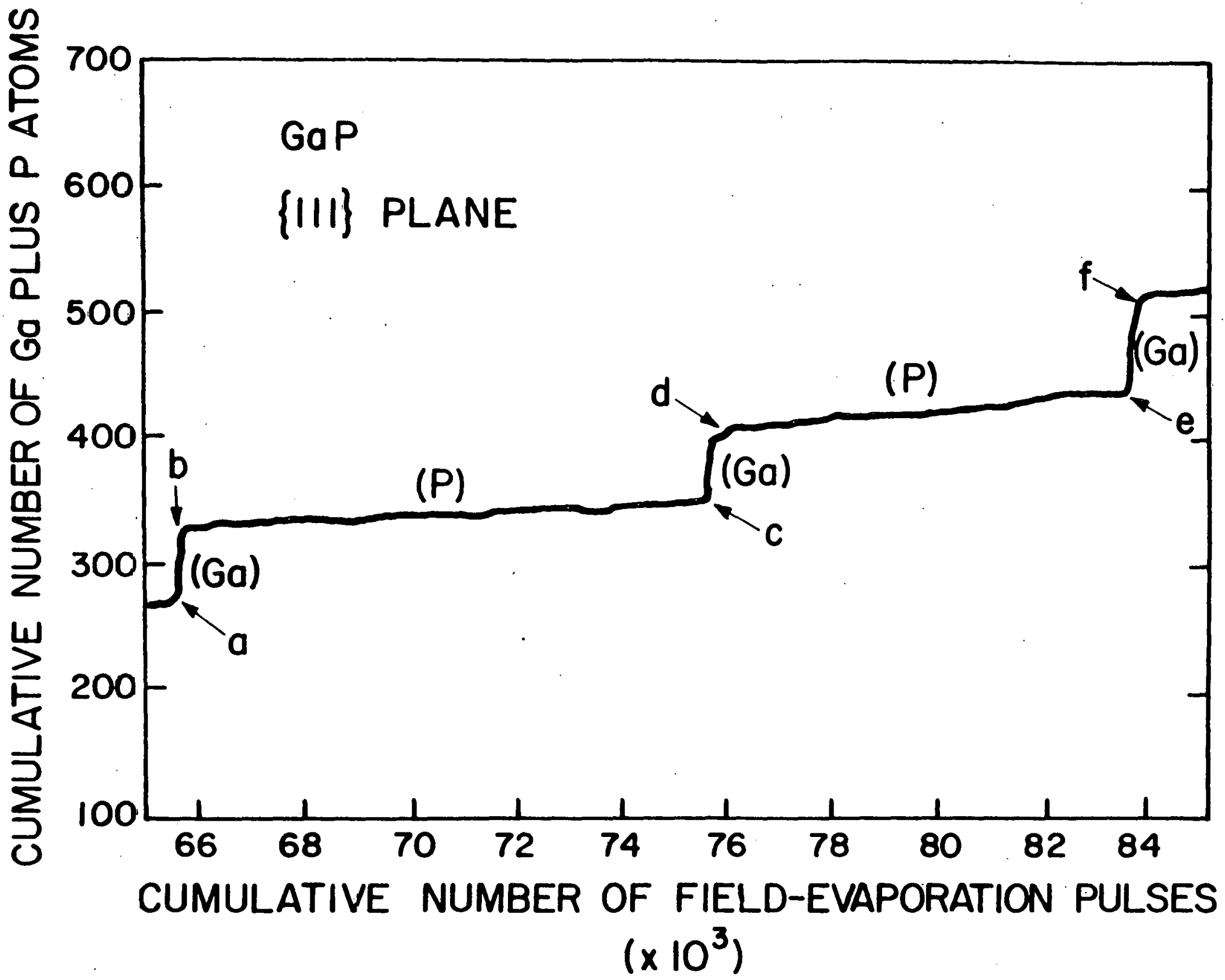


Figure $I$ is a plot of the cumulative number of $\mathrm{Ga}$ plus $P$ atoms as a function of the cumulative number of field evaporation pulses for the $\{111\}$ plane. The abscissa is proportional to the time that elapsed during the field evaporation process, therefore the slope of this curve is proportional to the field-evaporation rate. Thus, this figure shows that the field-evaporation rate of the Ga atoms-from the $\{111\}$ plane -- was greater than this same quantity for the $P$ atoms. It is also clear from fig. I that the field-evaporation behavior was step-like in nature. This step-like behavior is consistent with the zinc-blende type structure of GaP; that is, for stoichiometric GaP the chemistry is such that one $\{111\}$ plane should consist wholly of $\mathrm{P}$ atoms and the following \{111\} plane should consist only of $\mathrm{Ga}$ atoms. This chemical behavior of the $\{111\}$ planes repeats itself periodically throughout the crystal lattice.

Figure 2 is a plot of the number of $P$ atoms versus the number of Ga atoms for the data exhibited in fig. 1. The region $a-b$ in fig. 2 corresponds to the region $a-b$ in fig. 1 ; the region $b-c$ in fig. 2 corresponds to region $b-c$ in fig. 1 , etcetera. For the data shown in fig. 2 the ratio of $G a$ to $P$ atoms, from one \{1II\} layer to the next $\{111\}$ layer, was approximately equal to two to three. The expected value of this ratio was unity because of the required stiochiometry of the \{1ll\} planes of the zinc-blende type structure. In other data ${ }^{(6)}$ we have found that the ratio of $\mathrm{Ga}$ to $P$ atoms varied between unity and very large numbers depending on the measured value of the parameter $\mathbb{N}_{\text {ion }} / \mathbb{N}_{\text {pulse }}$.

Figure 3 is a plot of the frequency of occurrence of atoms as a function of the number of atoms detected per field evaporation event; the upper value to the latter quantity was eight since our digital timer has eight channels. ( 7 ) The value of the quantity $N_{\text {ion }} / N_{\text {pulse }}$ for the data in figs. $3 a$ and $3 b$ was 0.01 and greater than 0.02 , respectively. For $N_{i o n} / N_{\text {pulse }}$ equal to 0.01 the frequency of occurrence of atoms decreased rapidiy as a function of the number of atoms detected per field evaporation event. When the ratio $\mathrm{N}_{\text {ion }} / \mathrm{N}_{\text {pulse }}$ exceeded 0.02 the frequency of occurrence was approximately a constant for one to eight atoms detected per field-evaporation event. This implied that for $\mathbb{N}_{\text {ion }} / \mathbb{N}_{\text {pulse }}>0.02$ a large number of fieldevaporated ions were most likely undetected. Thus many of the heavier -- and therefore slower moving -- Ga ions were undetected.

4. DISCUSSION

In this section a qualitative discussion of possible mechanisms to explain the results presented in figs. 1 to 3 is given; further discussion is given elsewhere. (

The fact that the field-evaporation rate of gallium was greater than the fieldevaporation rate of phosphorous -- see fig. I -- was explained on the basis of a simple bond-cuunling argument. An examination of a crystal model of GaP showed that -- 
Figure 2: The cumulative number of $P$ atoms versus the cumulative number nf Ga atoms for the compound semiconductor GaF. 'Ihis data was plotted from the data exhibited in fig. 1. The regions $a-b, b-c$, etc., correspond to these same regions in fig. 1 . 


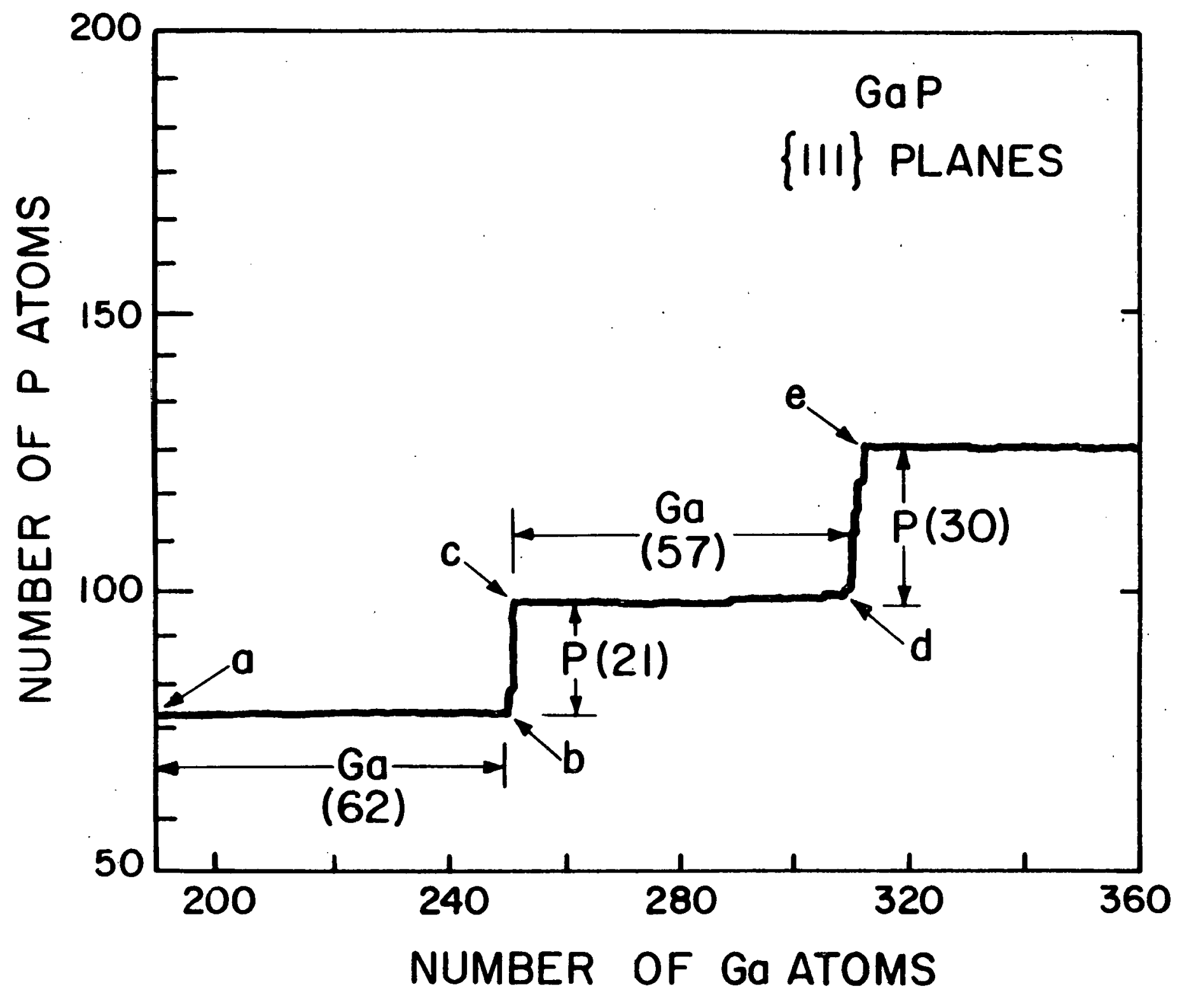


for a lattice viewed along the [īi]] direction -- the first layer (Ga atoms.) is, separated from the second layer ( $P$ atoms) by a $3 a_{0} / 4$, where $a_{0}$ is the lattice parameter of GaP. Each $\mathrm{Ga}$ atom in the first layer has only one first nearest-neighbor atom -- a $P$ atom -- in the second layer. While the second layer ( $P$ atoms) is separated from the third layer (Ga atoms) by $a_{0} / 4$, and the $P$ atoms in the second layer have three first nearest-neighbor Ga atoms in the third layer. Thus the bonding of a $\mathrm{Ga}$ atom in the first layer to a $\mathrm{P}$ atom in the second layer is weaker than the bonding of a $P$ atom in the second layer to the three $G a$ atoms in the third layer. This weaker bonding implies that the activation energy for field evaporation of $\mathrm{Ga}$ is less than that of $P$ and, therefore, the field-evaporation rate of $\mathrm{Ga}$ is greater than that of $P$. The above argument was based on the fact that we viewed the crystal along the [III] direction and hence considered the (III) planes. This is important because GaP is a noncentrosymmetric crystal structure; that is, it does not have inversion symmetry. When a crystal model of GaP was viewed along the [III] direction the details and conclusions of the above argument were exactly reversed. Thus, we concluded that our FIM specimen had been mounted such that [III] direction was pointing towards the viewing screen.

The data exhibited in fig. 2 show very clearly the chemistry of five different (III) layers; note that the chemistry alternated from $\mathrm{Ga}$ to $\mathrm{P}$ to $\mathrm{Ga}$, etcetera. Since the size of the probe hole and tip-to-probe hole distance were constant during the course of the analysis the number of $\mathrm{Ga}$ atoms detected per (III) plane should have been equal to the number of $\mathrm{P}$ atoms detected in the subsequent (III) plane. The fact that this was not the case can be understood on the basis of the following possible mechanisms: ( 1 ) selective field evaporation of $\mathrm{P}^{+\mathrm{n}}$ or $(\mathrm{PH})^{\mathrm{tn}}$ ions by the steadystate voltage $\left(\mathrm{V}_{\mathrm{dc}}\right)$; and $(2)$ the pulse field-evaporation of the complexes (PH) ${ }^{+n}$ and/or $(\mathrm{GaP})^{+n}$ followed by the immediate dissociation of these complexes into charged and uncharged species. In a paper on composition measurements for the alloy $\mathrm{Pt}_{3} \mathrm{Co}^{(8)}$ we have considered seven other mechanisms that could have caused an erroneous composition measurement; in a more extensive version of this paper ${ }^{(\delta)}$ we show that these seven mechanisms were not capabie of explaining the observed deficiency of $P$ atoms.

Mechanism (I) represents a straightforward explanation of the missing $P$ atoms. It should be noted that since the specimen was analyzed in the presence of a partial pressure of hydrogen $\left(<4 \times 10^{-5}\right.$ Torr) the formation of $(\mathrm{PH})^{\text {th }}$ was possible. At this pressure of hydrogen the surface of the specimen field evaporated very slowly at the value of $V_{d c}$ corresponding to $f=0.15$, thus we could not rule out -- in this experiment -- completely the formation of $(\mathrm{PH})^{+\mathrm{n}}$.

Mechanism (2) suggested the following four reactions:

$$
\begin{aligned}
& (\mathrm{PH})^{+n} \rightarrow \mathrm{P}+\mathrm{H}^{+n} ; \\
& (\mathrm{PH})^{+\mathrm{n}} \rightarrow \mathrm{p}^{+\mathrm{n}}+\mathrm{H} ; \\
& (\mathrm{GaP})^{+n} \mathrm{Ga}^{+\mathrm{n}}+\mathrm{P} ; \\
& (\mathrm{GaP})^{+\mathrm{n}} \rightarrow \mathrm{Ga}+\mathrm{P}^{+\mathrm{n}} ;
\end{aligned}
$$

and 
Reactions (I) and ( 3 ) would have produced a deficiency of $P$ atoms, reaction (4) a deficiency of $\mathrm{Ga}$ atoms and reaction (2) would have had no effect on the number of $P$ atoms detected. Thus reactions ( 1 ) and (3) may have contributed to the observed deficiency of $\mathrm{P}$ atoms in the (III) planes. We note that the single bond energies of $\mathrm{P}-\mathrm{H}$ and $\mathrm{Ga}-\mathrm{P}$ are $3.3^{(9)}$ and $0.25 \mathrm{eV}^{(10)}$, respectively. The smaller value of the single bond energy of $\mathrm{GaP}$ indicated that reaction (3) may have been more probable than either reaction (I) or (2). However, whether or not the dissociation actually took place depends on the details of the interatomic potential curves in the presence of the high local electric field near the $(\mathrm{PH})^{+\mathrm{n}}$ or $(\mathrm{GaP})^{+\mathrm{n}}$ molecules.

The data presented in fig. 3 -- in conjunction with other data ${ }^{(6)}$-- demonstrated very dramatically that the chemistry of a (III) plane was a function of the value of the quantity $\mathbb{N}_{\text {ion }} / \mathbb{N}_{\text {pulse. }}$. It was clear that it would be desirable to further reduce the value of $\mathrm{N}_{\text {ion }} / \mathrm{N}_{\text {pulse }}$ to unity in order to try to guarantee that the dissection of the GaP specimen occurred on a layer-by-layer basis.

However, inspite of the above problems, the results on GaP are important from the point of view that even in a compound semiconductor it is now feasible to pulse field evaporate almost on an atomic layer-by-layer basis, so that it should be possible to investigate a number of physical problems if the conditions of pulse field evaporation are correctly chosen.

\section{B. THE DETERMINATION OF THE COMPOSITION OF ORDERED Pt 3 CO BY ATOM-PROBE FIELD-ION} MICROSCOPY (Dr. M. Yamamoto)

\section{INTRODUCTION}

Atom-probe field-ion microscope (FIM) -- hereinafter called an atom probe -analyses were performed on specimens of fully ordered $\mathrm{Pt}_{3} \mathrm{Co}$. The purpose of the investigation was to study the effects of different important experimental variables on the composition measured by the atom probe technique. The dependence of the alloy's composition on the following variables was determined: (1) pulse fraction (f); (2) specimen temperature; (3) crystal plane; and (4) field-evaporation rate. It was demonstrated that the composition determined by atom probe analyses of $\mathrm{Pt}_{3} \mathrm{Co}$ was very sensitive to the above four variables. The observations were discussed in terms of possible field-evaporation mechanisms.

\section{EXPERIMENTAL DETAILS AND PROCEDURES}

The $\mathrm{Pt}_{3} \mathrm{Co}$ specimens used for our studies had an average composition of 23.93 at.\% Co and 76.06 at.\% Pt; the chemical analyses were performed by Ledoux and Company (New Jersey, U.S.A.). The alloys were heat treated to obtain a value of the BraggWilliams long-range order parameter of $0.95 \pm 0.05$, by a procedure described by Aidelberg. All of the experiments were performed employing an atom probe which has been described in detail. $(2,3)$ 


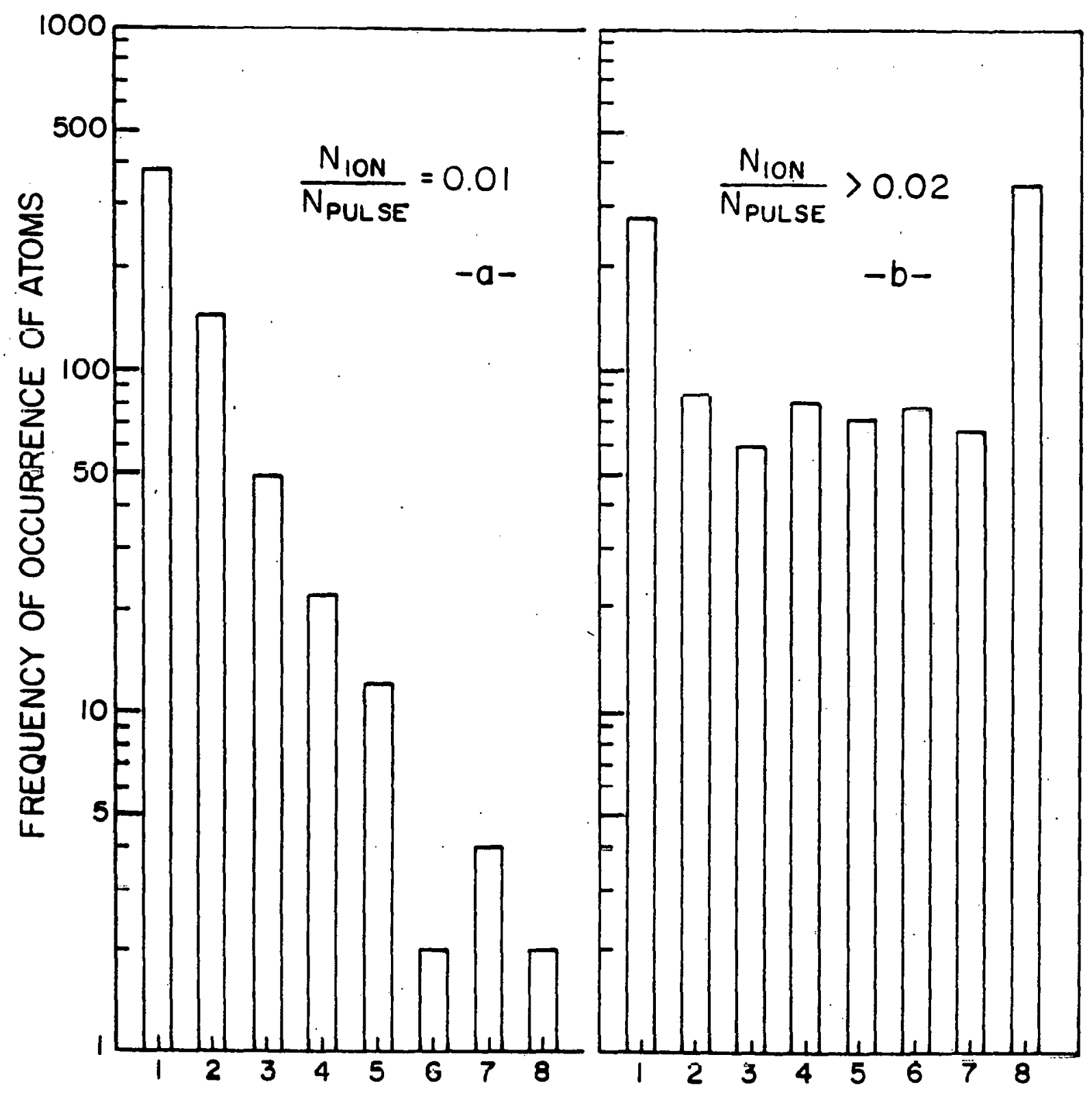

NUMBER OF ATOMS DETECTED PER FIELD EVAPORATION EVENT

Figure 3:: Frequency of occurence of atoms as a function of the number of atoms per field evaporation event for two different values of the ratio $\mathrm{N}_{\text {lons }} / \mathrm{N}_{\text {pulse. }}$ 
In our experiments the (200) superlattice and (111) fundamental planes were analyzed chemically at $25,35,60$ and $90 \mathrm{~K}$. The analyses were performed by first rotating the specimen so that the normal to the plane analyzed was in the center of the probe hole. In each analysis a cylinder of metal containing 1,000 to 3,500 Pt plus Co atoms was examined; in $83 \%$ of the runs the sample size was 1,200 to 1,600 atoms. The background pressure in the atom probe was in the range $(1.7-3.0) \times 10^{-10}$ Torr during each analysis.

At a given specimen temperature the value of $f$ was systematically varied from 0.048 to 0.237 . The quantity $f$ was given by the ratio $v_{p u l s e} / V_{d c}$ where $V_{d c}$ was the value of the steady-state voltage and $V_{\text {pulse }}$ was the value of pulse voltage used in the pulse field evaporation process. As the value of $f$ was increased the steadystate electric field was decreased; that is, the smallest value of $f$ corresponded to the largest value of the steady-state electric field.

The average field-evaporation rate was proportional to $\mathbb{N}_{\text {ion }} / \mathbb{N}_{\text {pulse }}$; where $\mathbb{N}_{\text {ion }}$ was the total number of Pt plus Co ions detected and $N_{\text {pulse }}$ the number of fieldevaporation pulses applied to the specimen to evaporate these ions. The pulse frequency was constant at a value of $60 \mathrm{~Hz}$. At each temperature the cobalt concentration was measured as a function of $\mathrm{f}$ while maintaining the ratio $\mathrm{N}_{i o n} / \mathbb{N}_{\text {pulse }}$ at a value which was either greater than or less than a given number -- see inset tables in Figs. 4 and 5 .

\section{RESULTS}

The principal results obtained in the experiments are show in figs. 4 and 5 where the measured cobalt concentration is plotted as a function of $f$. Figure 4 exhibits the results for the (111) fundamental plane; in this case every atomic plane consisted of 25 at.\% Co and 75 at.\% Pt. The experiments for this plane were performed at 35,60 and $90 \mathrm{~K}$. All of the data, with the exception of one point, were taken at a ratio of $N_{\text {ion }} / \mathbb{N}_{\text {pulse }}$ of less than 0.05 .

Figure 5 displays the results for the (200) superlattice plane; in this case the planes alternated periodically from 100 at.\% Pt to 50 at.\% Pt: 50 at.\% Co. Experimental results were recorded at $25,30,60$ and $90 \mathrm{~K}$ for the (200) plane for the ratio $\mathrm{N}_{\text {ion }} / \mathrm{N}_{\text {pulse }}$ both greater than and less than 0.02 . It is emphasized strongly that at $25 \mathrm{~K}$ the data for $\mathrm{N}_{\text {ion }} / \mathrm{N}_{\text {pulse }}$ greater than 0.02 yielded systematically larger values of the cobalt concentration.

All of the curves shown in figs. 4 and 5 consisted of two distinct régimes. In the first régime the cobalt concentration increased linearly with $f$ and the slope of each straight line decreased as the specimen temperature was increased. In the second régime the cobalt concentration was essentially independent of $f$ and reached an asymptotic value that was a function of the specimen's temperature for the (200) plane and almost independent of temperature for the (111) plane. For the (111) plane 
Figure 4: The measured cobalt concentration (at.\%) as a function of the pulse fraction ( $f$ ) -- for the (III) fundamental plane of Pt ${ }_{3} \mathrm{Co}$ -- at 35,60 and $90 \mathrm{~K}$. The inset table gives the values of the quantity $\mathrm{N}_{\text {ion }} / \mathrm{N}_{\text {pulse }}$ employed. The pulse frequency was
$60 \mathrm{~Hz}$. 


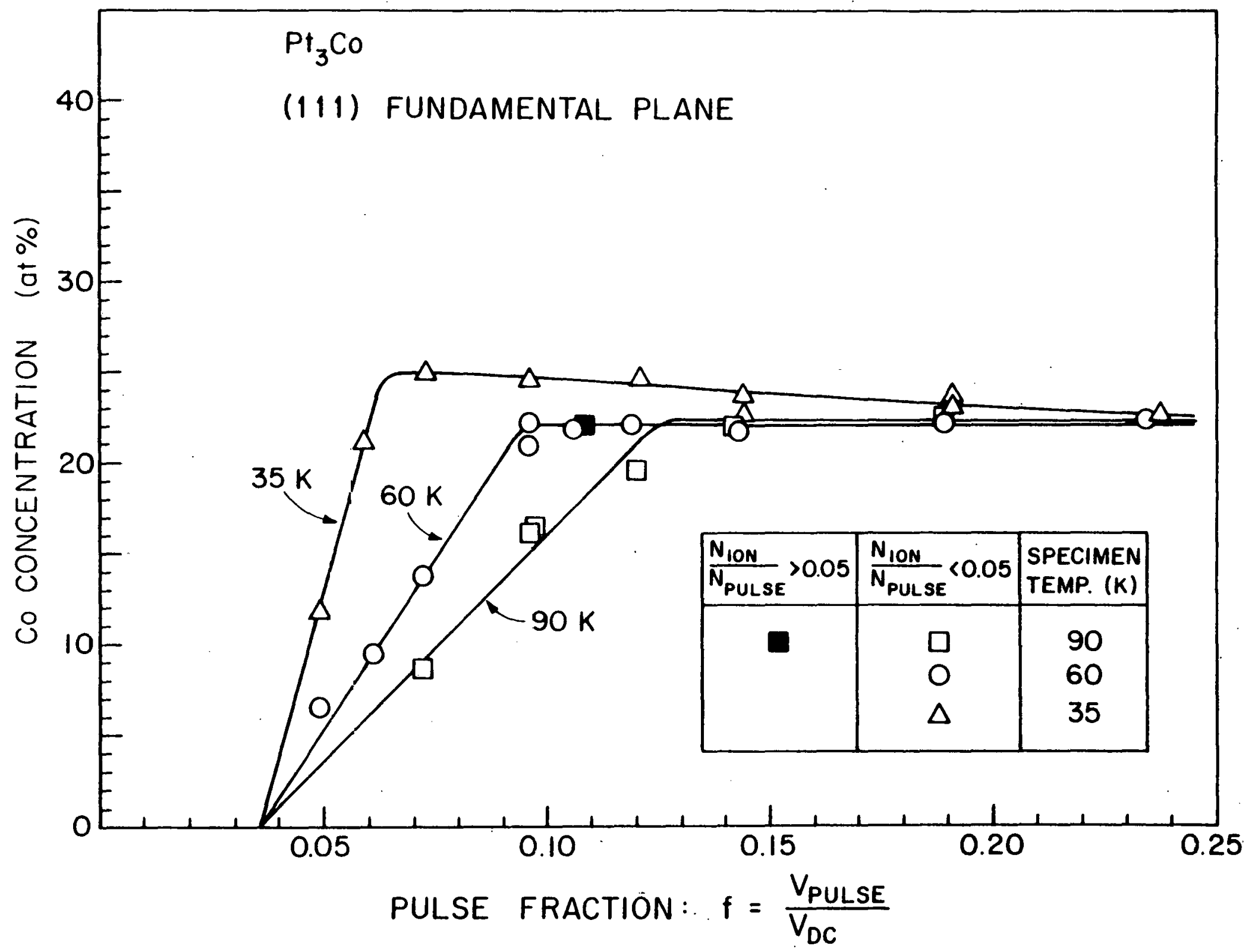


Figure 5: The measured cobalt concentration (at.\%) as a function of the pulse fraction $(f)$. - for the (200) superlattice plane of $\mathrm{Pt}{ }_{3} \mathrm{Co}$ - at $25,35,60$ and $90 \mathrm{~K}$. The inset table gives the values of the quantity $\mathbb{N}_{i o n} / \mathbb{N}_{\text {pulse }}$ employed. 'l'he pulse trequency was $60 \mathrm{~Hz}$. 


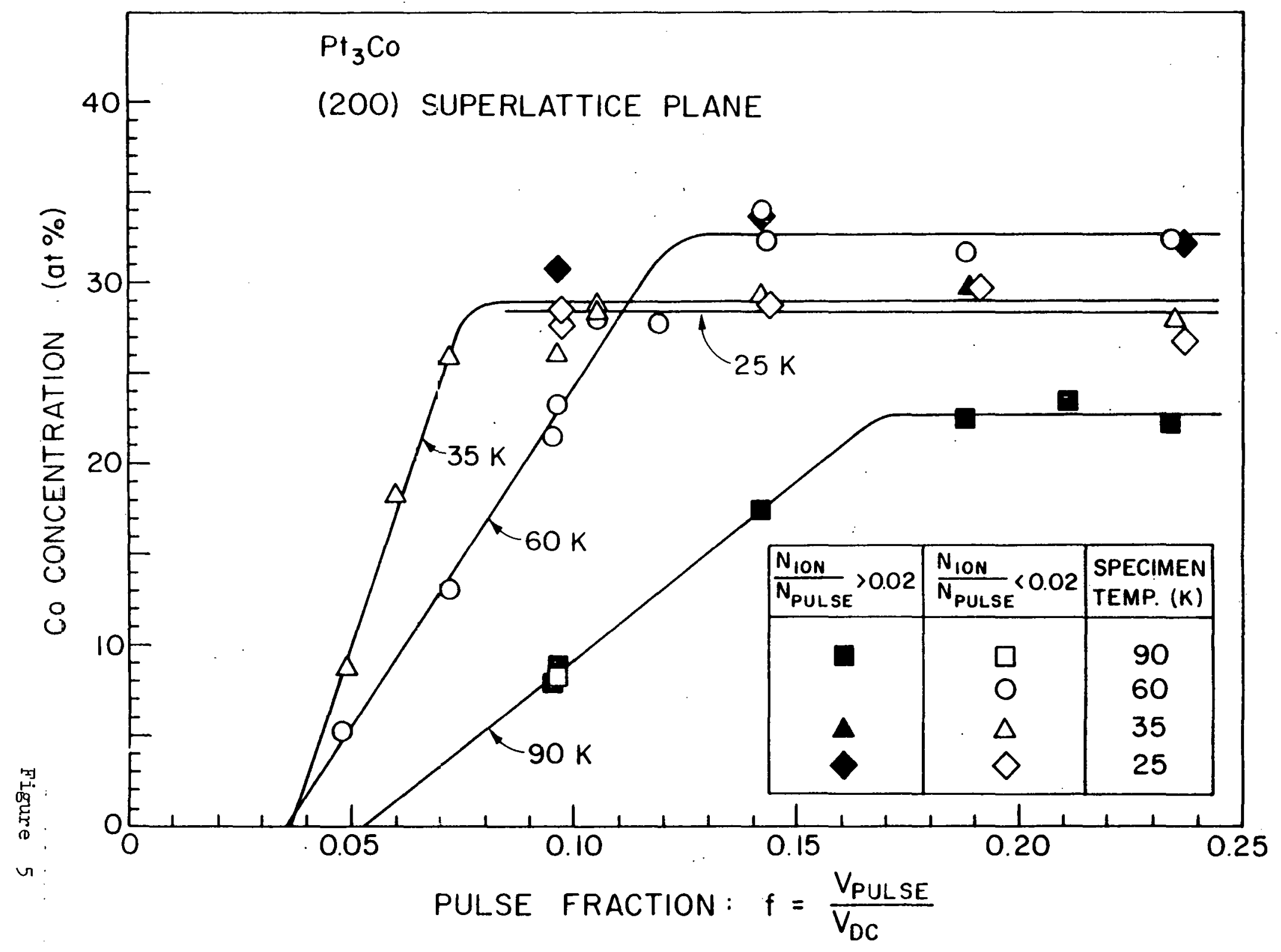


the asymptotic concentration was 222 at.\% Co; while for the (200) plane it varied from 22.3 to 32.7 at.\% Co. Also note that for both the (200) and (111) planes there was an extrapolated threshold value of $f$-- below this value the apparent cobalt concentration was zero. All of the extrapolated threshold values were the same -$f$ equal to 0.036 - with the exception of the $90 \mathrm{~K}$ curve for the (200) plane (see fig. 5).

\section{DISCUSSION}

In:this section we present a qualitative discussion of possible mechanisms which explain the results presented in figs. 1 and 2. A more complete discussion is presented elsewhere. The following possible mechanisms were considered: (1) selective field evaporation of Co or Pt atoms by the steady-state voltage $\left(\mathrm{V}_{\mathrm{dc}}\right)$; (2) the pulse field evaporation of a complex (PtCo) ${ }^{\text {th }}$ followed by immediate dissociation of this complex into charged and uncharged species; (3) selective chemical reaction of the $\mathrm{Pt}$ and Co atoms with either (or both) $\mathrm{H}_{2}$ and $\mathrm{He}$-- from the background vacuum -- to form complexes; (4) selective physical sputtering of either Pt or Co atoms by the polarized atoms in the gas phase; $(12,13,14)(5)$ the Chevron detector efficiency was different for the two species; (6) all of the species were not focused simultaneously onto the Chevron detector; (7) the number of ions evaporated per pulse exceeded the number of channels (eight) available in the digital timer; (8) lateral displacement of either Pt or Co atoms in the cyrstallographic plane while the field-evaporation pulse was being. applied to the specimen; and (9) two ions of the same species struck the Chevron detector simultaneously. In the longer paper we have shown that the possible mechanisms number (3) to (9) were not capable of explaining our experimental data.

The results for the (111) plane were essentially explained on the basis of the selective field evaporation of Co at the steady-state voltage. At large values of $f$ the value of $V_{u}$ was small, thus at small values of the steady-state electric field the Co atoms were not preferentially field evaporated. At smaller values of $f$-- for example, less than 0.12 at $90 \mathrm{~K} \mathrm{--} \mathrm{the} \mathrm{value} \mathrm{of} v_{d c}$ was greater, so that the steady-state electric field was large enough to selectively field evaporate Co atoms. As $f$ was decreased further the value of $V_{d c}$ was concomitantly increased and more and more of the Co atoms were selectively field evaporated, while the steadystate electric field was on the specimen. This implied that when the field-evaporation pulse was applied the plane had a deficiency of co atoms, so that the measured cobalt concentration decreased. This model was sufficient to explain our observations that at 35,60 and $90 \mathrm{~K}$ the asymptotic values of the cobalt concentration were only slightly less than the measured average concentration of 23.93 at.\%. 
The results shown in fig. 5 for the (200) plane could not be explained soley in terms of the selective field evaporation of Co. In particular note that the asymptotic concentration of $\mathrm{Co}$ at $60 \mathrm{~K}$ was 32.7 at.\%, while at $90 \mathrm{~K}$ it approached 22.7 at.\%. To explain the different asymptotic values we postulated the following possible reactions:

and

$$
\begin{aligned}
& (\mathrm{PtCo})^{+\mathrm{n}} \rightarrow \mathrm{Pt}+\mathrm{Co} ; \\
& (\mathrm{PtCo})^{+\mathrm{n}}+\mathrm{Pt}+\mathrm{Co}^{+\mathrm{n}} ; \\
& \left(\mathrm{Pt}_{2}\right)^{+\mathrm{n}}+\mathrm{Pt}^{+\mathrm{n}}+\mathrm{Pt} ; \\
& \left(\mathrm{Co}_{2}\right)^{+\mathrm{n}}+\mathrm{Co}^{+\mathrm{n}}+\mathrm{Co} ;
\end{aligned}
$$

Reactions (1) and (3) would have resulted in a measured alloy composition that was Pt rich, while reactions (2) and (4) would have yielded a value that was co rich. An examination of the crystallography of the $\mathrm{Pt}_{3} \mathrm{Co}$ lattice indicated that reaction (4) was not very probable. Therefore, we have suggested that the observed variation in the asymptotic values of the cobalt concentration can be explained on the basis of reactions (1), (2) or (3). Reaction (2) or (3) would explain our observations of Co rich alloys at 25,35 , and $60 \mathrm{~K}$. The linear increase in the cobalt concentration in régime 1 can be explained on the basis of the selective field-evaporation model suggested for (III) plane.

From the results and discussion presented in this paper it is clear that there are intrinsic problems in the quantitative measurement of the composition of the ordered alloy $\mathrm{Pt}_{3} \mathrm{Co}$, and that the dependence of the alloy's composition on the fundamental experimental variables must be understood -- in detail -- before it can be claimed that an absolute composition has been measured. This conclusion also applies to any other new alloy that is to be studied by the atom probe technique.

C. AN ATOM-PROBE FIELD-ION MICROSCOPE STUDY OF THE STOICHIOMETRY OF ORDERED Ni 4 MO (Dr. M. Yamamotin)

\section{INTRODUCTION}

Atom-probe field-ion microscope (FIM) analyses -- hereinafter called an atom probe -- were performed on specimens of ordered $\mathrm{Ni}_{4} \mathrm{Mo}$. The (2ll) fundamental and (I01) superlattice planes of the body-centered tetragonal (BCT) lattice were analyzed chemically on a layer-by-layer basis. In the case of (2ll) ${ }_{B C T}$ fundamental planes the chemistry of each individual plane was determined as a function of depth; for eight successive (211) $\mathrm{BCT}$ layers an average Mo concentration of 17.2 at.\% was measured -- as compared to 19.4 at.\% Mo by conventional chemical techniques. Possible sources of this discrepancy were discussed. The $(101)_{B C T}$ superlattice planes were found to exhibit a more complicated field evaporation behavior; the characteristic step-like field evaporation behavior was due to the partial field evaporation of a plane of 
Mo atoms followed by the continued field evaporation of this Mo plane, intermixed with the field evaporation of the following three planes of Ni atoms. Finally, a plane of $\mathrm{Ni}$ atoms was found to field evaporate. This field evaporation behavior was the result of the required crystallographic stacking of planes in the ordered $\mathrm{Ni}_{4}$ Mo structure and it repeated itself throughout the specimen. Our observations demonstrated that complicated field-evaporation processes -- as well as chemistry -could be followed as a function of depth.

\section{EXPERIMENTAL DETAIIS AND PROCEDURES}

The $\mathrm{Ni}_{4} \mathrm{Mo}$ specimens used for our studies had an average composition of 80.6 at.\% $\mathrm{Ni}$ and 19.4 at.\% Mo; the chemical analyses were performed by the Chemical Analytical Facility of the Cornell Materials Science Center. Specimens in the form of wires were heat treated to obtain a highly ordered state by a procedure described by Aidelberg. (11) All of the experiments were performed employing an atom probe which has been described previously in detail. $(2,3)$

In our experiments the (211) fundamental and (101) superlattice planes of the BCT lattice were chemically analyzed, in detail, on a layer-by-layer basis. The analyses were performed by rotating the FIM specimen so that the normal to the plane analyzed was in the center of the probe hole. The background pressure in the atom probe was in the low $10^{-10}$ Torr range and the specimen temperature was $60 \mathrm{~K}$, during each analysis. The pulse fraction ( $f$ ) was given by the ratio $\mathrm{V}_{\text {pulse }} / \mathrm{V}_{\mathrm{dc}}$; where $\mathrm{V}_{\text {pulse }}$ and $\mathrm{V}_{\mathrm{dc}}$ were the steady-state and pulse voltages, respectively. The value of $f$ used was 0.10 and the pulse frequency was constant at a value of $60 \mathrm{~Hz}$. 3. RESULTS .

The mass spectra -- that is, the number of events versus the mass-to-charge ratio -- for the $(211)_{\mathrm{BCT}}$ fundamental and the $(200)_{\mathrm{BCT}}$ and $(101)_{\mathrm{BCT}}$ superlattice planes of ordered $\mathrm{Ni}_{4} \mathrm{Mo}^{\mathrm{BC}}$ consisted of essentially $\mathrm{Ni}^{+2}, \mathrm{Mo}^{+2}$, and $\mathrm{Mo}^{+2}$. These charge states of $\mathrm{Ni}$ and $\mathrm{Mo}$ in ordered $\mathrm{Ni}_{4}$ Mo were different from the ones observed for pure $\mathrm{Ni}$ or $\mathrm{Mo}$; for the pure elements $\mathrm{Ni}^{+\mathrm{I}}, \mathrm{Ni}^{+2}, \mathrm{Mo}^{+2}, \mathrm{Mo}^{+3}$, and $\mathrm{Mo}^{+4}$ were detected. In all of the spectra of $\mathrm{Ni}_{4} \mathrm{Mo}$ the $\mathrm{Ni}^{+2}$ portion of each spectrum overlapped with $\mathrm{MO}^{+3}$ isotopes; however, the peaks associated with the five naturally occurring isotopes of $\mathrm{Ni}\left(\mathrm{Ni}^{58}, \mathrm{Ni}^{60}, \mathrm{Ni}^{61}, \mathrm{Ni}^{62}, \mathrm{Ni}^{64}\right)$ and the seven naturally occurring

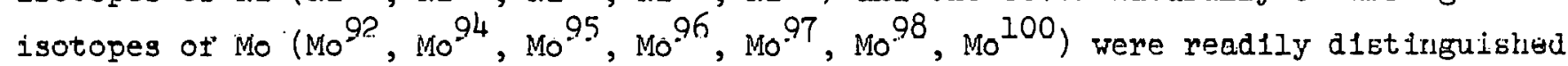
from one another in the regions containing $\mathrm{Ni}^{+2}$ and $\mathrm{Mo}^{+3}$, or $\mathrm{Mo}^{+2}$.

The following designations were used in our analyses of the spectra. The region consisting of solely the $\mathrm{Ni}^{+2}$ isotopes was called $\mathrm{A}$; that is, the isotopes ${ }^{58} \mathrm{Ni}^{+2}$, $60 \mathrm{Ni}^{+2}$ and ${ }^{61} \mathrm{Ni}^{+2}$. Region $\mathrm{B}$ consisted of $92 \mathrm{Mo}^{+3}$ and ${ }^{62} \mathrm{Ni}^{+2}$ and region $\mathrm{C}$ was composed of the isotopes ${ }^{94} \mathrm{Mo}^{+3},{ }^{95} \mathrm{Mo}^{+3}, 96 \mathrm{Mo}^{+3}, 97 \mathrm{Mo}^{+3}, 98 \mathrm{Mo}^{+3},{ }^{100} \mathrm{Mo}^{+3}$ and $\left({ }^{64} \mathrm{Ni}^{+2}\right)^{+}$. The

+ This isotope was neglected in determining the composition of the alloy, since its isotopic abundance is only $0.904 \%$. 
seven naturally occurring isotopes of Mo that evaporated in the +2 charge state were referred to as region D. A detailed discussion of the mass spectrum of $\mathrm{Ni}_{4}$ Mo is given in a more extensive version of the present paper.

Figure 6 displays a special type of composition profile for the (211) $\mathrm{BCT}$ fundamental plane of $\mathrm{Ni}_{4} \mathrm{Mo}$; the procedure used to generate this data has been previously described. $(4,5)$ Each of the three graphs in fig. 6 consists of a plot of the cumulative number of atoms -- of specified species -- versus the cumulative number of field evaporation pulses; the latter quantity is proportional to both time and depth. The graph in the top third of fig. 6 displays the cumulative number of $\mathrm{Ni}$ plus Mo atoms -- from regions $A, B, C$ and $D$-- versus the number of field-evaporation pulses. Each step in this figure corresponds to the pulse field evaporation of one (2l1) ${ }_{B C T}$ fundamental plane of atoms. The graphs displayed in the center and bottom of fig. 6 show the layer-by-layer pulse field evaporation behavior -- for the same

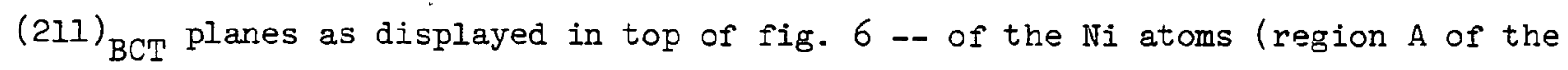
spectrum) and the Mo atoms (regions $C$ and $D$ of the spectrum), respectively.

Figure 7 presents detailed information on the chemistry of eight successive

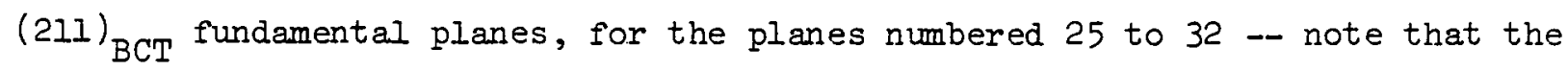
corresponding planes 28 to 32 were displayed in fig. 6 . The top graph in fig. 7 reveals the Mo concentration, in at.\%, for each of these eight (2ll) ${ }_{B C T}$ planes as a function of plane number (depth). The minimum and maximum concentrations observed were 14.4 and 19.5 at.\%, respectively; the average concentration -- for these eight planes -- was 17.2 at.\%. The lower four graphs in fig. 7 show how the number of atoms per plane varied as a function of plane number (depth), for the different regions of the spectrum; for example, the bottom graph exhibits the number of atoms per plane in the $C$ and $D$ regions (Mo atoms) as a function of the plane number.

Figure 8 exhibits the pulse field evaporation behavior of four groups of (101) $\mathrm{BCT}$ superlattice planes -- the groups are numbered 6 to 9. The topmost graph in fig. 8 displays the cumulative number of $\mathrm{Ni}$ plus Mo atoms (regions $\mathrm{A}, \mathrm{B}, \mathrm{C}$ and $\mathrm{D}$ ) as a function of the cumulative number of field-evaporation pulses. Each major step corresponds to the removal of a group of planes consisting of one layer of Mo atoms and four layers of $\mathrm{Ni}$ atoms; for example, the step labeled number 7 consisted of these five layers. That this was the case can be seen from the center and bottom graphs in fig. 8 plus fig. 9. The first hint of this behavior came from a comparison of the rate of field evaporation exhibited towards the end of each step. The vertical parallel lines, in fig. 8 , help to show that the last layer to field evaporate, within each major step, consisted of solely $\mathrm{Ni}$ atoms.

Figure 9 shows the cumulative number of Mo atoms (regions $C$ and $D$ ) versus the cumulative number of $\mathrm{Ni}$ atoms (region A) for group numbers 7 and 8 of fig. 8 . From 
Figure 6: The pulse field evaporation behavior of the (2ll) $B C T$ fundamental plane of $\mathrm{Ni}_{4} \mathrm{Mo}$. The graph at the top gives the cumulative number of Ni plus Mo atoms, the center graph the cumulative number of Ni atoms and the bottom graph the cumulative number of Mo atoms; in all three cases as a function of the cumulative number of field evaporation pulses. The pulse fraction was 0.10 , the pulse frequency was a constant at $60 \mathrm{~Hz}$ and the temperature of the specimen was $60 \mathrm{~K}$. 


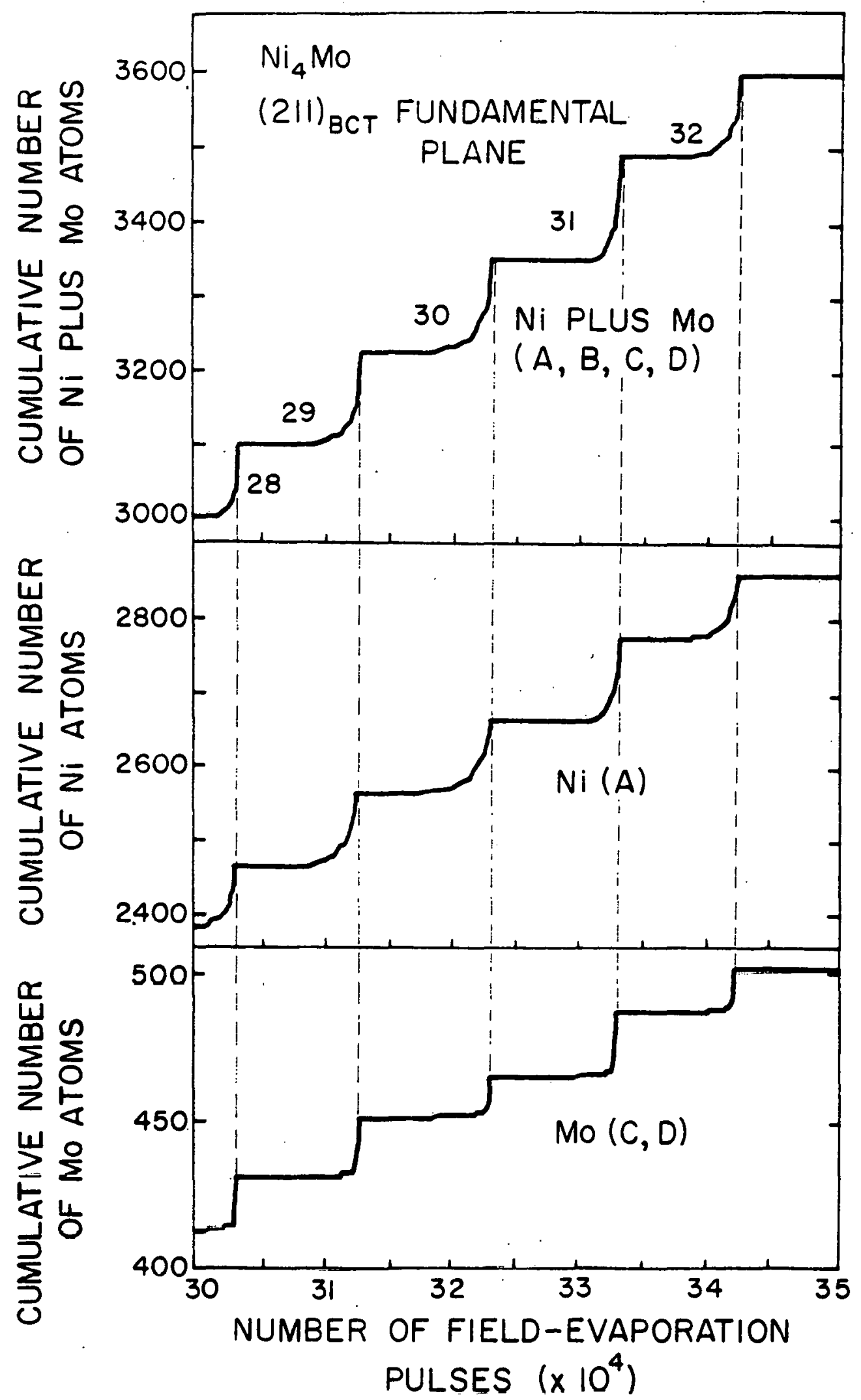

Figure 6 
Figure 7: The graph at the top gives the Mo concentration, in at.\%, as a function of the plane number; note the correspondence to the plane numbers given in fig. 6. The next. frum graphs give the total number of atoms per plane for four different cases: (I) Ni plus Mo atoms in regions $A, B, C$, and $D$ of the spectrum; (2) $\mathrm{Ni}$ atoms in region $\mathrm{A}$ of the spectrum; (3) $\mathrm{Ni}$ plus Mo atoms in region $B$ of the spectrum; and (4) Mo atoms in regions $C$ and $D$ of the spectrum. All of this data was taken under the same conditions as the data exhibited in fig. 6. 


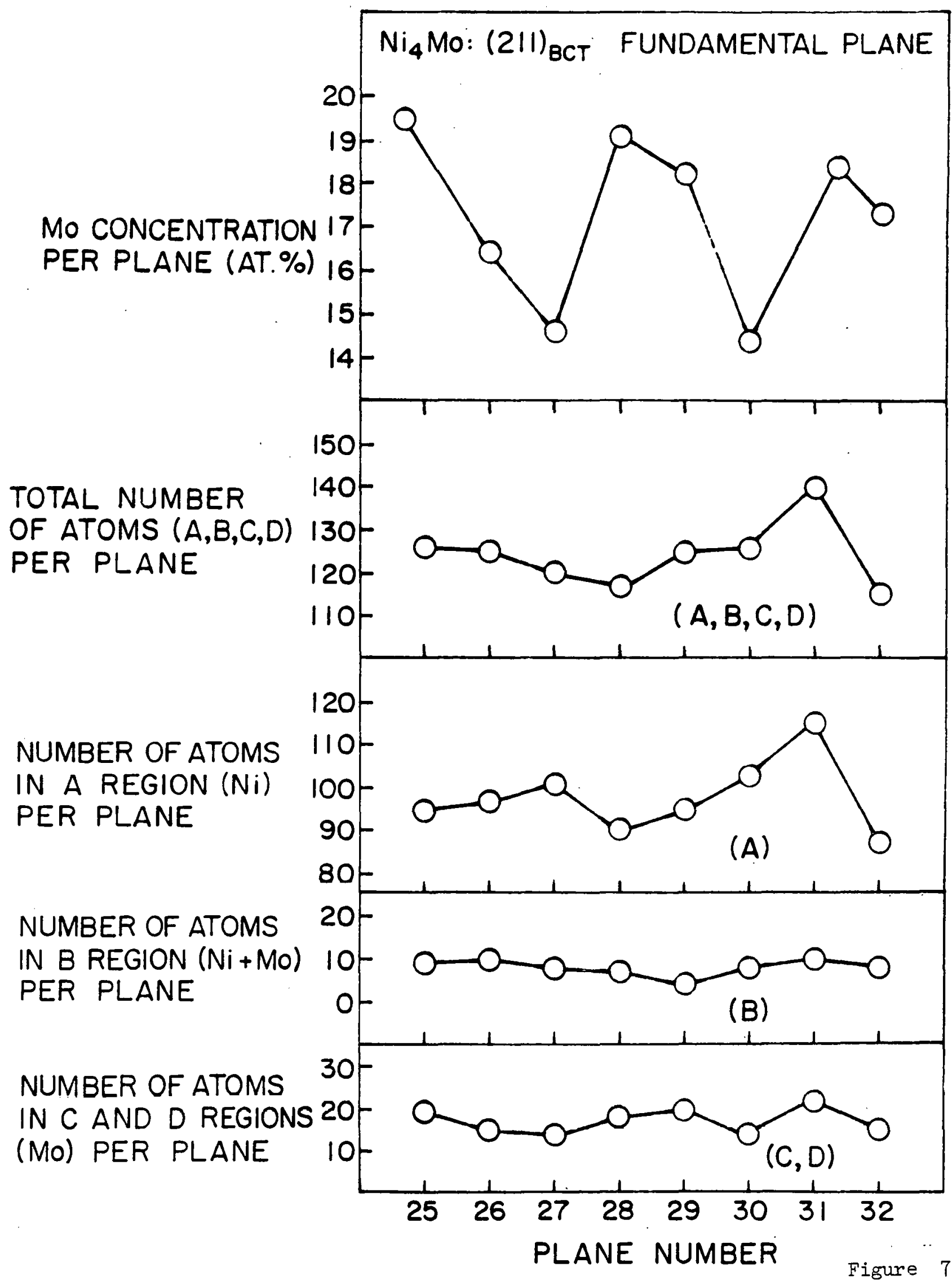


Figure 8: The pulse field evaporation behavior of the (101) $\mathrm{BCT}$ superlattice plane of $\mathrm{Ni}_{4} \mathrm{Mo}$. The graph at the top of the figure gives the cumulative number of $\mathrm{Ni}$ plus Mo atoms, the graph in the center the cumulative number of $\mathrm{Ni}$ atoms and the graph at the bottom the cumulative number of Mo atoms; in all three cases as a function of the cumulative number of field evaporation pulses. The pulse fraction was 0.10 , the pulse frequensy was constant. at. $6 n \mathrm{~Hz}$ and the temperature of the specimen was $60 \mathrm{~K}$. 


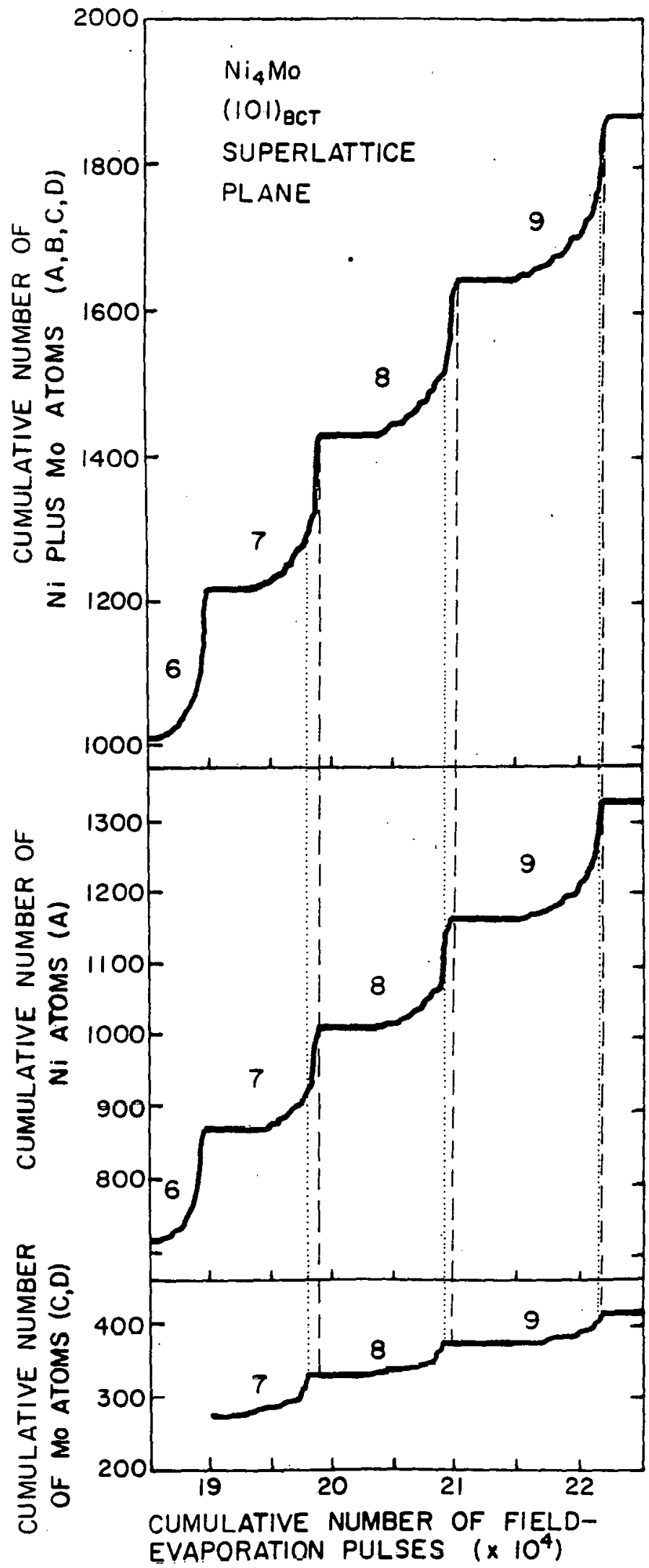

Figure 8 
Figure 9: The cumulative number of Mo atoms as a function of the cumulative number of $\mathrm{Ni}$ atuins. This figure was plotted from the data presented in fig. 8 -- note the correspondence of the group numbers. 


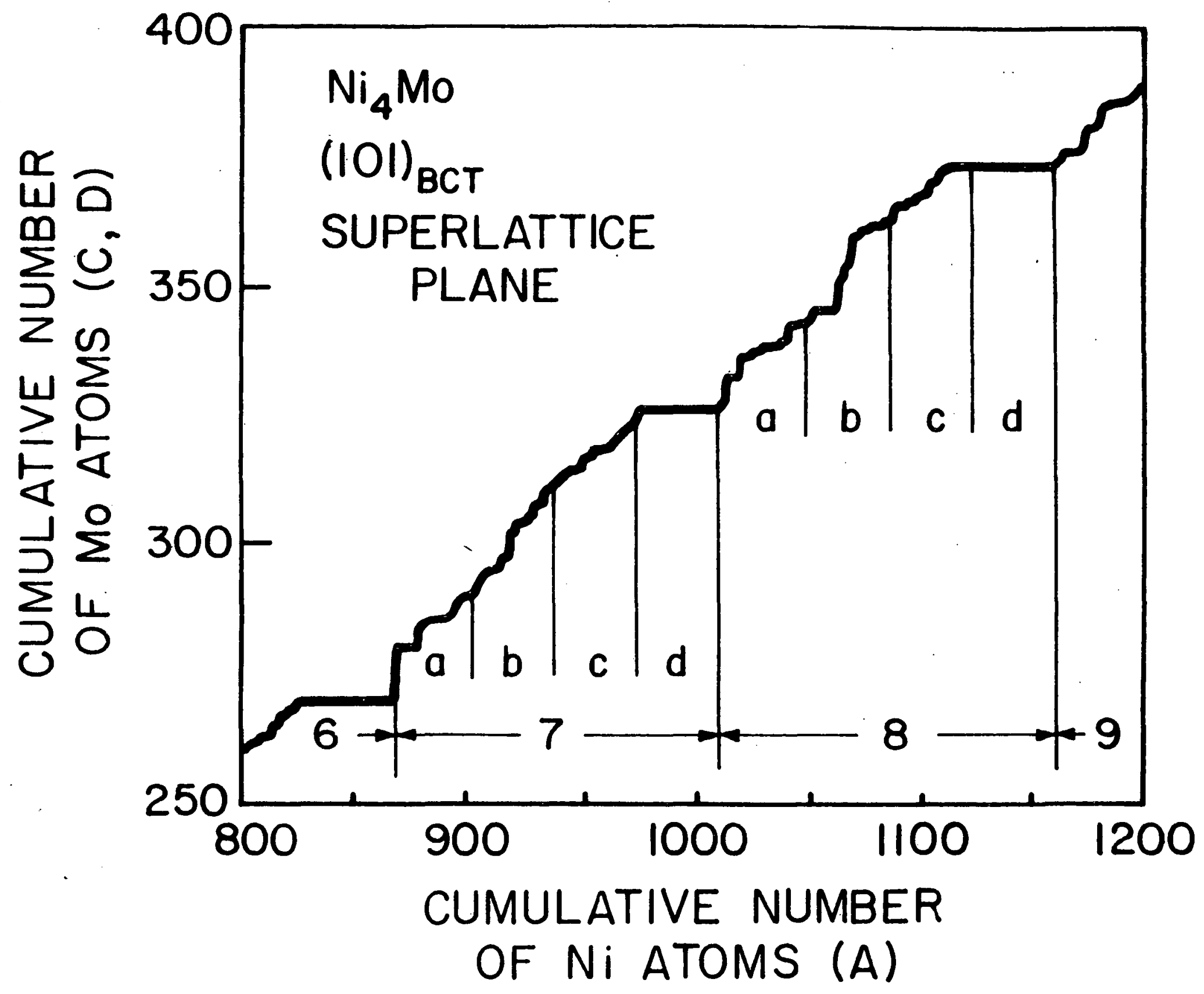


an examination of the beginning of group number 7 it was clear that the first atoms to field evaporate were $\mathrm{Mo}$ and the last oneswere $\mathrm{Ni}$; the latter $\mathrm{Ni}$ atoms were denoted by the letter d. After the first Mo atoms had been field evaporated a mixture of Ni plus Mo atoms were field evaporated; this behavior was denoted by the letters a, $\mathrm{b}$ and $\mathrm{c}$ to convey the point that three planes of $\mathrm{Ni}$ atoms were involved. It is emphasized that during the pulse dissection of these three planes Mo atoms from the topmost plane were still being field evaporated.

4. DISCUSSION

Figures 6 and 7 demonstrated that it was possible to determine the composition, in this ordered alloy, on a plane-by-plane basis. Every (2ll) ${ }_{B C T}$ fundamental plane of $\mathrm{Ni}_{4} \mathrm{Mo}$ should contain 80 at.\% $\mathrm{Ni}$ and 20 at.\% Mo if the alloy were perfectly. stoichiometric and fully ordered; that is, if the Bragg-Williams long-range order parameter were equal to unity. However, in our case we should have observed an average value of 80.6 at.\% $\mathrm{Ni}$ and 19.4 at.\% Mo (see $\xi 2$ ). The fact that the average Mo concentration for these eight planes was 2.2 at.\% less than expected value of 19.4 at.\% could have had its origin in the following possible sources: (1) the alloy may not have been fully ordered; (2) the value of $f$ employed was too small; and (3) the temperature of the specimen was too high.

The possibility that the alloy was not fully ordered cannot be answered precisely, because we were unable to measure the Bragg-Williams long-range order parameter for this alloy by the FIM technique. (11) The reason for this was the fact that only the Mo atoms gave rise to a visible image; however, excellent FIM !1mages were obtained and it is our opinion that the specimens were almost fully ordered. ( 1 ) The second two possible sources of the discrepancy were suggested by our results on $\mathrm{Pt}_{3} \mathrm{Co},(15)$ where it was discovered that the meusured co concentration wais a furcliun of the temperature of the specimen and the value of $f$ employed -- that is, the value of $\mathrm{V}_{\mathrm{dc}} \cdot$ Our results on $\mathrm{Pt}_{3} \mathrm{Co}$ implied that the use of a larger value of $f$ and a lower specimen temperature may bring the atom probe measurements in closer agreement with the average value obtained by conventional chemical analyses. It is noted that the very detection of $\mathrm{Ni}$ atoms -- which were invisible in the FIM image -- indicated that they were not all selectively field evaporated at $v_{d c}$ from the (2li) ${ }_{B C T}$ furdamental plane.

The graphs exhibited in the center and bottom of fig. 6 shed some light on the field-evaporation behavior of the $(211)_{B C T}$ fundamental plane. These graphs show that the $\mathrm{Ni}$ atoms began to field evaporate before the Mo atoms and that the rate of field evaporation for the Mo atoms was greater than for the $\mathrm{Ni}$ atoms once a certain fraction of the $\mathrm{Ni}$ atoms had been field-evaporated; the slope at any point on each 
experimental curve is proportional to the rate of field evaporation, since the abscissa is proportional to time. Thus the activation energy for the field evaporation of Mo atoms decreased as the size of the plane decreased. This indicated that the field evaporation behavior of Mo atoms, from this plane, changed as the Ni atom concentration decreased.

The results presented in figs. 8 and 9 demonstrated that the field evaporation behavior of the $(101)_{B C T}$ superlattice plane was considerably more complex than the field-evaporation behavior of the $(21 I)_{B C T}$ fundamental plane -- see fig. 6 . First, our observations proved that even though the $\mathrm{Ni}$ atoms were invisible in an FIM image that they had not all been selectively field evaporated at $v_{\text {dc }}$. Second, the complex field evaporation behavior discussed in \$ 3 demonstrated that the pulse dissection technique, in conjunction with a computer controlled atom probe, can be used to unravel how the two different species field had evaporated.

From the results and discussion presented in this paper it is our conclusion that the atom probe technique can be used, in this complicated ordered structure, to follow: (1) the physics and chemistry of the field evaporation process; and (2) the chemistry of the alloy as a function of position throughout the specimen.

\section{DIRECT EXPERIMENTAL DETERMINATION OF THE PARTICLE REFLECTION COEFFICIENT OF LOW-} ENERGY ${ }^{3}$ He AND ${ }^{4}$ He ATOMS FROM THE (IIO) PLANE OF TUNGSTEN ( $\mathrm{J}$. Amano)

\section{INTRODUCTION}

When an energetic ion beam is made to impinge on a solid target a fraction of the incident ions eventually become implanted as atoms in the target and the remaining fraction are reflected from the target. In the case of low-energy light projectiles-such as hydrogen or heliums ions--impinging on a heavy target a significant fraction of the projectiles can be reflected from the target. (16) The reflection is a result of the fact that--since the mass of the projectile atom is less than the mass of the target atom--backscattering of the projectile atom is possible through the angular range 90 to $180^{\circ}$. Thus a light projectile ion can enter a heavy target and undergo a series of plastic collisions with atoms of the target and eventually be backscattered out of the target; as a result of these backscattering events the projectile has become a reflected particle.

It is extremely difficult to measure a yield of reflected particles at implantation energies of less than 1 kev--by conventional techniques--as most of the backscattered particles are neutral atoms at these low incident ion energies. (17) Monte Carlo computer simulation techniques have been used extensively to calculate theoretical values of the yield of reflected particles. (18-21) Recently van Gorkum and Kornelsen (22) used thermal desorption spectrometry to measure the entrance probahility of 8 to 5000 $\mathrm{eV}^{4} \mathrm{He}^{+}$ions incident on the (100) surface of tungsten; the particle reflection coefficient $\left(R_{N}\right)$ is one minus the entrance probability. They found that the entrance 
probability for normal incidence was within $20 \%$. of unity for ion energies greater than $250 \mathrm{eV}$.

For the past few years we have been studying the properties of light gases-helium and hydrogen--in metals using the atom-probe field-ion microscope (FIM) technique. To date we have studies: (I) the range profiles of low-energy (100 to $1500 \mathrm{eV}){ }^{3} \mathrm{He}$ and ${ }^{4} \mathrm{He}$ atoms implanted in tungsten, at $60 \mathrm{~K}$, parallel to the [110] direction; $(23-26)$ (2) the diffusive behavior of interstitial ${ }^{3}$ He and ${ }^{4}$ He atoms in tungsten between $90^{\circ}$ and $110 \mathrm{~K} ;(23,24,27)$ and (3) the diffusive behavior of ${ }^{H}$ in tungster between 25 and $45 \mathrm{~K} .^{(28)}$ As part of an earlier study ${ }^{(23)}$ preliminary values of $\mathrm{R}_{\mathrm{N}}$ were determined for 300 and $475 \mathrm{eV}^{4} \mathrm{He}^{+}$implantations performed, in tungsten; at $60 \mathrm{~K}$. In this paper we present very detailed results on the measurement of $R_{N}$ for 100 to $1500 \mathrm{eV}^{3} \mathrm{He}$ and ${ }^{4} \mathrm{He}$ 1on implanled in situ in tungsten at $60 \mathrm{~K}$; the ion beam was parallel to the [110] direction, within $\pm 5^{\circ}$, and experimental values of $k_{N}$ decreased from 0.85 to 0.25 as the energy of the incident helium ion beam was increased from 100 to $1500 \mathrm{eV}$. Our experimental data were also compared with values of $\mathrm{R}_{\mathrm{N}}$ calculated employing Biersack's and Haggmark's TRIM program $(20)$ and Robinson's and Torren's MARLOWE code. (30)

2. EXPERIMENTAL BACKGROUND AND PROCEDURE

The value of the particle reflection coefficient $\left(R_{N}\right)$ was determined by measuring the particle retention coefficient $\left(\mathrm{T}_{\mathrm{N}}\right)$; van Gorkum and Kornelsen call $\mathrm{T}_{\mathrm{N}}$ the entrance probability. These two quantities are, of course, related to one another through the expressinn

$$
\mathrm{R}_{\mathrm{N}}+\mathrm{T}_{\mathrm{N}}=1 \text {. }
$$

The quantity $T_{\mathrm{N}}$ was measured directly by the atom-probe field-ion microscope (FIM) technique. The procedure consisted of flrst Implanling He or He ili situ, in tungsten, at a standard reference temperature of $60 \mathrm{~K}$; the ion beam impinged normal, within $\pm 5^{\circ}$, to the (110) plane. At $60 \mathrm{~K}$ we have demonstrated that both ${ }^{3} \mathrm{He}$ and ${ }^{4} \mathrm{He}$ in tungsten are completely immobile; $(23,24,27)$ therefore, the helium did not diffuse out of the specimens at this implantation temperature. The range profiles of the implanted helium atoms were determined with a depth resolution equal to one (110) interplanar spacing $(2.24 \mathrm{~A})$, employing the pulse field-evaporation technique to dissect each (110) plane on an atom-by-atom basis. ${ }^{(23-26)}$ The total number of imilanted helium atoms detected was used to determine $\mathrm{T}_{\mathrm{N}}$ at each implantation energy.

$\mathrm{All}$ of the ${ }^{3} \mathrm{He}^{+}$irradiations and the majority of the ${ }^{4} \mathrm{He}^{+}$ion irradiations were performed employing a specially constructed differentially pumped low-energy ( $\leq 3 \mathrm{keV})$ gas ion beam system for the in situ irradiations of FIM specimens. (3I) This ion beam system produced a magnetically mass-analyzed high current density $\left(>0.5 \mu \mathrm{A} \mathrm{cm}^{-2}\right.$ ) beam of ${ }^{3} \mathrm{He}^{+}$or ${ }^{4} \mathrm{He}$ ions. Typical implantation conditions are given in Table 1. 
The tungsten FIM specimens were prepared from Materials Research. Corporation VP-grade polycrystalline wire with the fiber axis parallel to the [110] direction. The VP-grade polycrystalline wire was recrystallized at $2000^{\circ} \mathrm{C}$ at a background gauge pressure of $6 \times 10^{-9}$ Torr, in order to obtain a grain diameter that was much greater than the maximum profiling depth. The sharply pointed FIM specimens were prepared by standard electropolishing tehcniques that we have already described. $(23,32)$

\section{ANALYSIS}

The quantity $\mathrm{T}_{\mathbb{N}}$ was defined by the equation

$$
\mathrm{T}_{\mathrm{N}}=\alpha \mathrm{N}_{\mathrm{He}}^{\mathrm{C}} /\left(\Phi_{\mathrm{d}} \mathrm{A}_{\mathrm{hkl}}\right) \text {; }
$$

where $\mathrm{N}_{\mathrm{He}}^{\mathrm{C}}$ is the corrected total number of helium atoms detected after an implantation in a specimen to a given fluence $\left(\Phi_{d}\right), A_{h k l}$ is the absolute value of the area of the (hkl) plane analyzed and $\alpha$ is a correction factor that results from the physical mechanism for the field desorption of tungsten-helium molecules that formed on the surface of the FIM specimen. The quantity $\mathrm{N}_{\mathrm{He}}^{\mathrm{C}}$ is given by

$$
\mathrm{N}_{\mathrm{He}}^{\mathrm{c}}=\mathrm{N}_{\mathrm{He}}^{\mathrm{m}} / \eta
$$

where $\mathbb{N}_{\mathrm{He}}^{m}$ is the measured number of helium atoms and $n$ is the detection efficiency of the Chevron detector. (18) The expression for $\mathrm{A}_{\mathrm{hkl}}$ is given by

$$
\mathrm{A}_{\mathrm{hkl}}=\mathrm{N}_{\mathrm{W}}^{\mathrm{C}} / \rho_{\mathrm{hkl}} \text {; }
$$

where $\mathrm{N}_{\mathrm{W}}^{\mathrm{C}}$ is the corrected average number of tungsten atoms per ( $h k I$ ) plane and $\rho_{h k l}$ is the atomic density of the (hkl) plane analyzed. The value of $\mathrm{N}_{\mathrm{W}}^{\mathrm{c}}$ is given by

$$
\mathrm{N}_{\mathrm{W}}^{\mathrm{c}}=\mathrm{N}_{\mathrm{W}}^{\mathrm{m}} / \mathrm{n} \text {; }
$$

where $N_{W}^{m}$ is the measured number of helium atoms. The detection efficiency of a Chevron ion detector has been shown to be independent of the mass of the ion, for an ion energy greater than $5 \mathrm{keV}$ ( $^{(34)}$ Since all of the pulse field-evaporation experiments involved a. total ion encrgy, for both hellum and tungsten, that was at least a factor of two greater than $5 \mathrm{keV}$ we safely assumed that there was no mass dependence effect on the detection efficiency. Thus the final expression used to calculate $T_{N}$ is given by

$$
\mathrm{T}_{\mathrm{N}}=\alpha \mathrm{N}_{\mathrm{He}}^{\mathrm{m}} \rho_{h k l} /\left(\mathrm{N}_{\mathrm{W}}^{\mathrm{m}} \Phi_{\mathrm{d}}\right) \text {. }
$$

It is emphasized very strongly that eqn. (6) is totally independent of $n$, so that $T_{N}$ is directly proprotional to the ration $N_{\mathrm{He}}^{m} / N_{\mathrm{W}}^{m}$ at constant values of $\Phi_{\mathrm{a}}$, and implantation and analysis temperature. Finally, the equation for $R_{N}$ follows directly from eqn. (I) and it is given by

$$
\mathrm{R}_{\mathrm{N}}=\left[I-\alpha \mathrm{N}_{\mathrm{He}}^{\mathrm{m}} \rho_{\mathrm{hkl}} /\left(\mathrm{N}_{\mathrm{W}}^{\mathrm{m}} \Phi_{\mathrm{d}}\right)\right] ;
$$

for the (110) plane the value of $\rho_{110}$ is equal to $1.4 \times 10^{15} \mathrm{~cm}^{-2}$. 
Table 1: Typical experimental conditions during an in situ implantation with either ${ }^{3} \mathrm{He}^{+}$or ${ }^{4} \mathrm{He}^{+}$ions.

Ion source pressure

Atom probe pressure

Tip tempcrature

$3 \mathrm{He}^{+}$or ${ }^{4} \mathrm{He}^{+}$flux

Total ion fluence

Total irradiation time

Uncertainly in irradiation direction

Pump-down time to $3 \times 10^{-10}$ Torr after

an irradiation

$$
\begin{aligned}
& \approx 10^{-4} \text { Torr } \\
& \approx 10^{-7} \text { Torr }^{\dagger} \\
& \text { fint? } \mathrm{K} \\
& \approx 3.2 \times 10^{12} \text { ions } \mathrm{cm}^{-2} \mathrm{sec}^{-1} \\
& (3-5) \times 10^{1.5} \text { ions } \mathrm{cm}^{-2} \\
& 20-30 \text { min } \\
& \pm 5^{\circ} \text { maximum. } \\
& 0.5 \text { hour }
\end{aligned}
$$

+ This pressure was due mainly to helium gas. 
The correction factor $\alpha$ is necessary because Mïller and co-workers $(35-38)$ have shown that helium can be field adsorbed on tungsten surfaces. The physical origin of the field adsorption effect is the classical dipole-dipole interaction. In the presence of the large electric fields $\left(>4.5 \mathrm{VA}^{-1}\right)$ involved in field-ion microscopy dipole moments are induced for both the helium and tungsten atoms. The induced dipole moments are large enough to bind the helium atoms to the tungsten surface-hence the name field adsorption. During pulse field-evaporation experiments Müller and co-workers measured a certain ratio of metal-helide ions to single helium ions which was a function of the crystallographic region of the tip analyzed and the temperature of the specimen. For the (110) plane Müller and co-workers determined a relative abundance of $\mathrm{WHe}^{+3}$ to $\left(\mathrm{W}^{+3}+\mathrm{WHe} \mathrm{H}^{+3}\right)$ of $0.6 \pm 0.05$ at a specimen temperature of $60 \mathrm{~K}$. If one assumes that each tungsten atom on the (110) plane field adsorbed one helium atom ${ }^{\dagger}$ then the ratio of $\mathrm{He}^{+}$to $\left(\mathrm{WHe}^{+3}+\mathrm{He}^{+}\right)$is $0.4 \pm 0.05$; helium was only detected in the singly charged state. This implies that the factor $\alpha$ is $1 /(0.4 \pm 0.05)$ or $2.5 \pm 0.36$; that is, the range of $\alpha$ is from 2.22 to 2.86 . We further assumed that each implanted helium atom became field adsorbed instantaneously when it reached the surface as a result of the pulse field-evaporation process used to dissect the specimen. 4. RESULTS AND DISCUSSION

Figure 10 exhibits an integral profile for a $500 \mathrm{ev}^{4} \mathrm{He}^{+}$ion implantation parallel to the [110] direction--within $\pm 5^{\circ}-$ at $5 \mathrm{~K}$. The depth resolution was $2.24 \AA$ [one (110) interplanar spacing] fur the atom-probe FIM analysis. 'l'he minimum step height on the abscissa corresponds to the detection of one helium atiom. A total of $32{ }^{4} \mathrm{He}$ atoms were detected for this integral profile. In fig. II we have plotted $\mathrm{N}_{\mathrm{W}}^{\mathrm{m}}$ versus the depth from the irradiated (110) surface (in $\AA$ ). The open circles indicate the values on $\mathrm{N}_{\mathrm{W}}^{\mathrm{m}}$ for each (110) plane that was pulse field-evaporated while the solid circles represent averages for groups of ten (110) planes. The oscillations about these average values are connected with the physics of the field-evaporation process and we have discussed them elsewhere. (31) The values of $N_{W}^{m}$, $N_{\text {He }}^{m}$ for each of the initial

+ The experiments of Mũller and co-workers indicated that this is, indeed, the case. 
Figure 10: An integral profile for the oase of a $500 \mathrm{eV}$ He ion implantation into a tungsten specimen which was maintained at $60 \mathrm{~K}$ both during the implantation and the atom-probe FIM analysis. The ion beam. was paralle] to the [110] direction, within $\pm 5^{\circ}$, of tungsten. The graph exhibits the cumulative number of helium atoms as $a$ function of depth from the irradiated (110) surface-in $\AA$. 


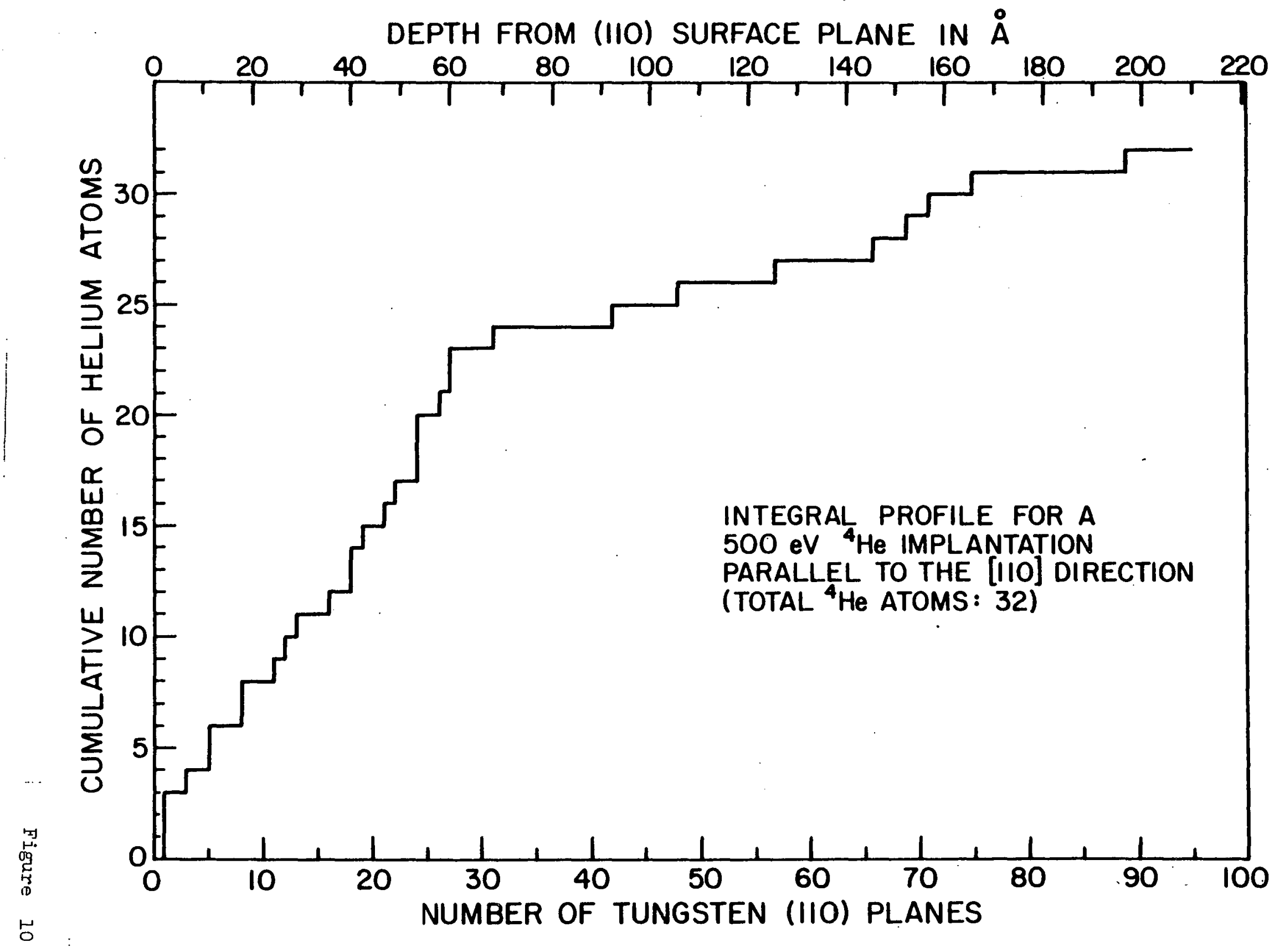


Figure 11: The measured number of tungsten atoms detected per (110) plane $\left(N_{W}^{m}\right)$ as a function of depth (in $\AA$ ) from the (110) irradiated surface. The open circles indicate the number of tungsten atoms for each (110) plane pulse field-evaporated, while the solid circles represent average values for 10 (110) planes. 

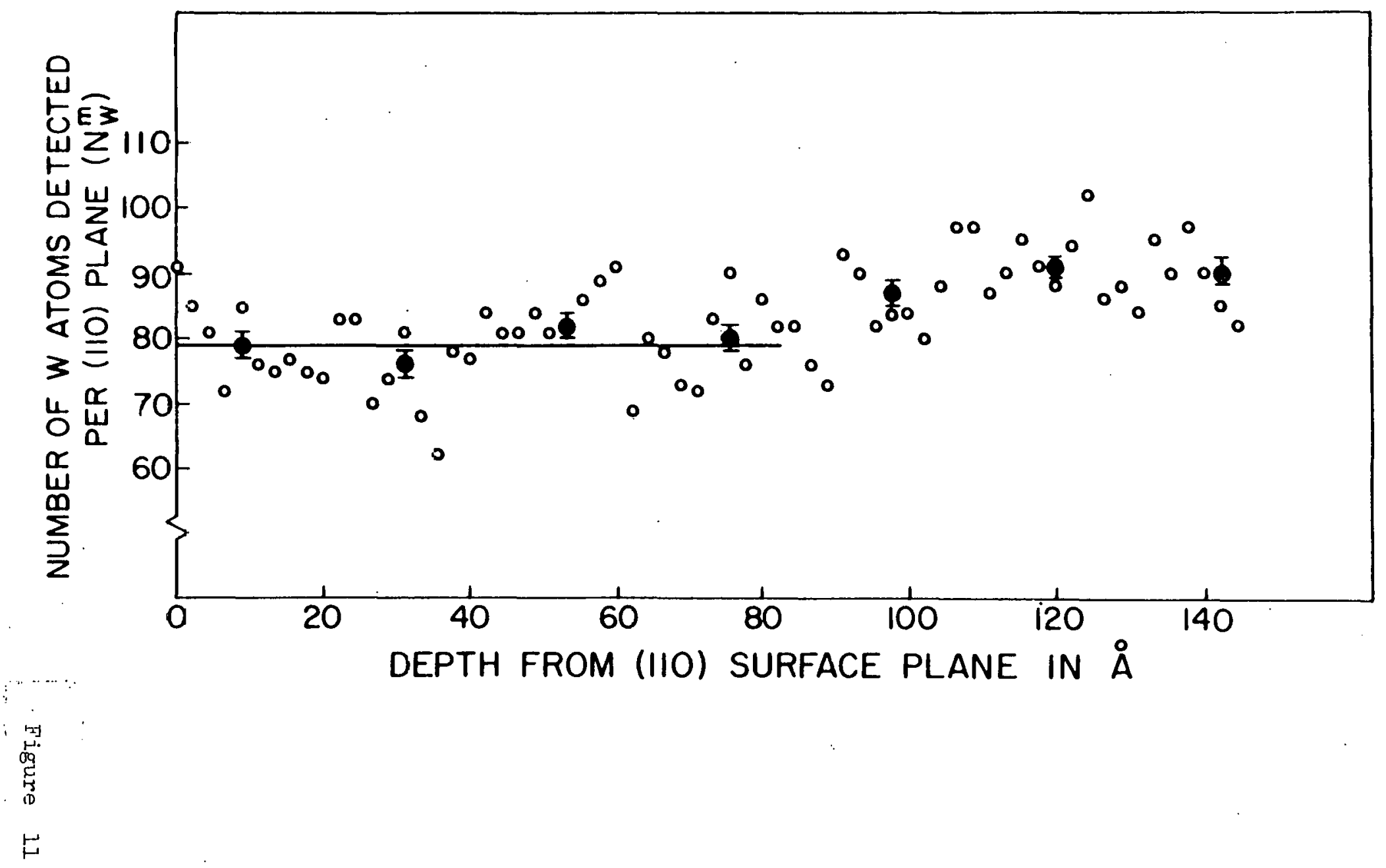
helium ion energies employed are listed in Tables 2 and 3 for all the ${ }^{3} \mathrm{He}$ and ${ }^{4} \mathrm{He}$ implantations, respectively, performed at $60 \mathrm{~K}$. The measured values of $\Phi_{d}$ and the calculated values of $T_{N}$ and $R_{N}$ are also listed in Tables 2 and 3 for ${ }^{3} \mathrm{He}$ and ${ }^{4} \mathrm{He}$, respectively.

In fig. 12 we have plotted the experimental values of $R_{N}\left(R_{N}=1-T_{N}\right)$ as a function of the ion energy of the incident helium ions. The error bars associated with each data point were calculated employing the spread in the range of $\alpha$; that is, $\alpha$ equal to $2.5 \pm \begin{aligned} & 0.36 \\ & 0.28\end{aligned}$. Values of $R_{N}$, determined employing the TRIM (TRansport of Ions in Matter) Monte Carlo simulation program, are also indicated in fig.12. (40) The TRIM program employed a Moliére interatomic potential and an impact parameter dependent electronic stopping power, The experiment.a.l values nf $B_{\mathbb{N}}$ dscrossed from 0.0 .85 to 0.25 as the energy of the incident helium ion beam was increased from 100 to 1500 eV. The values of $R_{N}$ calculated employing the TRIM program are in fair agreement with our experimental values between 300 and $1500 \mathrm{eV}$. Below $300 \mathrm{eV}$ the experimental values of $R_{N}$ were somewhat greater than TRIM values. Possible reasons for this differ-. ence below $300 \mathrm{eV}$ are as follows: (1) many-body collisions effects; (2) surface relaxation effects; and (3) the use of an amorphous solid model in the TRIM. Finally we note that the experimental values of $R_{N}$ were not prerise enough to detect significant differences between the sets of ${ }^{3} \mathrm{He}$ and ${ }^{4} \mathrm{He}$ values.

\section{E. SEGREGATION OF SOLUTE ATOMS TO VOIDS IN FAST-NEUTRON IRRADIATED REFRACTORY METALS AIND ALLOYS (H.Morikawa)}

\section{INTRODUCTION}

A number of mechanisms for the nucleation and growth of the voids and interstitial dislocation-loops that are observed in fast-neutron, ion or electron-irradiated metals have been proposed. Void-nucleation mechanisms have received considerable theoretical $(41,42)$ and experimental $(43,44)$ attention. It has been suggested, many times, that void nucleation may occur either homogeneously or heterogeneously; in the latter case at defects such as impurity atoms (particularly the interstitial impurities $\mathrm{He}, \mathrm{C}, \mathbb{N}$ or 0 ), depleted zones, precipitates, gas bubbles, etc. Although no single mechanism is able 
Taile 2: Values of the parameters revelant to the measurement of the particle retention $\left(T_{N}\right)$ and particle reflection $\left(R_{N}\right)$ coeficicients for $3_{\mathrm{He}}$ on the (110) plane of tungsten at $60 \mathrm{~K}$.

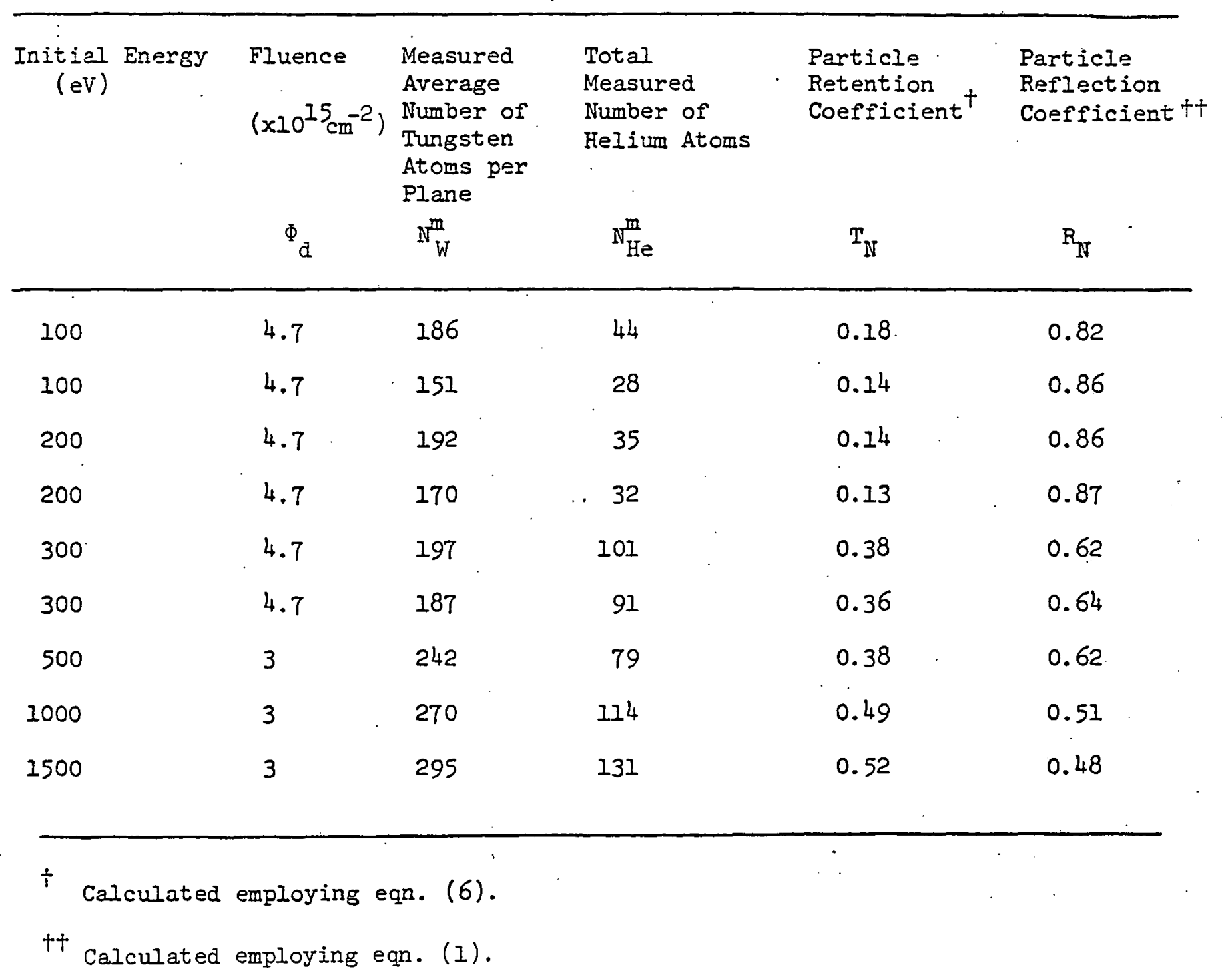


Taje = 3: Values of the parameters revelant to the measurement of the particle retention $\left(T_{N}\right)$ and particle reflection $\left(R_{N}\right)$ coeficients for ${ }^{4} \mathrm{He}$ on the (110) plane of tungsten at $60 \mathrm{~K}$.

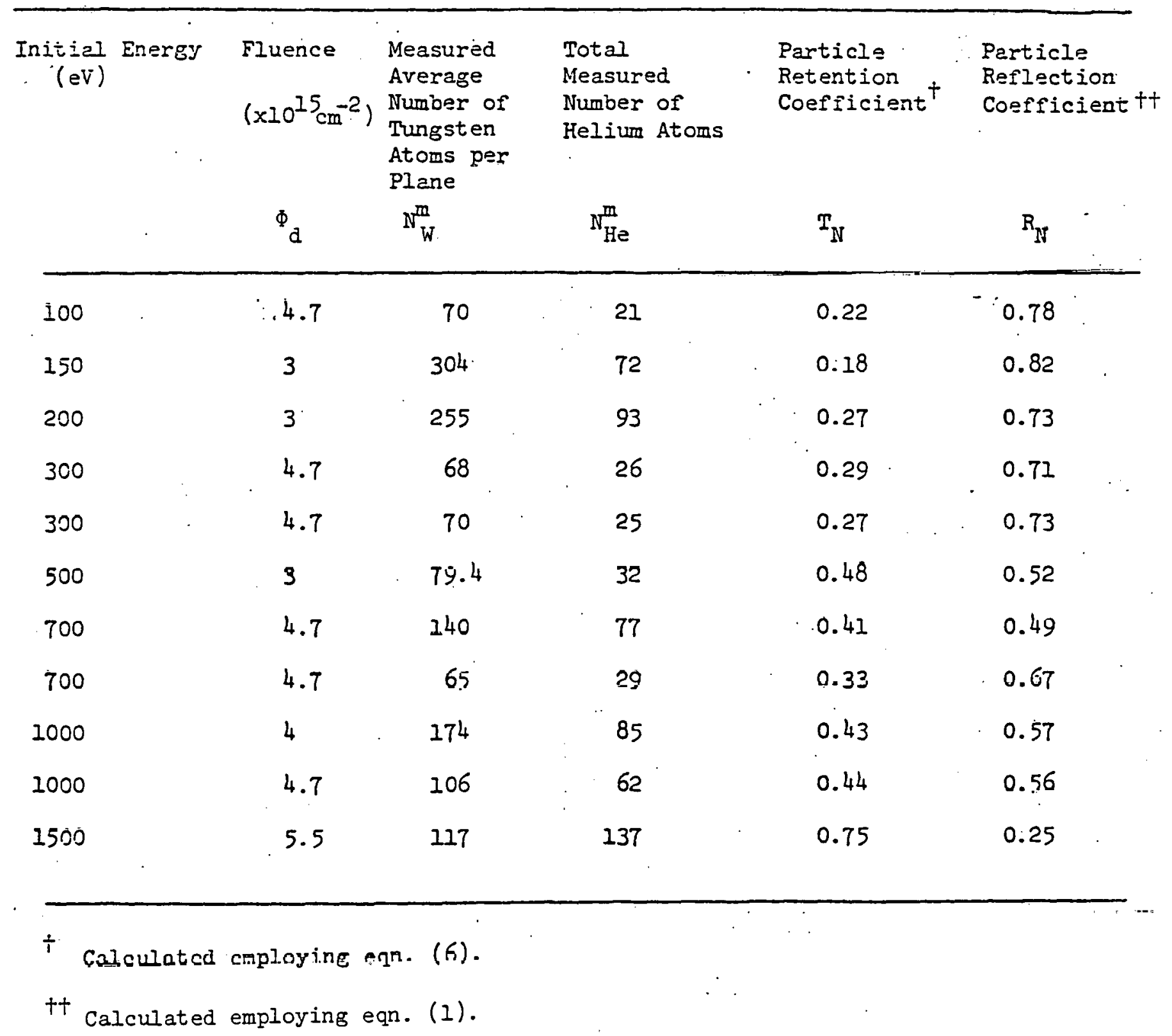




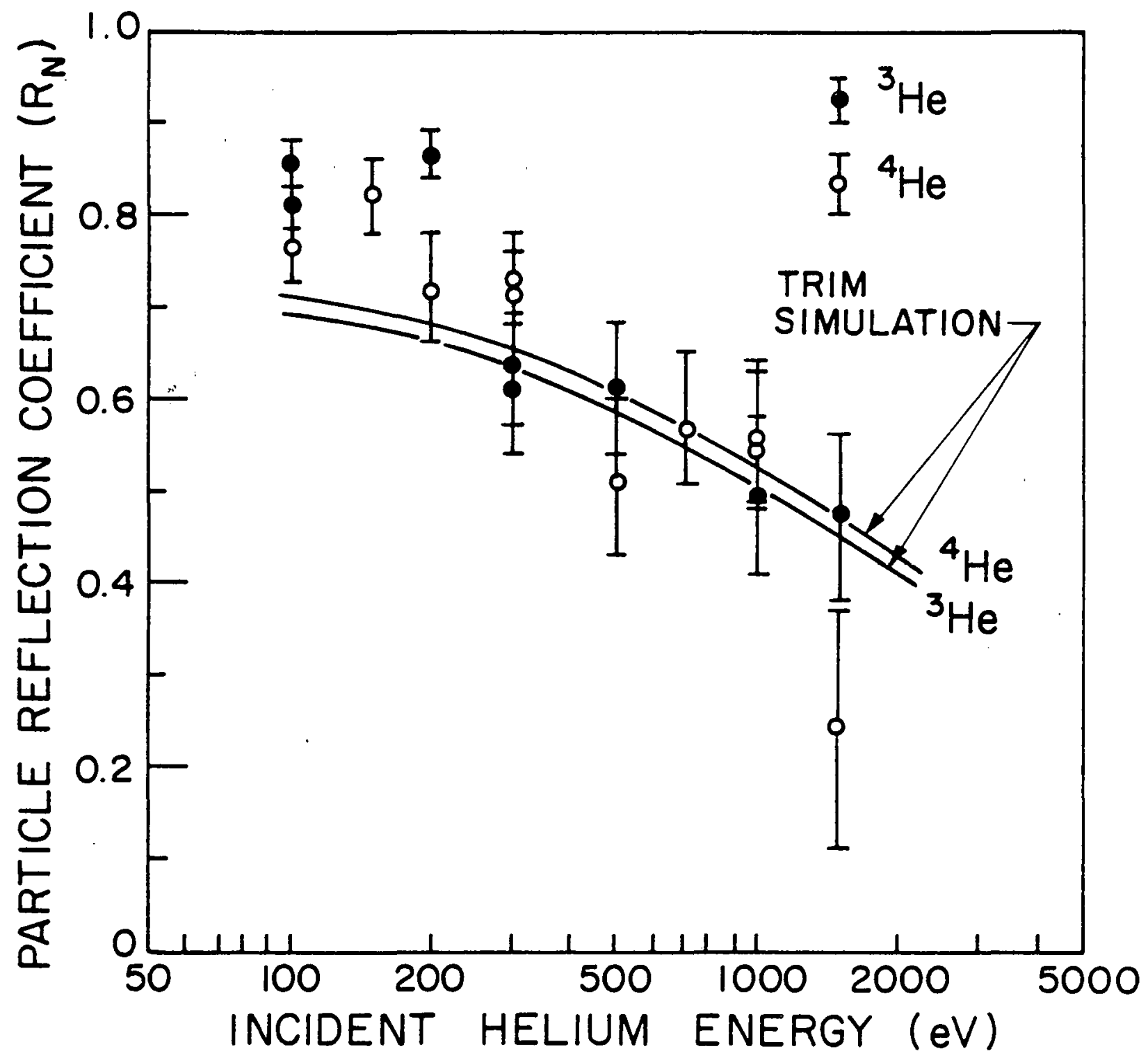
energy of the incident helium ions in $\mathrm{N}$. 
to explain all of the experimental observations, it is generally believed that impurities or alloying additions are a major factor in controlling the void nucleation rate. (44)

The void-growth problem has been modeled by employing either diffusion-limited kinetics $(45)$ in which the void growth-rate is determined by the vacancy diffusivity or surface-reaction limited kinetics ${ }^{(46)}$ in which the void growth-rate is determined by the ability of the sink-lattice interface to absorb point defects. In both models impurity atoms or alloying additions are expected to have a strong effect on the growth rate. In addition segregation (equilibrium or non-equilibrium) of foreign atoms to the voids or dislocations may have a profound influence on their sink properties by, for example: (I) changing the elastic strain-field around a sink and hence changing the bias of the sink to vacancies or self-interstitial atoms (SIAs) ${ }^{(47)}$; modifying the surface-reaction kinetics; and (3) inhibiting the climb of dislocations. If tightly-bound SIA-solute atom or vacancy-solute atom complexes form, then a substantial amount of non-equilibrium segregation of the solute to point defect sinks must occur. $(48-50)$

Observations of massive non-equilibrium solute segregation to voids have been made that were based either on the segregation-induced strain-field around the void or on the irradiation-induced precipitation ${ }^{*}$ of second-phase particles. (51-53) Direct chemical identification of Si segregation to voids in neutron-irradiated aluminum (54) and Si segregation to dislocation loops in ion-irradiated stainless steel (55) has been accomplished employing a scanning-transmission electron-microscope (STEM) equipped with an energy-dispersive X-ray analyzer. Although this method is clearly superior to the more indirect methods previously employed, it is, at present, of limited usefulness in the study of segregation effects in the bcc metals and alloys for the following reasons: ( 1 ) the distance between voids in the bcc metals ( $\approx 200 \AA$ ) is of the order of minimum diameter which is analyzed chemically; (2) the concentration limit of detect-

* See special issue of Journal of Nuclear Materials [83, 1-238 (1979)] on irradiation induced segregation effects for a reasonably up-to-date review of this field. 
ability is $5000 \mathrm{wt} \mathrm{ppm}$; and (3) the detectable elements range from $\mathrm{Na}$ to $\mathrm{U}$ in the periodic table, so that one cannot detect the low atomic-number elements such as $\mathrm{H}$, $\mathrm{He}, \mathrm{C}, \mathrm{N}$ and $\mathrm{O}$, which are believed to be particularly important impurities in the bcc metals ${ }^{* *}$. Because of the unique capability of the atom-probe FIM to identify chemically all of the elements, in addition to providing quantitative chemicalanalysis on an atomic scale, the atom-probe FIM is ideally suited to study segregation effects in the bcc metals and alloys.

\section{A BRIEF REVIEW OF OUR PREVIOUS WORK IN THIS AREA}

Recently we published an article ${ }^{(56)}$ entitled "Direct Observation of Solute Segregation to Voids in a Fast-Neutron Irradiated Mo/1.0 at.\% Ti Alloy." In this work we employed the atom-probe field-ion microscope (FIM) to study segregation effects to voids, in a Mo/l.0 at.\% Ti alloy specimen; this specimen had been irradiated with fast neutrons at $\sim 700^{\circ} \mathrm{C}$, to a fluence of $\sim 1 \times 10^{22} \mathrm{n} / \mathrm{cm}^{2}$ ( $E>I \mathrm{MeV}$ ), in the row 7 midplane position of EBR-1l. It had been shown previously by several other research groups, that this alloy exhibits an enhanced swelling relative to pure Mo under fast-neutron irradiation. The results of the present work, on this alloy, indicated that: (I) titanium does not segregate significantly to voids; (2) the concentration of titanium in solid solution and the spatial distribution of titanium was not affected significantly by the irradiation at $700^{\circ} \mathrm{C}$; (3) carbon was not detected in solid solution in either the irradiated or unirradiated specimens; (4) the preceeding two results indicated that large-scale resolution of $\mathrm{TiC}$ or $\mathrm{Mo}_{2} \mathrm{C}$ precipitates had not occurred as a result of the irradiation; and (5) segregation of carbon to a void was detected. The small amount of carbon segregation which had been detected may have been sufficient to enhance the nucleation rate and/or change the sink properties of a void and thus affect the void growth-rate.

**

The values mentioned in points 1 to 3 are for a JEM 100CX TEMSCAN. The use of electron-energy-loss-spectroscopy (EELS) is useful for the detection of these low atomic-number elements; however the application of this technique to the study of irradiation induced segregation effects has not yet been made. 


\section{AN EXAMPLE OF EVIDENCE FOR THE SEGREGATION OF CARBON TO A VOID}

Three successive stages in the FIM examination of a void are shown in fig. 13; the diameter of this void was estimated to be greater than $50 \AA$. Figure 13a:ishows the void prior to the atom-probe FIM analysis and indicates--via the white circle--the chemically analyzed region. The chemical analysis was interrupted and a second observation of the void was made as shown in fig. 13b. Note that the void was still present in the specimen, which indicated that the material adjacent to this void was still in the process of being chemically analyzed. The atom-probe FIM analysis was then continued until the entire region surrounding the void had been pulse fieldevaporated atom-by-atom and hence chemically analyzed. The FIM image of the specimen, taken after the atom-probe FIM dnalysis had been completed, clearly indicated that the void was no longer present in the specimen as shown in fig. $13 \mathrm{c}$.

The Ti integral-profile showing the spatial distribution of $T i$ in the region surrounding the second void and for the region leading away from this void is presented in fig. 14. The point at which the atom-probe FIM analysis was intermupted and a visual observation of this void was made is also indicated in this figure. Within the expected statistical fluctuations the slope of the integral profile in the region of the void was essentially the same as the slope in the region leading away from the void. Thus the Ti was approximately uniformly distributed within the analyzed region. Furthermore, the measured $\mathrm{Ti}$ concentration was $(0.20 \pm 0.05)$ at $\% \mathrm{Ti}$; this value is in approximate agreement with the measured range of $\mathrm{Ti}$ concentration for the unirradiated alloy (see table 4). Therefore no evidence of massive segregation of Ti to the voids was found. In addition to titanium, carbon was also detected at a concentration of $\sim(0.08 \pm 0.03)$ at.\%c. The carbon integral-profile is presented in fig. 15, which shows an approximately uniform distribution of carbon throughout the analyzed region. This indicates that the carbon was probably not contained in a TiC precipitate associated with the void. No evidence of a precipitate was found in the FIM images. The presence of carbon around this void is in sharp contrast with the failure to detect any carbon in solid solution in the unirradiated alloy. This result indicates that either: (1) the carbon had segregated to a pre-existing void during the irradiation; 
Figure 13: Three FIM micrographs showing a void (see white circles) in a neutron-irradiated specimen; (a) is before, (b) is during, and $(c)$ is after an atom-probe analysis. The solid-black circle below the white circles in the probe hole. 

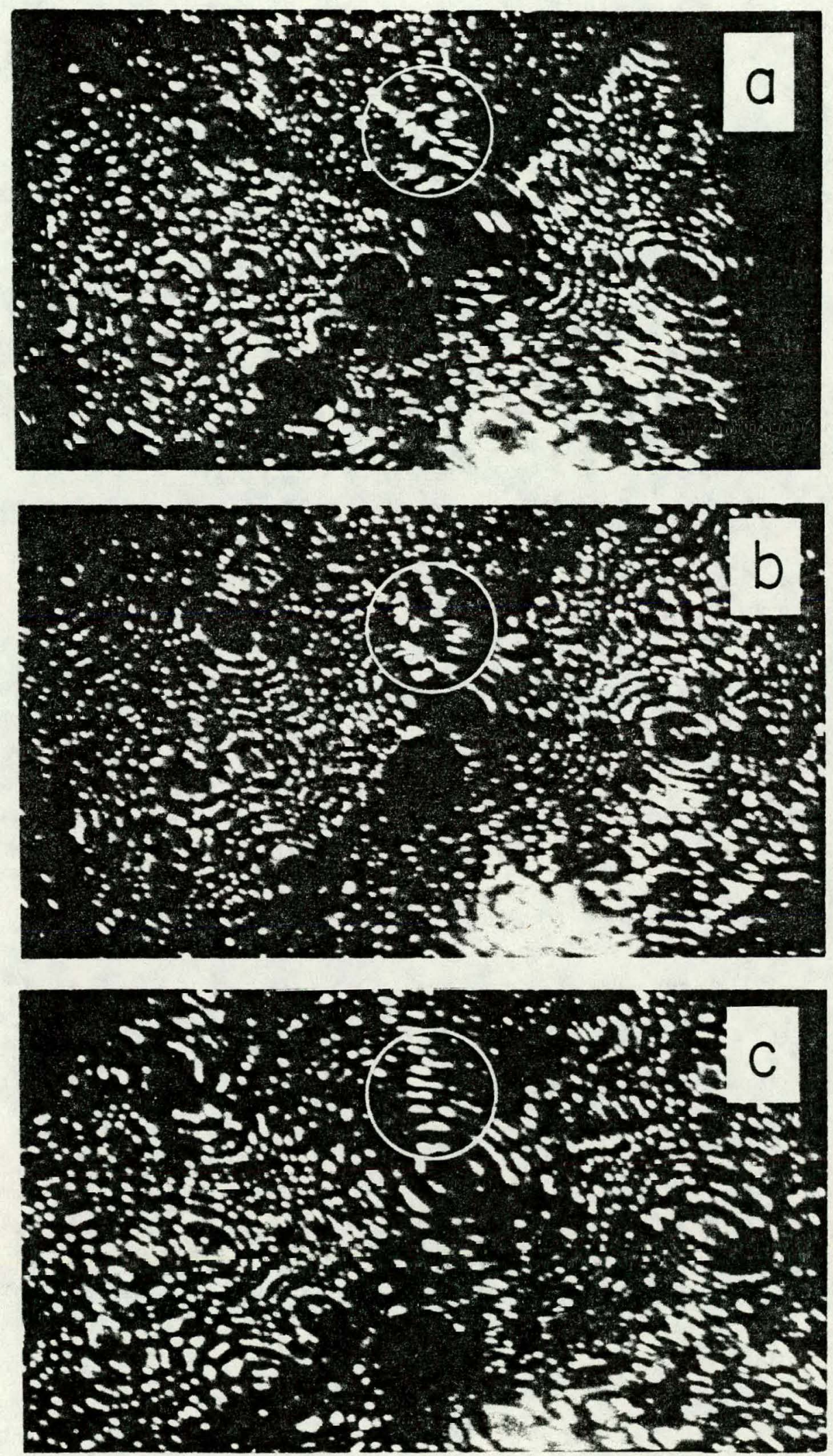
or (2) the carbon was initially incorporated into a void embryo which subsequently grew into a void.

An atom-probe FIM analysis of a region which did not contain any voids was also performed. The integral profile exhibiting the spatial distribution of the Ti. remaining in solid solution in the irradiated alloy is shown in fig. 16. The Ti appears to be approximately uniformly distributed with no evidence that strong clustering of Ti atoms had occurred. A concentration of $(0.27 \pm 0.05)$ at.\% $\mathrm{Ti}$ was measured, which is within the range of the measured $\mathrm{Ti}$ concentration for the unirratiated alloy (see Table 4). This result shows that both the concentration of the Ti remaining in solid solution and the spatial distribution of the Ti were not affected by the irradiation. Thus a very substantial irradiation-induced resolution of Ti from the TiC precipitates had not occurred. Furthermore no carbon was detected in this mun which indicates that carbon was not left in solid solution in the irradiated material. This result confirms the observation that the carbon detected during the analysis of the void must have been associated with the void. The measured composition for the irradiated alloy is summarized in table 5 which can be compared with the chemical analysis of the unirradiated alloy that is presented in table 4.

The results on the irradiated and the unirradiated Mo/1.0 at.\% Ti are now summarized: (1) no evidence of very significant segregation of Ti to voids in the neutron-irradiated alloy has been found; (2) the concentration of $\mathrm{Ti}$ remaining in solid solution and the spatial distribution of the $\mathrm{Ti}$ was not significantly affected by fast-neutron irradiation at $700^{\circ} \mathrm{C}$; (3) carbon was not detected in solid solution in either the irradiated or the unirradiated alloy; (4) results 2 and 3 indicate that large scale resolution of the TiC or $\mathrm{Mo}_{2} \mathrm{C}$ precipitates had not occurred as a result of the irradiation: one cannot rule out some resolution of TiC because of the range of $\mathrm{Ti}$ concentrations detected in the unirradiated control specimens; and (5) segregation of carbon to a void in the irradiated alloy was detected.

* Chang and Perlmutter $(57)$ have shown that TiC precipitates do not thermally dissolve in $\mathrm{Mo} / \mathrm{I}$ at.\% $\mathrm{Ti}$ for temperatures less than $\approx 1600^{\circ} \mathrm{C}$. 


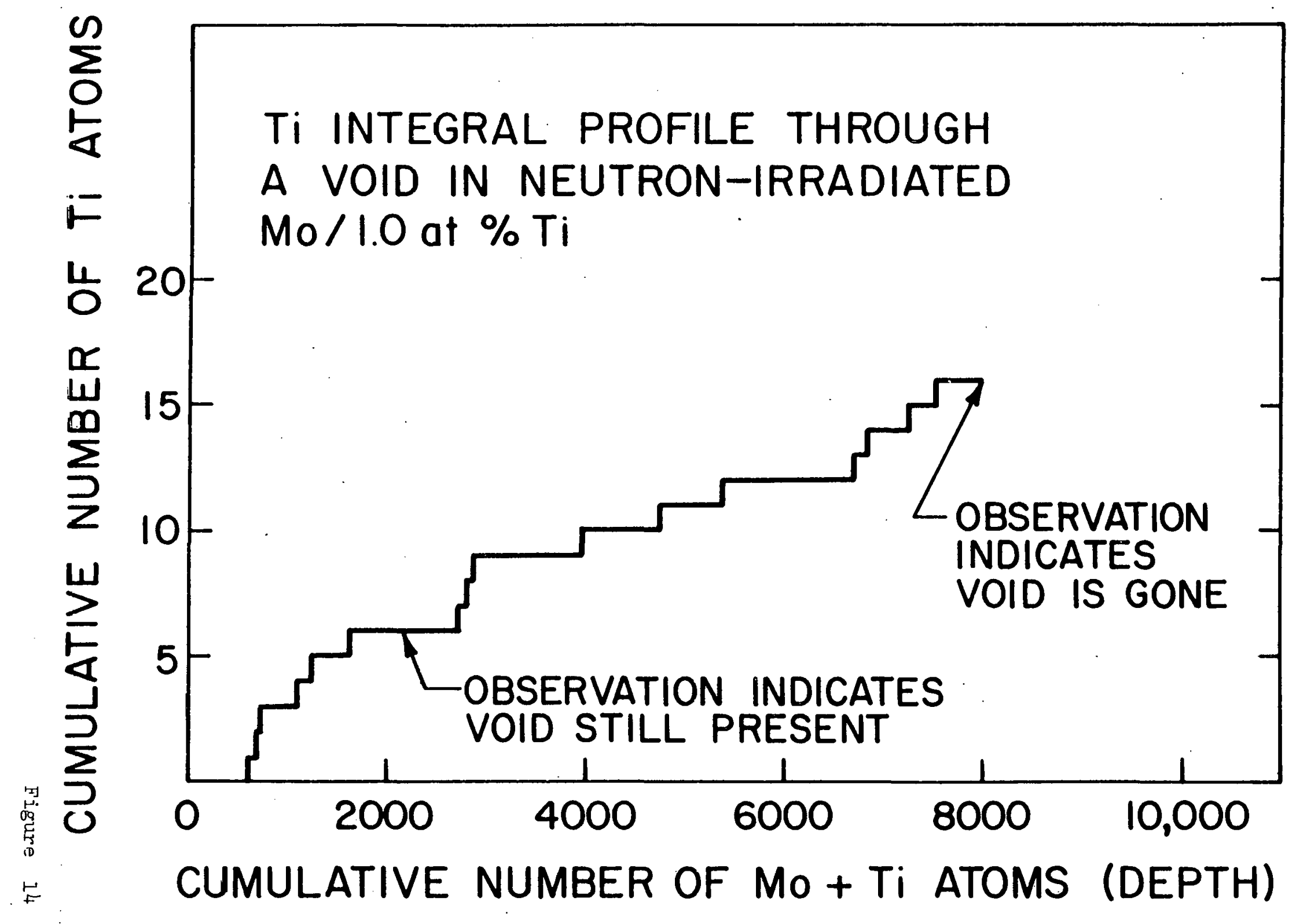


Figure 14: The Ti integral profile for the region surrouning and leading away from the void show in fig.13 for a neutron-irradiated specimen. The average $\mathrm{Ti}$ concentration is $(0.20 \pm 0.05)$ at.\% $\mathrm{Ti}$; on the depth scale. 10,000 (Mo + Ti) atoms is approximately: equal to $200 \mathrm{~A}$. 
Table 4: Comparison of the composition of a Mo/1.0 at\% Ti alloy determined by the FIM atom-probe technique versus the composition supplied by the manufacturer

\begin{tabular}{|c|c|c|c|c|c|}
\hline \multirow{2}{*}{$\begin{array}{l}\text { Run } \\
\text { Number }\end{array}$} & \multicolumn{3}{|c|}{ Number of atoms } & \multicolumn{2}{|c|}{ Concentration $(a t \%)^{a}$} \\
\hline & Mo & $\mathrm{Ti}$ & $\mathrm{C}$ & $\mathrm{Ti}$ & $C$ \\
\hline 1 & 10,680 & 40 & 0 & $0.37 \pm 0.06$ & $<0.01$ \\
\hline 2 & 5,408 & 28 & 0 & $0.52 \pm 0.10$ & $<0.02$ \\
\hline 3 & 10,884 & 30 & 0 & $0.27 \pm 0.05$ & $<0.01$ \\
\hline \multicolumn{4}{|c|}{ Universal Cyclops Steel } & 0.90 & 0.24 \\
\hline
\end{tabular}

a) The \pm values were calculated from the $\sqrt{\mathbb{N}} / \Sigma \mathbb{N}$ values where $\mathbb{N}$ is the number of atoms detected. 
Figure 15: The carbon integral profile for the region surrounding and leading away from the void shown in fig.l3 for a neutronirradiated specimen. The average carbon concentration is $(U .08 \pm 0.03)$ at. $\% \mathrm{C}$; on the depth scale, 10,000 (Mo + Ti) atoms is approximately equal to $200 \AA$. 


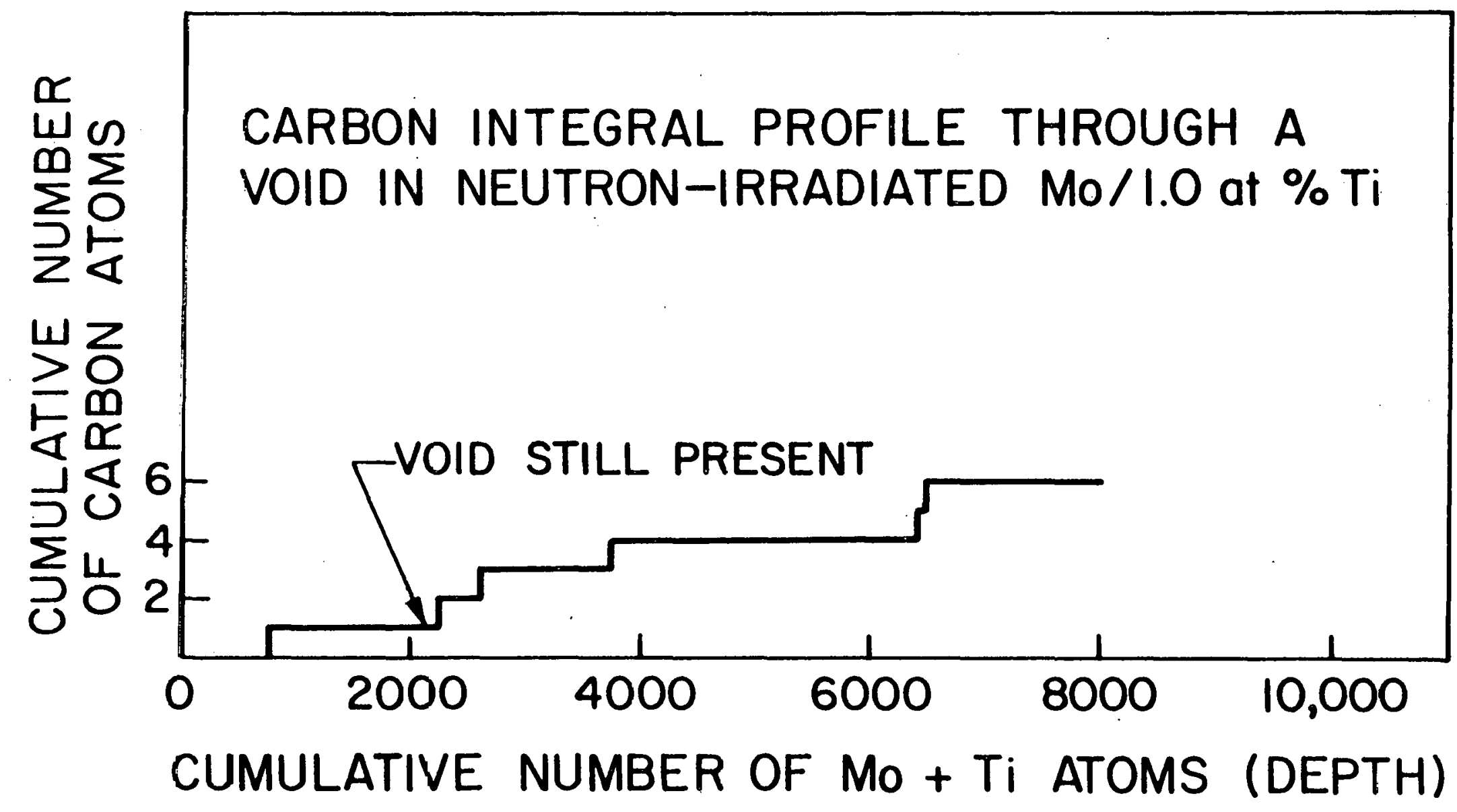


Figure 16: The Ti integral profile through a region not containing any voids in a neutron-irradiated specimen. The average Ti concentration is $(0.27 \pm 0.05)$ at.\% Ti; on the depth scaje, 10,000 (Mo $+\mathrm{Ti}$ ) atoms is approximately equal to $200 \AA$. 


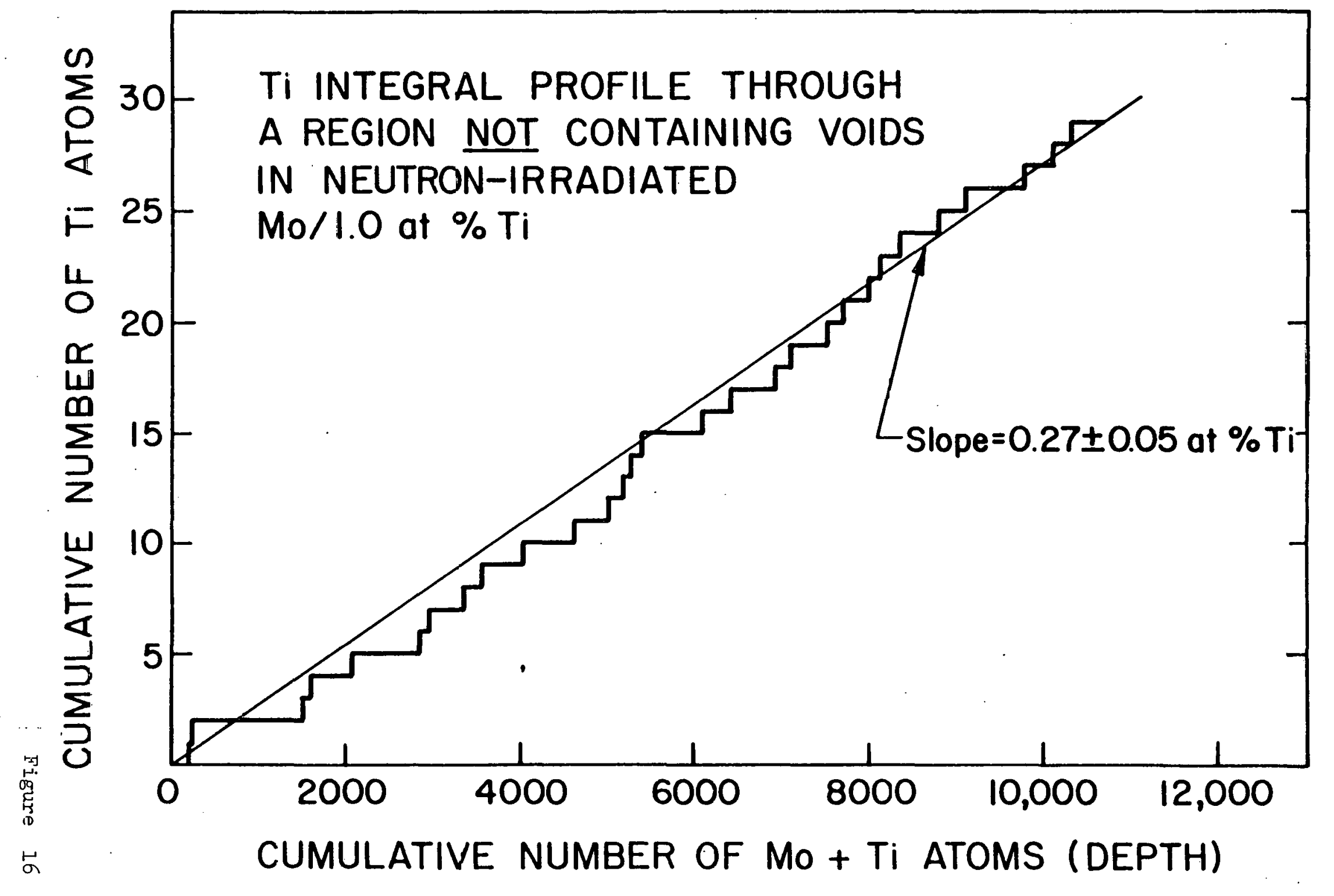


Table 5: The composition of a neutron-irradiated Mo/1.0 at\% Ti alloy determined by the atom-probe FIM technique

\begin{tabular}{|c|c|c|c|c|c|}
\hline \multirow[t]{2}{*}{ Region analyzed } & \multicolumn{3}{|c|}{ Number of atoms detected } & \multicolumn{2}{|c|}{ Concentration $\left.(\text { at } \%)^{a}\right)$} \\
\hline & Mo & $\mathrm{Ti}$ & $\mathrm{C}$ & $\mathrm{Ti}$ & $\mathrm{C}$ \\
\hline Void number I & $7^{1 / 3}$ & 3 & 0 & $0.11 \pm 0.2$ & $\therefore 0.1$ \\
\hline Void number 2 & 8,003 & 16 & 0 & $0.20 \pm 0.05$ & $0.8 \pm 0.03$ \\
\hline Void free region & $.10,663$ & 29 & 0 & $0.27 \pm 0.05$ & $<0.01$ \\
\hline
\end{tabular}

a) The \pm values were calculated from the $\sqrt{\mathbb{N}} / \Sigma N$ values where $N$ is the number of atoms detected. 
4. DISCUSSION

The enhanced swelling of the alloy Mo/1.0 at.\% Ti relative to pure Mo $(58-60)$ has been attributed primarily to an increase in the void number-density and to a lesser degree to an increase in the average diameter (or volume) of the voids in the alloy (59). These observations suggest that both the nucleation rate and the void growth-rate were larger in the alloy than in pure Mo.

The results presented implied that the enhanced swelling cannot be attributed to the massive segregation of $\mathrm{Ti}$ to voids. The kinetic model calculation of Johnson and $\operatorname{Iam}^{(61)}$ indicated that no enhanced segregation effects can be expected when the binding enthalpies between a solute atom and a SIA and between a solute atom and a vacancy are zero. In addition, in the case of voids the amount of enhanced segregation was also found to be a function of the diameter of the void by Johnson and Lam [see fig. 5 in (62) ]; the solute enhancement-factor decreased with decreasing void-diameter. Therefore, our experimental observations may indicate that the values of the binding enthalpies between $\mathrm{Ti}$ and the two elementary point defects (the vacancy and the SIA) are vanishingly small, Unfortunately, no measurements of these important binding enthalpies exist for the Mo/l at.\% $\mathrm{Ti}$ alloy, although we note that $\mathrm{Ti}$ is oversized with respect to Mo ${ }^{(63)}$; this latter fact may imply that tightly-bound mixed dumbells (64) do not form in the Mo(Ti) system. It is clear that experimental values of the binding enthalpies are required to make detailed quantitative conclusions regarding the absence of massive nonequilibrium segregation to voids in the Mo(Ti) system. Massive nonequilibrium-segregation of $\mathrm{T} i$ to the dislocations can probably be ruled out on the basis of the absence of segregation to voids, although equilibrium segregation of $T i$ to dislocations remains a possibility. We also note that whatever segregation had occurred it did not seem to affect the ability of the dislocations to climb in the presence of the supersaturation of point defects created by the irradiation conditions. For if segregation had decreased the ability of the dislocations to climb, this would have increased the vacancy-SIA recombination rate and hence suppressed void formation (i.e., swelling). Since the swelling was enhanced in the Mo/l.0 at.\% $\mathrm{Ti}$ 
alloy relative to pure Mo we do not believe that there was extensive segregation of $\mathrm{Ti}$ to the dislocations.

The small degree of carbon segregation which was detected may have been sufficient to enhance the nucleation rate and, therefore, to increase the void number-density in the Mo/1.0 at.\% $\mathrm{Ti}$ alloy with respect to pure Mo. In addition the carbon may have had an effect on the sink properties of the void that increased the void growth-rate; this would explain the slightly larger void-diameter in the neutron-irradiated alloy $(60)$. The carbon that was detected may have come from a small amount of irradiation-induced resolution of MoC (or TiC).

We realize, of course, that the results obtained to date do not represent $A$. definitive answer to the question of the mechanism of swelling enhancement in the Mo/ 1.0 at.\% $\mathrm{Ti}$ alloy, but they do show that it is now possible to obtain quantitative chemical information on an atomic scale that is fine enough such that the present approach may ultimately provide the information required to answer this question. 5. CURRENT RESEARCH ACTIVITIES AND OBJECTIVES

Over four years ago we sent a total of seventy specimens, in the form of wires, to Oak Ridge National Laboratory (ORNL) to be fast neutron irradiated. This summer we received these specimens back. The different types of specimens returned to us are as f'ollows: (a) pure tungsten; (b) W-1\%Re; (c) W-3\%Re; (d) W-5\%Re; (ê) W-10\%Re; (f) W-25\%Re; (g) pure molybdenum; (h) Mo-0.5\% Ti; (i) Mo-0.5\%Ti-0.08\%Zr; (j) Mo-10\%Re; (k) pure iron; and (1) Fe-3\%Si. For each of the above twelve types of alloys there are five specimens.

At present we have started to examine these specimens by atom probe field-ion microscopy. The objectives of the present research program are to:

(1) Try to find evidence for radiation induced precipitation (RIP) that is homogeneous on a fine scale--that is, the formation of precipitates at a number density of greater than $10^{17} \mathrm{~cm}-3$ that are not associated with structural defects (dislocations, interfaces and voids). Cauvin and Mart in $(65)$ have found evidence for homogeneous RIP in undersaturated aluminum ( $z i n c$ ) alloys employing electron irradiation. And Sikka and Moteff ${ }^{(66)}$ 
have found evidence for a metastable phase in a first-neutron irradiated tungsten (rhenium) alloy. Thus, the tungsten (rhenium) specimens are particularly useful in searching for RIP that is homogeneous on a fine scale.

(2) Study all the alloys for examples of RIP that is heterogeneous on a fine scale; for example, segregation to voids that exist at a number density greater than $10^{17} \mathrm{~cm}^{-3}$.

(3) Search for the species that are responsible for the nucleation of voids. In particular; the voids are being examined for the interstitial impurities helium, carbon, nitrogen and oxygen.

F. GROWTH OF SILICON AND III-V COMPOUND SEMICONDUCTING WHISKERS FOR THE STUDY OF METAL-SEMICONDUCTOR AND INSULATOR-SEMICONDUCTOR INTERFACES (J.C. Barbour,

\section{B. Reding and B. Moser)}

\section{INTRODUCTION}

As part of the new program on the nature of metal-semiconductor and insulatorsemiconductor interfaces it was concluded that the preparation of the silicon specimens could best be done in our own laboratory. A main reason for this is that the electrical properties of silicon are extremely sensitive to the level of dopants used and that there is a need to control these levels in order to obtain optimum images of silicon (see $\xi \vec{G}$ ); in addition, it is known that the diffusive properties of point defects are also very sensitive to the doping level. Also there are a lack of whisker growing facilities $(67,68)$ in the United States for supplying our research efforts with the necessary whiskers for our research efforts on semiconductors using field-ion and atom-probe microscopy--therefore we felt it an absolute must to be able to prepare our own semiconducting whiskers. A deficit in quantity exists for both

* The silicon whiskers currently being used by our group. (see $\S G$ ) were supplied by Dr. R.S. Wagner, Bell Laboratories (Murray Hill, New Jersey) and this supply will suon be exhausted. 


$$
-45
$$

p-type and n-type whiskers. Also, a correlation between the concentration of dopant gases in the Vapor-Liquid-Solid (VLS) technique and the resulting dopant levels (and resistivities) of the silicon whiskers is not known. Furthermore, the lack of a local whisker growing facility means we cannot regulate the shape and size of the whiskers used. Finally, to extend the research to gallium phoside (GaP) or gallium arsenide (GaAs) a system is needed which can be used to grow whiskers of these compounds as well as silicon whiskers. Therefore, the whisker growing facility we have built, at Cornell, is a unique system in which specimens can be grown by the VLS technique; also, the doping levels of whiskers can be controlled to yield specific resistivities and, therefore, we are able to relate resistivity measurements to our FIM and atom-probe studies.

\section{BACKGROUND}

Whiskers are filamentary crystals which show a single preferred direction of growth. These crystals, having a high ( $\geq 10)$ ratio of length to diameter, may grow to centimeters in length while to only fractions of a millimeter in diameter. Furthermore, the fact that whiskers have a filamentary character indicates the tip is a preferred growth site. Sears ${ }^{(T 1)}$ employed the Frank $(69)$ dislocation model of crystal growth to explain the preferred site and unidirectional nature of whiskers, whereas Wagner ${ }^{(67)}$ suggested a new concept--the vapor-liquid-solid mechanism--to describe whisker growth.

\subsection{Nucleation}

The first step in growing a crystal is the nucleation of a small particle capable of continuing the growth process before evaporating from the crystal surface. Consequently, atoms must condense (homogeneously or heterogeneously) in clusters and grow beyond a critical radius (Lawson $(70), p .176)$. If no heterogeneous nucleation sites are present, the vapor must be supersaturated to a level of 25 to 50 percent thereby increasing the probability for homogeneous nucleation. However, if impurities, dislocations or other heterogeneous nucleation sites exist, clusters can form at supersaturation levels of only I to. 5 percent. Once the nucleus has a radius greater than its critical radius, the nucleus is stable and will continue to grow. This growth 
process occurs by atoms condensing on the nucleus and then diffusing over its surface to sites where they can attach. Suitable attachment sites are ones, corresponding to a large number of nearest neighbor, in which the surface energy of the nucleus is lowered by the addition of more atoms. If a perfect crystal had a small cluster of atoms on a face, this cluster would act as a reception site for diffusing atoms and the cluster would grow until the face was completely close-packed resulting in a loss of sites for attachment. Therefore, if growth is to continue on that face, atoms will again need to condense in a cluster to form a location for growth.

\subsection{Dịslocation Theory}

Frank ${ }^{(69)}$ theorized that real crystal growth proceeded by the condensation of atoms at a screw dislocation protruding from the crystal surface so that a closepacked face would never be formed. The screw dislocation serves as a self-perpetuating step at which atoms accomodate preferrentially thereby allowing crystal growth at low supersaturations. Theoretically, only one screw dislocation is necessary to support the growth of a crystal, and those crystals with a single axial dislocation are called whiskers. In silicon whiskers, the axial direction is observed to be the $<111>$ direction. Thus, the tip of a whisker is theoretically a fast-growing accommodation site due to the protruding screw dislocation. Price et al. (72) extended this concept by postulating impurities arriving at the fast-growing tip should become buried during rapid growth but impurities arriving on the slow-growing sides accumulate and block further growth resulting in uniaxial whiskers.

Nevertheless, the dislocation model has many shortcomings. First, studies show the <lll> direction of growth in epitaxial silicon is the slowest direction of growth rather than the fastest direction assumed in the dislocation theory. Furthermore, the dislocation model of Frank was not concerned with impurity effects; yet, in the absence of impurities, silicon is deposited as nodules or films and only when certain impurities are present is filamentary growth observed. Moreover, large whiskers have been observed to abruptly stop growing. Ruth and Hirth ${ }^{(74)}$ explain this phenomenon of abrupt growth cessation by dislocation slip from the crystal; yet, Hirth and Frank (75) 
show that dislocation slip is highly improbable for whiskers with a diameter greater than 0.1 microns. Consequently, a contradiction arises between the dislocation theory and experimental observations. Another shortcoming arises when dislocation theory is used to explain morphological instabilities. Theoretically, complex dislocation interactions are necessary to explain branching and kinking of whiskers; however, no experimental evidence exists to support the theory. Lastly, the greatest shrotcoming is the lack of experimental observation of axial screw dislocations in all whiskers. Detection of axial dislocations is necessary to prove the dislocation model. But as Wagner ${ }^{(67)}$ points out, axial dislocations are present in only some crystals leaving the questions to where did the dislocation go.or was a dislocation ever present?

\subsection{Vepor-Liquid-Solld. (VLS) Theory}

Morphology, stmuctural defects and the role of impurities in silicon whiskers were studied by Wagner who observed the following characteristics:

(i) Silicon whiskers can be grown dislocation free.

(ii) Certain impurities are necessary to grow whiskers.

(iii) Filamentary growth is a two-stage process in which an initiai leader grows quickly, followed by a slow thickening of the leader.

(iv) The impurity concentration in the leader is greater than in the subsequent epitaxial growth.

(v) The main direction of growth for silicon whiskers is the <ll1s alrection.

(vi) Silicon needles can be regrown from partly evaporated whiskers without changing their morphology and defect structure. As a result of Wagner's etudy a new concept in whisker formation was proposed--the vapor-liquidsolid technique.

The main characteristic of VIS growth is that a liquid globule. in which the crystal material is soluble, is located between the vapor and the developing crystals. The liquid in the form of a hemisphere remains on the tip of the whisker as the crystal grows under it (see fig. 17). In practice, small impurity particles are 
placed on the crystal substrate to act as the liquid forming agent and thereby control the area of whisker growth on the substrate. This liquid acts as a preferential site for deposition because the liquid has a large accommodation coefficient. (A measure of how well a deposition region can accommodate new atoms, unity being the upper limit.) In fact, theoretical calculations show a smooth liquid surface should have an accommodation coefficient of unity because the surface is made up of steps only atomic distances apart. By comparison, a screw dislocation has a smaller accommodation coefficient than a perfect liquid, and a perfect crystal is smaller still. Thus, atoms in the vapor will' condense more on the liquid interface than on the solid substrate yielding a supersaturated liquid. Consequently, the supersaturated material will precipitate out at the solid-liquid interface causing the crystal to grow under the liquid. For an isothermal deposition temperature, the liquid solution in contact with the crystalIine substrate trys to remain at the equilibrium concentration. However, the liquid receives a flux of material from its vapor-liquid-interface causing a concentration gradient to be set up in the solution. This gradient is the driving force for diffusion of the precipitating material from the vapor-liquid interface to the liquid-solid interface. Therefore, material transport in the liquid is diffusion controlled and occurs in an isothermal setting.

2.4. Requirements For A Vapor-Liquid-Solid Growth Mechanism In ordui for the VLS mechanism to yield whiskers the liquid globule must be ctablc. The atability of a liquld droplet of radius $r$ under its own vapor depends on the degree of supersaturation $\sigma$, the vapor-liquid interfacial energy $\alpha$, and the liquid molar volume $V$ such that the minimum critical radius is given by $r_{m i n}=\frac{2 \alpha V}{R T h n} \cdot A s$ a result, the diameter of a whisker is limited for VIS growth. For example, whiskers with submicron dimensions achieve stability by increasing the supersaturation of the liquid. Thus, the supersaturation level needs to be high while the initial leader is growing.

Further, Wagner $(67)$ has identified several requirements for the solution-forming agent: (1) the agent must form a liquid solution with the crystalline material to be grown at the deposition temperature. (The fact that whisker growth is usually optimum 


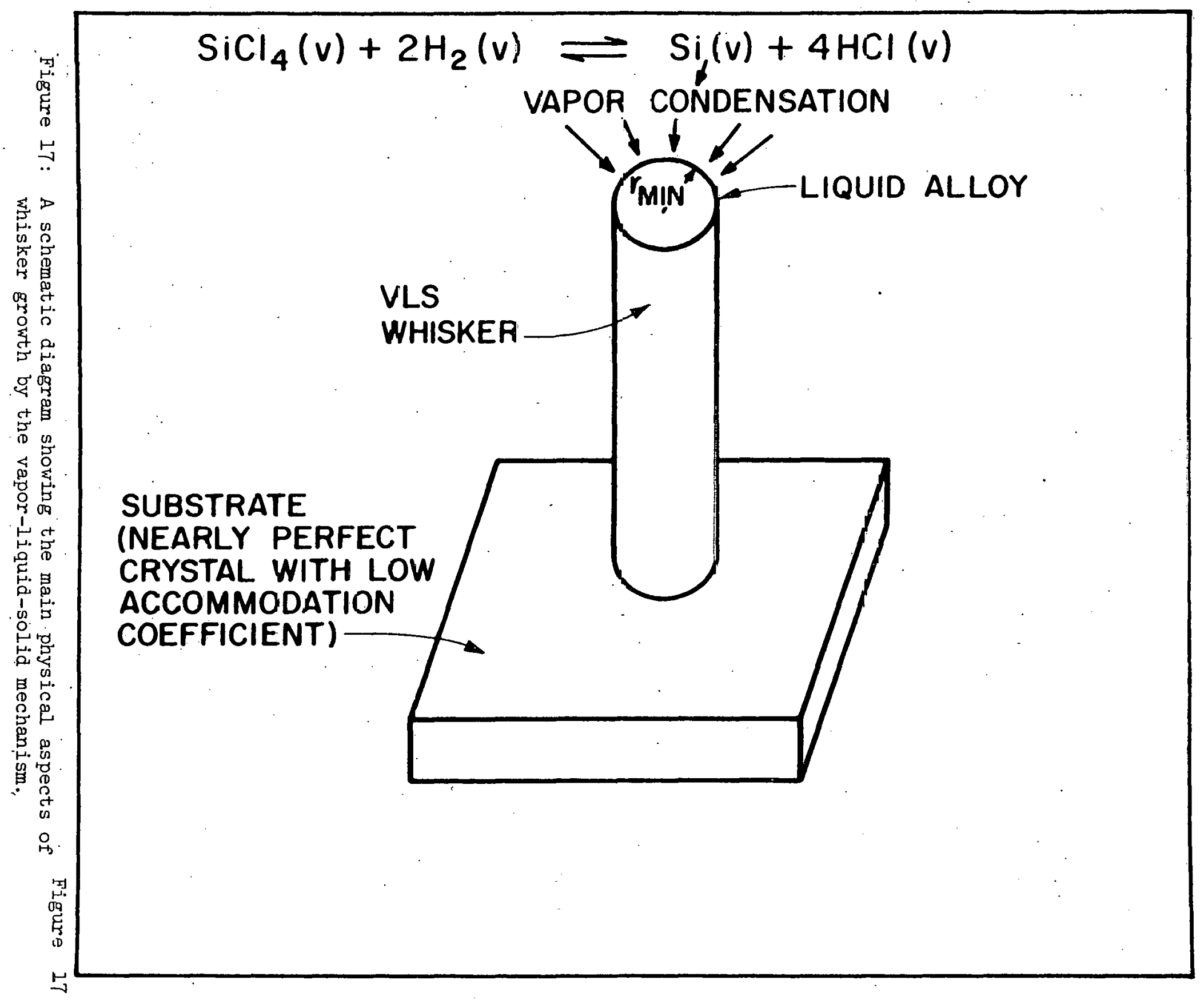


at temperatures 100 to $200^{\circ} \mathrm{C}$ below the optimal temperatures for epitaxial film growth by the CVD process is worthy of note.) (2) The agent must be more soluble in the liquid than in the solid at the deposition temperature. Moreover, to reduce the amount of impurities in the solid, the agent should have a low solid solubility. (The solid solubility has been determined to be $2 \times 10^{-5}$ atomic percent at about $1000^{\circ} \mathrm{C}$.) (3) The equilibrium vapor pressure of the agent over the liquid should be small because evaporation causes a change in the liquid volume resulting in a change in the cross sectional area of the whisker. (4) The agent must be inert with other substances in the deposition area. (If the agent is not inert, then the temperature must be selected such that an intermediate solid phase of the agent with one of the substances in the vapor does not form.) (5) A small contact angle between the liquid and the substrate, due to the nature of interfacial energies, yields a large growth area; therefore, whisker growth requires a large contact angle. (6) For controlled growth in a single direction, the liquid-solid interface must be well defined crystallographically. For example, silicon whiskers grow in the <lll> direction with the liquidsolid interface being the (111) plane parallel to the (111) surface of the silicon substrate.

\subsection{Explanation of Shortcomings In Dislocation Theory}

Wagner's VLS theory explains the shortcomings of the dislocation models for filamentary cyrstal growth. First, impurities aid whisker growth because impurities are necessary for filamentary growth rather than nodular or film growth. Next, the final stages of growth and the abrupt stoppage of growth can be explained employing the VLS concept without reference to the crystal's dimensions. That is, growth may cease at high temperatures due to evaporation of the agent, or growth may cease due to temperature fluctuations or vapor supply fluctuations causing the agent to fall off the tip. Thirdly, morphological instabilities can be directly related to conditions in the deposition environment; such as, temperature gradients, vapor supply concentration gradients, temperature fluctuations, vapor supply fluctuations, codeposition of liquid-forming impurities, etc. For example, a whisker branches when 
the liquid droplet breaks up into smaller droplets which then grow in a direction different than the initial direction due to a temperature gradient. Kinking similarly takes place owing to a temperature gradient when the droplet wets the side faces of the needle to increase surface area. Therefore, to eliminate branching and kinking of whiskers, the deposition zone should have a steady supply of vapor and should be isothermal.

\section{EXPERIMENTAL WORK}

\subsection{Work In Progress}

An initial test system for the growth of silicon whiskers was built in our group at Cornell University. A schematic diagram of the apparatus is shown in fig. 18. The substrate used is a single crystal silicon wafer supplied by the General Eleotric Corporation, Syracuse, New York, with the $\{111\}$ crystal planes parallel to the wafer surface. Gold is used as a nucleating agent in which gold particles cut from 99.999 at.\% pure gold foil are aligned in an array on the substrate. A mixture of hydrogen gas and hydrogen gas saturated with tetrachlorosilane $\left(\mathrm{SiCl}_{4}\right)$ is introduced into the reaction chamber which is heated by a tube furnace to maintain an isothermal deposition zone at about $1000^{\circ} \mathrm{C}$. The hydrogen is reduced by the following reaction to yield silicon:

$$
2 \mathrm{H}_{2}+\mathrm{SiCl}_{4} \stackrel{\mathrm{T}_{\mathrm{R}}}{\stackrel{t}{t}} 4 \mathrm{HCl}+\mathrm{Si}
$$

The deposition process can be explained in terms of the gold-silicon phase diagram exhibited in fig. 19.

Silicon is produced at temperature $\mathrm{T}_{\mathrm{R}}$ and condenses on the gold forming a liquid alloy film of composition $C_{A}$. Further deposition of silicon causes the film to thicken until the entire agent becomes a gold-silicon liquid alloy. The composition of the alloy then changes from $C_{A}$ to $C_{B}$, the equilibrium concentration of liquid gold in solid silicon at $\mathrm{T}_{\mathrm{R}}$. (Note, the entire process is considered to occur isothermally.) The high concentration of silicon in the vapor causes the droplet to become supersaturated. When the supersaturation is large enough a crystal of silicon nucleates homogeneously in the liquid or heterogeneously at the liquid-solid interface and begins to grow due to a steady silicon supersaturation of the liquid. For steady-state 
Figure 18: A diagram illustrating the apparatus used to grow whiskers by the vapor-liquid-solid technique; see the text for a description of the apparatus. 


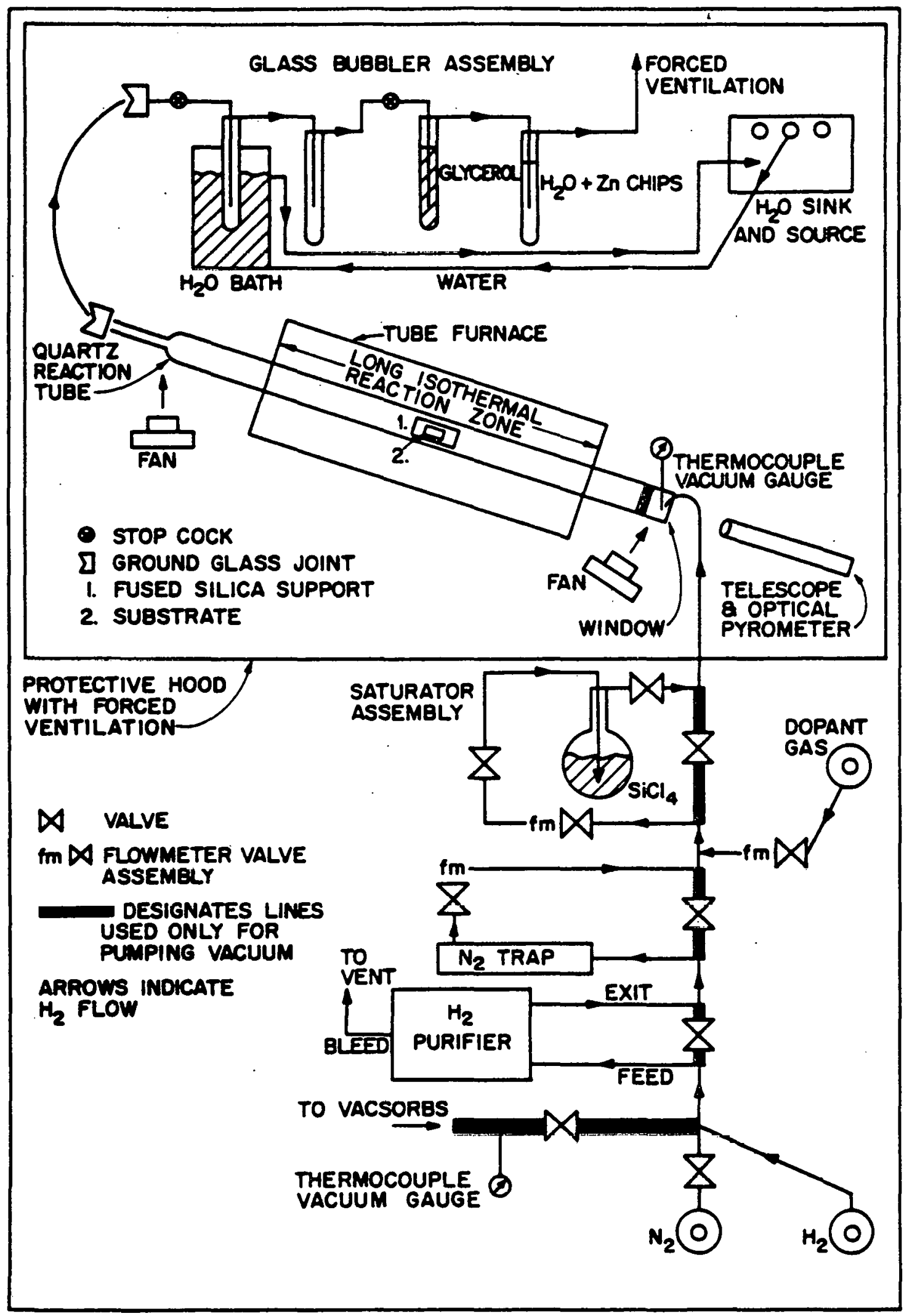




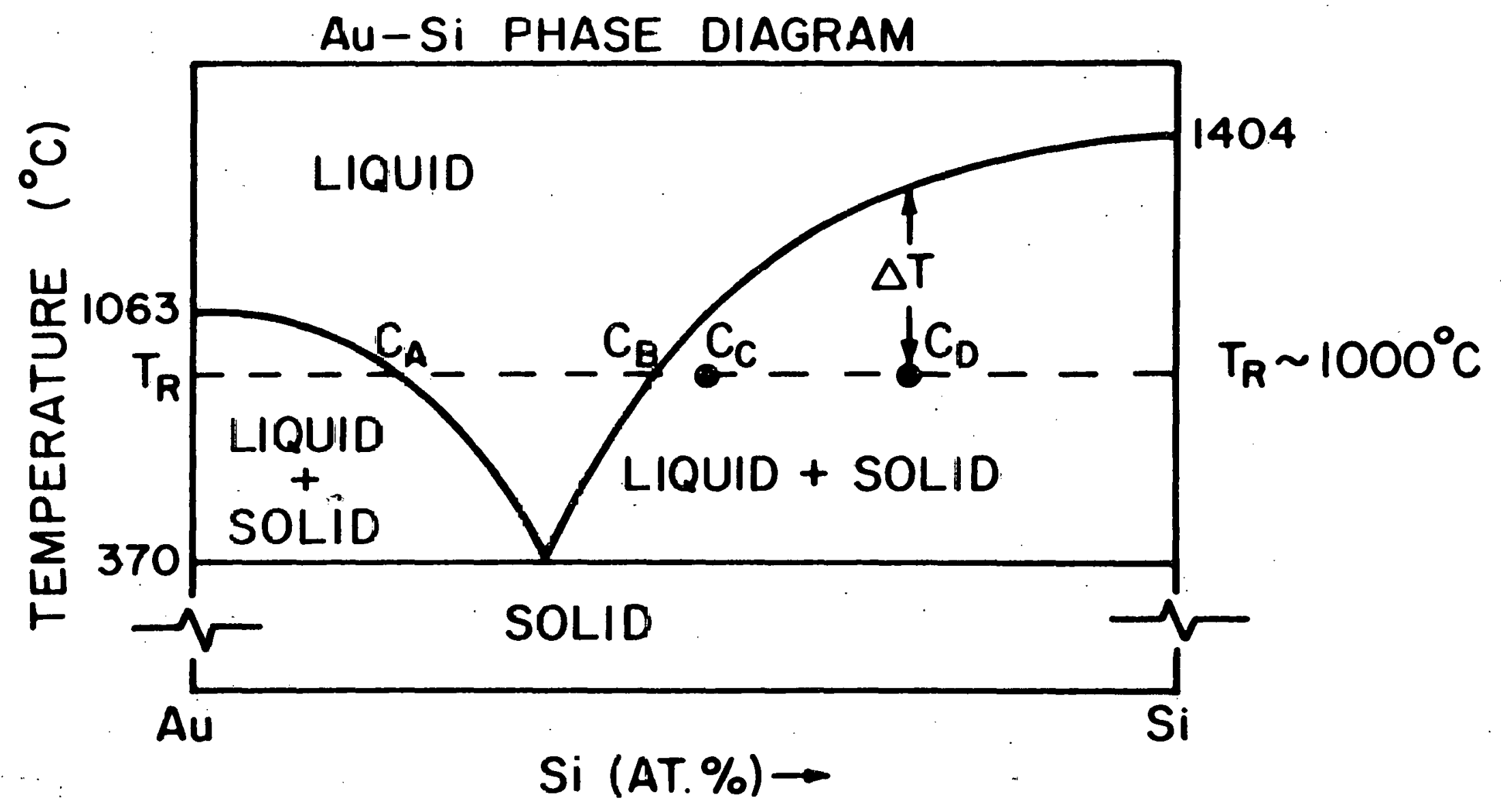


VIS: growth, the composition of the Iiquid at the vapor-liquid interface is some value $C_{D}$ while the composition near the solid-liquid interface is $C_{C}$. The lower concentration near the solid, due to silicon precipitation, causes a composition gradient $\left(\mathrm{C}_{\mathrm{D}^{-}}\right.$ ${ }_{C}$ ) which serves as the driving force for silicon to diffuse to the solid-liquid interface. The quantity $\left(C_{C}-C_{B}\right)$, which may be very small, is the supersaturation required for nucleation and growth.

Wagner suggests the VLS growth rate $v\left(\mathrm{cmsec}^{-1}\right)$ for a given total gas flow $\mathrm{f}\left(\mathrm{cm}^{3}\right.$ $\mathrm{sec}^{-1}$ ), a $\mathrm{SiCl}_{4} / \mathrm{H}_{2}$ mole ratio $\mathrm{m}_{\mathrm{R}}$, and for a reaction tube cross section $\mathrm{A}\left(\mathrm{cm}^{2}\right)$ can be estimated by

$$
v=\frac{\mathrm{fm}_{\mathrm{R}} \mathrm{M}}{\mathrm{AV} \mathrm{o}_{0} \rho} ;
$$

where $V_{0}$ is $22.4 \times 10^{3}\left(\mathrm{~cm}^{3} \mathrm{~mole} \mathrm{e}^{-1}\right) \cdot \mathrm{M}$ is the molecular weight of $\mathrm{SiCl}_{4}$ (169.92 gm Mole $\mathrm{gm}^{-1}$ ), and $\rho$ is the density of solid silicon (2.33 $\mathrm{gm} \mathrm{cm}^{-3}$ ). For our apparatus, $A$ is approximately $15 \mathrm{~cm}^{2}, \mathrm{~m}_{R}$ is about $0.02--$ the effect of varying $m_{R_{I}}$ on the whisker growth rate is being studied--and the flow rate is near $10 \mathrm{~cm}^{-3} \mathrm{sec}^{-1}$ yielding a growth rate of $4.3 \times 10^{-5} \mathrm{~cm} / \mathrm{sec}^{-1}$ or $1.56 \mathrm{~mm} \mathrm{hr}{ }^{-1}$. Thus, for a crystal to reach a length of appriximately 2 centimeters, the time of growth is about 13 hours.

\subsection{D esign Considerations}

Once the initial flow of the system was designed, the major consideration was in the area of safety. Since hot hydrogen reacts explosively with oxygen from the air, the entire apparatus is evacuated to a pressure of less. than $10^{-4}$ Torr before hydrogen is introduced. Furthermore, if the system can obtain a vacuum of $10^{-4}$ Torr before hydrogen is introduced. Furthermore, if the system can obtain a vacuum of $10^{-4}$ Torr, then a negligible amount of poisonous dopant gases and corrosive silicon tetrachloride will leak out during operation. The dopant gases used are diborane (for p-type doping) and phosphine (for $n$-type doping); both are highly toxic with threshold limits of less than a few tenths of a part per million. Therefore, the number of bends and the length of tubing leading to the reaction chamber was minimized to give efficient and rapid evacuation of the system. The system was also leak tested using a helium leak detector.

In addition to oxygen, other impurities are not wanted in the reaction tube because they interfere with whisker growth. Thus the hydrogen purifier and liquid nitrogen trap were added to significantly reduce impurities in the hydrogen carrier gas. Finally, the incompatibility of corrosive silicon tetrachloride $\left(\mathrm{SiCl}_{l_{4}}\right)$ with other materials in the system necessitated the use of stainless steel tubing for much of the system.

\subsection{Equipment,}

The apparatus (fig. 18) can be divided into the following subsystems: vacuum system; gas flow system; saturator assembly; reaction chamber assembly; and bubbler 
assembly. The vacuum system is composed of two vacsorb pumps attached to the main system separately, three thermocouple vacuum gauges capable of measuring to $0.8 .10^{-\frac{4}{4}}$ Torr (one for each vacsorb and one for monitoring pressure in the reaction chamber), and a number of vacuum lines. In fact, all gas flow lines in the system are pumped by the vacsorbs, but those sections designated by thick dark lines in fig. 18 are used solely for creating a vacuum. Specifically, all lines on the entrance side of the reaction chamber are 0.25 inch diameter stainless steel tubing; yet in contrast, the entire system on the exit side of the reaction chamber is made of glass. Another part of the gas flow system is the hydrogen purifier. The unit presently being used, a Matheson Laboratory Hydrogen Purifier Model 8361, is temporarily on loan from the Materials Science Center. Its capacity for delivering ultra-pure hydrogen is slightly above 1000 cubic centimeters per minute when the hydrogen feed gas pressure is 200 pounds per square inch (psi) and the discharge pressure is atmospheric. A liquid nitrogen trap is located just down stream from the purifier to cool the hydrogen and condense any residual impurities. Also many valves are indicated in fig. 18. These valves are Circle Seal stainless steel ball valves with viton o-rings and are capable of operating from moderate pressures down to $10^{-4}$ Torr. In addition, three flowmeters are in the system. One, a Matheson model 600 flowmeter capable of controlling hydrogen flow rates from 12 to $380 \mathrm{scc} \mathrm{m} \mathrm{m}^{-1}$, is used for monitoring the flow through the saturaton..assembly. Another, a Matheson model 602 capable of controlling hydrogen flow rates from 80 to $2450 \mathrm{scc} / \mathrm{min}$, is used for regulating the main flow of hydrogen through the system. The third meter, a Matheson model 602, regulates the flow of dopant gases over a range of $1-230 \mathrm{scc} / \mathrm{min}$.

A round bottom flask which holds one liter of tetrachlorosilane $\left(\mathrm{SiCl}_{4}\right)$ is the saturator through which hydrogen is bubbled. The hydrogen saturation by $\mathrm{SiCl}_{4}$ is governed by the silicontetrachloride partial pressure which depends on the temperature of the saturator. Presently, a low-temperature slush bath is used for maintaining a constant temperature at the saturator. The slush is formed by adding liquid nitrogen to a solvent (typically carbon tetrachloride); however, the nitrogen boils off and must be refurbished periodically. Further, a new solvent is necessary for each new isothermal temperature. Therefore, variable low-temperature electric refrigerator capable of chilling to $-40^{\circ} \mathrm{C}$ would be superior to the slush bath.

The reaction chamber assembly is composed of a quartz reaction tube, a Marshall tube furnace, and a telescope/optical-pyrometer unit. In order for the reaction tube not to melt at the deposition temperature, the tube must be made of quartiz. A Marshall furnace, temporarily supplied through the Materials Science Center, is used becuase of its reliability in maintaining an isothermal reaction zone at $1000^{\circ} \mathrm{C}$. Lastly, the optical pyrometer is needed to monitor the growth rate of whiskers and to monitor the deposition temperature accurately to within $2^{\circ} \mathrm{C}$. 
Finally, the bubbler system is used to cool (by way of a water bath) the exiting gases, to monitor the flow rate and thereby the pressure of the exiting gases, and to reduce the hydrogen chloride concentration before the gases are vented to the atmosphere. Hydrogen chloride gas is removed by bubbling it through a water-zinc mixture in which the gas reacts to form a $z$ inc-chloride solution and hydrogen gas. An important note about the glass system is the use, at all glässglass interfaces, of halocarbon, (hydrocarbon free) grease rather than a silicon vacuum grease which would form a silicote and crack open to the air in time.

\subsection{Substrate And Gold Preparation}

Both the silicon substrate and the gold nucleating agent are prepared as close as possible to the time of operation. First, the silicon wafer is cut to size (approximately one square centimeter) using a diamond saw. Then the main faces are ground with 600 grit carborundum and washed in acetone and toluene. Next the substrate is cleaned in an Alconox solution. A five minute etch in $1: 4\left(\mathrm{HF}: \mathrm{HNO}_{3}\right)$ solution follows, and then another five minute etch in 1:2:6 (HF: glacial acetic acid:

$\mathrm{HNO}_{3}$ ) is performed. Lastly, the substrate is rinsed in deionized, filtered water arid dried at $110^{\circ} \mathrm{C}$ under a normal atmosphere.

The gold is first sliced from a foil into fine particles. These pieces are then cleaned in acetone and toluene, and boiled in an Alconox solution. This process is followed by a two to three minute etch in aqua regia. Finally, the particles are rinsed in deionized, filtered water and dried.

4. SCOPE OF ACTIVITIES

Use of the experimental apparatus is to be directed toward first growing undoped silicon whiskers without dislocations. Along these lines, certain experimental limits are being established; such as growth rates, growth size, morphology aspects, deposition-temperature effects, silicon tetrachloride to hydrogen mole ratio effects, and nucleating agent dependence. Also, experiments can be conducted with other reduction reactions to give silicon in the vapor. Secondly doped silicon whiskers are being grown, and their resistivities related to the quality of FIM images. When growing these whiskers, experimental parameters such as the concentration level of dopant gases in the carrier gas are being investigated. Finally, the system can be extended to growing gallium arsenide and gallium phosphide whiskers.

\section{G. FIELD-ION MICROSCOPE IMAGING OF SILICON (B. Moser, J.C. Barbour, B. Reding)}

\section{INTRODUCTION}

As stated in the INTRODUCTION to this progress report a major effort was initiated to redirect the research program towards problems related to the chemistry of metalsemiconductor interfaces on the angstom scale and the effects of particle irradiation on the formation of metal silicides. As part of this program a strong effort was 
made during the past year to obtain high quality stable images of silicon. The work described in this section relates, of course, to the work detailed in the previous section on the growth of doped silicon whiskers by the VLS technique. Our objective is to use heavily doped silicon whiskers to obtain high quality FIM images.

In recent years, the field-ion microscope (FIM) has been used in the study of semiconductors $(77-89)$. A number of experiments on the imaging of silicon were con-

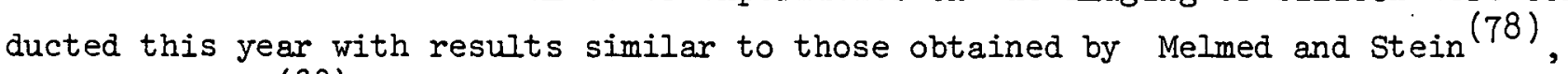
Sakurai et al. ${ }^{(88)}$ and a discussion of our experiments is the primary topic of this report. A section outlining the present research effort is also presented.

2. SPECTMEN PREPARATION

Single-crystal silicon whiskers grown by the VLS technique were obtained from Dr. J. Patel of Bell Laboratories and Dr. A. J. Melmed of the National Bureau of Standards. These whiskers differed considerably in size, the longest one was $2 \mathrm{~cm}$ and approximately $1 \mathrm{~mm}$ in diameter. A silicon specimen was mounted by soldering it with indium to a small segment of tungsten wire which had been screwed into a copper specimen holder. Each whisker was then chemically polished to a sharp point by repeated immersion in a solution consisting of $44 \%$ by volume $48 \%$ hydrofluoric acid and $56 \%$ by volume concentrated nitric acid. The specimen was rinsed in ethanol prior to the inspection of the tip with an optical microscope at a magnification of $500 x$.

\section{EXPERIMENTAL TECHNIQUES AND RESULTS}

Field-ion imaging was performed in a bakable FIM, which typicalily achieved a background pressure in the range of 0.3 to $3 \times 10^{-8}$ Torr. The FIM was cooled via a continuous-transfer-liquid-helium cryostat to temperatures in the range 15 to $80 \mathrm{~K}$. Hydrogen gas was then admitted into the FIM and the vollage lo the tip was Incruivul slowly until an ordered surface structure was discerned. Employing pure hydrogen as the imaging gas yielded an image in which continuous field evaporation of the surface atoms occurred. Resolution of poles could be observed almost exclusively along the $\{111\}-\{110\}$ zone lines. These lines appeared somewhat more intense than the other regions of the image which generally exhibited considerable disorder.

In an effort to achieve a more stable, well-ordered image, neon and helium were intorduced into the FIM. The silicon tips were imaged with each of these gaises as well as with mixtures of neon, helium and hydrogen. It was found that replacing hydrogen with neon and/or helium resulted in a more stable image but, at the typically low values of electric tield, 1t was not pussiule to detect an ordercd structure without the presence of hydrogen. We did enjoy limited success in imaging silicon in an atmosphere consisting predominantly of helium and neon. Because these gases have first ionization potentials which are greater than that of hydrogen, it was necessary 
to increase the specimen voltage substantially to obtain an ordered image. The silicon tips, however, generally fractured at the higher value of electric field strength. In the few cases in which the specimens did survive, we observed that helium/neon images exhibited greater stability and were more uniform in intensity though less intense, then when hydrogen was present.

Figure 20 is a field ion micrograph of a silicon whisker imaged at $8.9 \mathrm{kV}$ and $25 \mathrm{~K}$ in a gas mixture of $46 \%$ helium, $24 \%$ neon, and $30 \%$ hydrogen combined to give a total pressure of $5 \times 10^{-4}$ Torr. In fig. 21 the voltage on the tip was $13.6 \mathrm{kV}$. Here, the hydrogen valve had been closed but it was estimated that the residual hydrogen in the system amounted to approximately $2 \%$ of the total gas pressure. The composition of the gas mixture was $58 \%$ helium, $40 \%$ neon and $2 \%$ hydrogen. The partial pressure of hydrogen was increased slightly to obtain the micrograph exhibited in fig 22. In this case hydrogen made up 3\% of the total pressure; helium accounted for $58 \%$ and the remaining $39 \%$ was neon. In figures 21 and 22 , the total pressure was $4 \times 10^{-4}$ Torr and because of a problem with the cryostat, the temperature had risen to $125 \mathrm{~K}$. 4. DISCUSSION

The results obtained indicated that at the present state of the art, it is not feasible to attempt point defect studies of intrinsic silicon. If such a task were undertaken, the researcher would have to confine his attention to the \{lll\} planes, since it is these planes which most clearly exhibit atomic detail. However, even the best images of the \{IIl\} regions of silicon do not compare very favorably with FIM images of metallic specimens, such as tungsten. In an effort to obtain images of semiconductors in which more than just a few of the poles can be resolved, we are now growing heavily-doped silicon whiskers. The electrical properties of heavily-doped specimens should resemble those of metals and, hopefully, should image in a similar fashion.

The basic idea is to dope the specimen heavily enough, with $n$-type impurities, so thal the resistivity of the whisker is independent of temperature and approximately $10^{-3} \mathrm{ohm}-\mathrm{cm}$, for example, see fig. $8-3$ in Runyan (90). The heavy doping level of impurities decreases the electric field penetration depth $(\delta)$, where $\delta$ is given by

$$
\delta=\left[\mathrm{K} \varepsilon_{0} \mathrm{kT} /(2 \mathrm{np})^{1 / 2} \mathrm{e}^{2}\right]^{1 / 2}
$$

$K$ is the dielectric constant, $\varepsilon_{0}$ is the electric permittivity of free space, $n$ and $p$ the concentration of electrons and holes, respectively, and $e$ is the charge on an electron. Note that $\delta$ is proportional to $(n p)^{-1 / 4}$, so that increasing the concentration of electrons decreases $\delta$. The decrease in $\delta$ should result in a field evaporation behavior that is more akin to metals, that is, the silicon atoms should field evaporate from the kink sites rather than in clustersfrom several atomic layers. (91) 


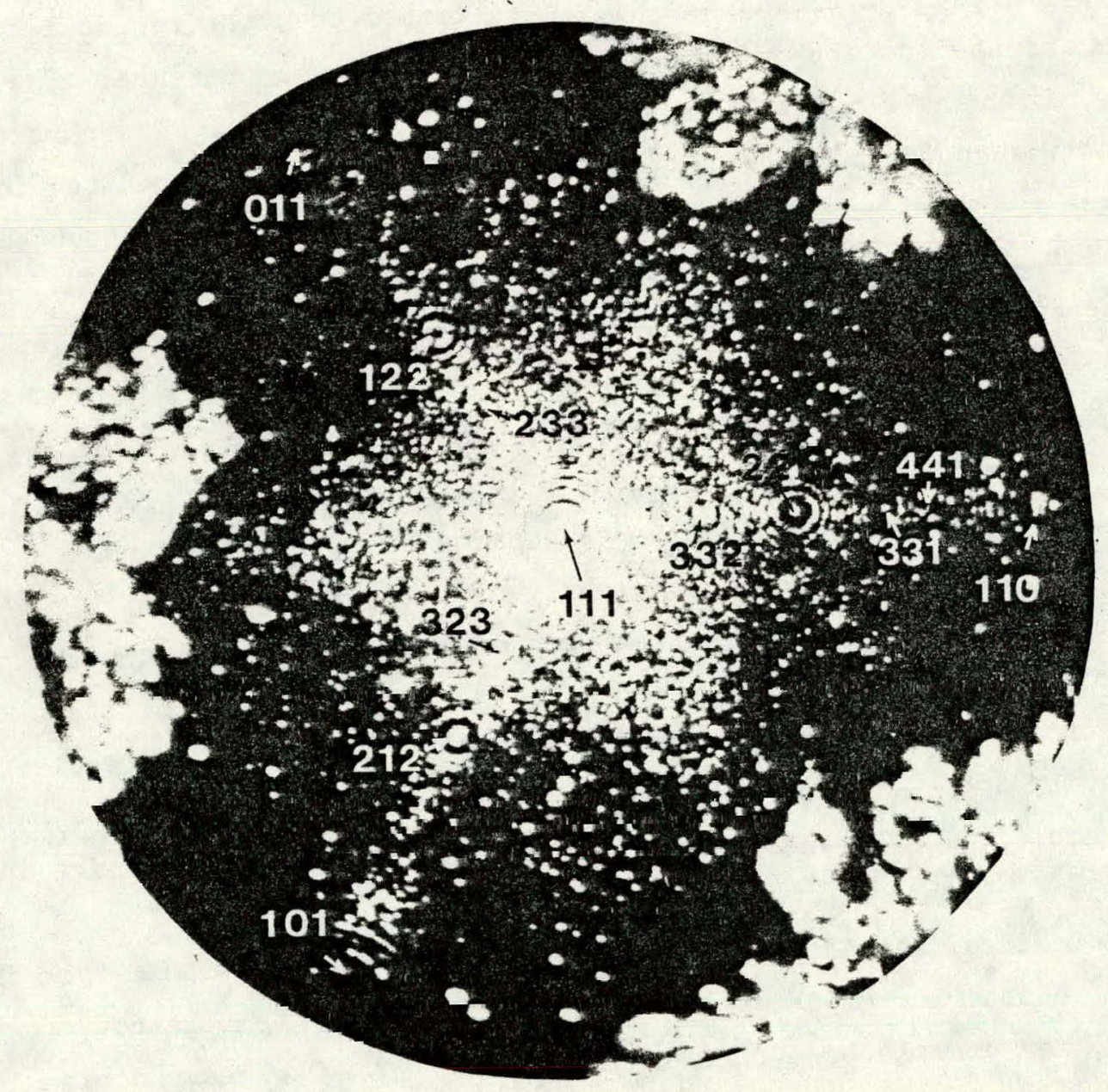

Figure 20: Field-ion micrograph of a silicon specimen at $8.9 \mathrm{KV}$ and $25 \mathrm{~K}$, imaged in hylroger-neon-helium mixture. 


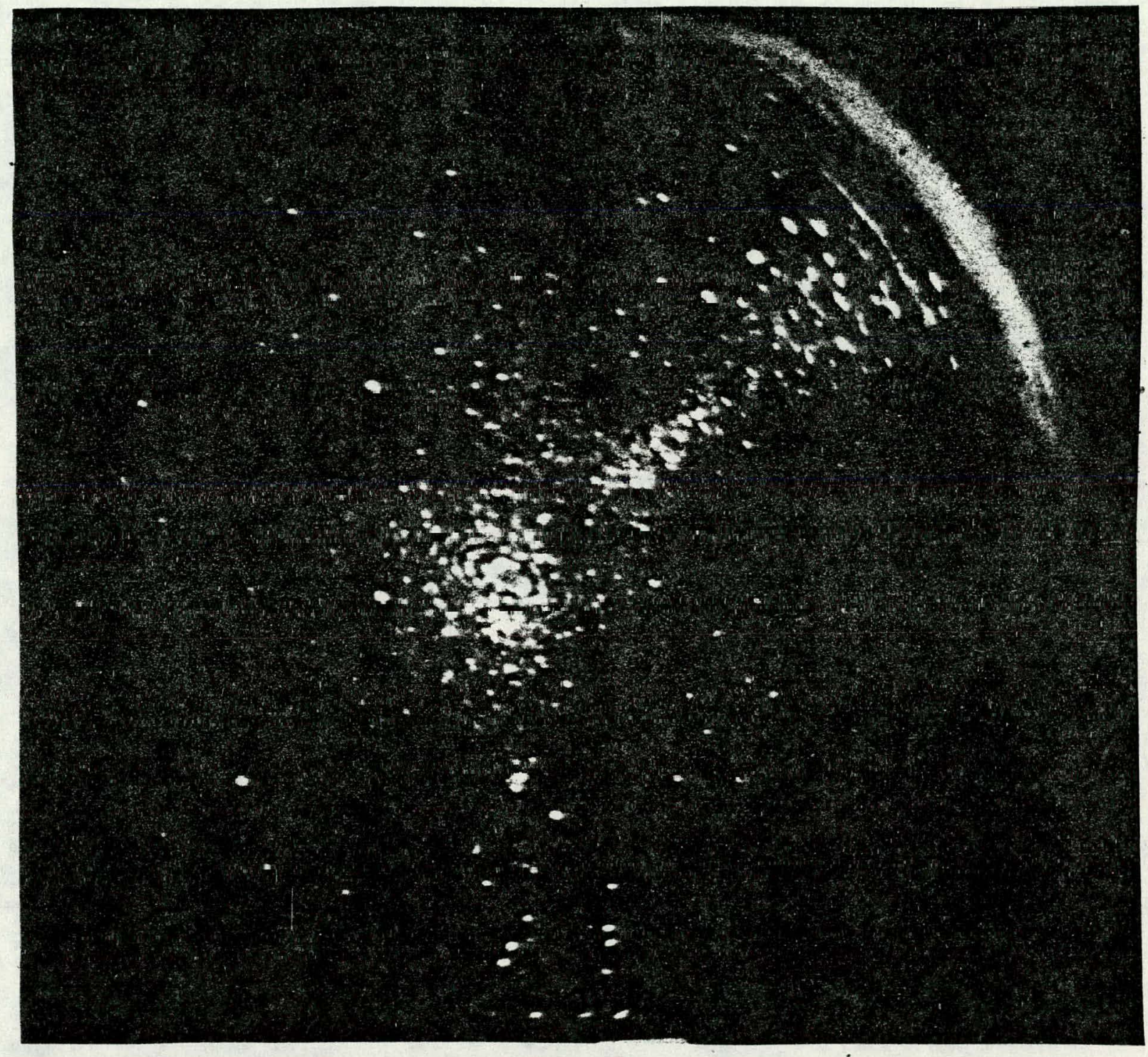

Figure 21: Field-ion micrograph of a silicon whisker imaged at $13.6 \mathrm{KV}$ and $125 \mathrm{~K}$ in neon-helium gas mixture. 


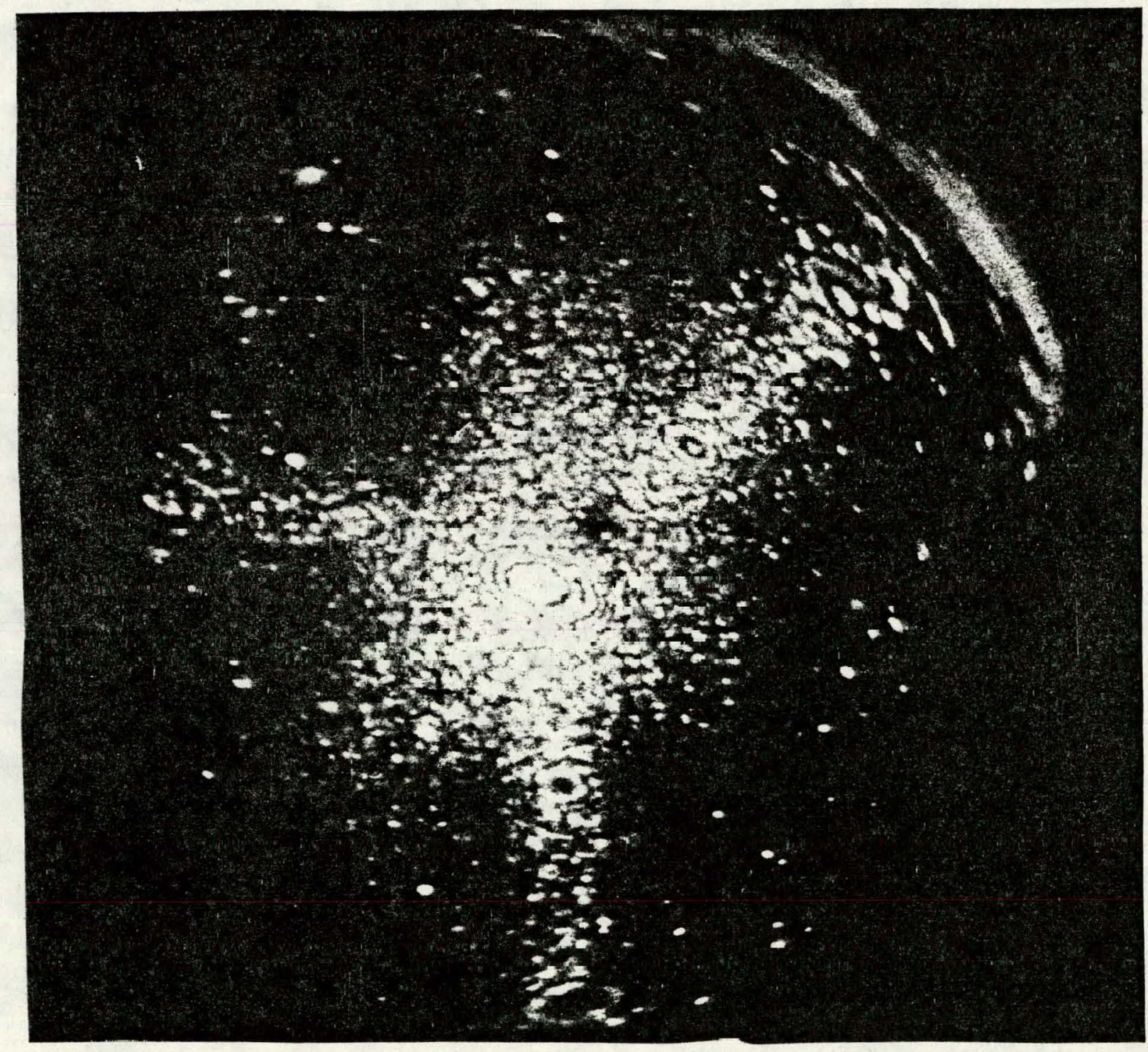

Figure 22: Field-ion micrograph of silicon at $13.8 \mathrm{KV}$ and $125 \mathrm{~K}$. The imaging gases were hydrogen, helium, and neon. 


\section{H. DIRECT OBSERVATION OF THE PRIMARY STATE OF DAMAGE IN ION-IRRADIATED PLATINUM AND TUNGSTEN (D. Pramanik)}

The work reported on in this section constituted the Ph.D. thesis research of D. Pramanik, which has appeared in the form of a DOE report. (92) Certain aspects of the research on the "Damage State of IonIrradiated Pure Platinum" appeared in last year's progress report (93) to the DOE. 'In this year's report the main conclusions of all this work are briefly summarized and then the work on "Nonlinear Effects in Irradiated Tungsten" is discussed in somewhat more detail.

\section{OVERALL SUMMARY}

The primary state of damage in platinum and tungsten caused by ions of varying mass and energy, was investigated using the field ion microscope (FIM). The damage could be classified into three morphological types: (a) depleted zones (DZs); (b) voids; and (c) dislocation loops. Platinum specimens of $99.999 \%$ purity were irradiated in situ at $60 \mathrm{~K}$ with $20 \mathrm{keV} \mathrm{Kr}{ }^{+}$ions to a dose of ( 3 to 5 ) $\times 10^{12}$ ions $\mathrm{cm}^{-2}$ and examined by the pulse field-evaporation technique at $60 \mathrm{~K}$. The experimental conditions were created such that each depleted zone was created by a single incident ion. All three morphological types were observed. The average damage level, given by the number of vacancies per cascade $(\nu)$, was satisfactorily described by the modified Kinchin-Pease expression. The dimensions of the DZs was satisfactorily explained by the linear cascade theory. The cumulative damage profile, obtained by summing over the damage due to individual DZs, very rapidly approached the theoretical damage profile as the number of DZs considered increased. The average structure of the DZs were similar to those produced in tungsten by ions of the same mass and energy. The dislocation loops were Frank loops and both vacancy and interstitial. loops were observed. 
Evidence was obtained that the vacancy type dislocation loops were produced by the collapse of dense DZs. A detailed study was also made of the damage produced in four-pass zone-refined tungsten irradiated in situ at $10 \mathrm{~K}$ with 20,45 and $60 \mathrm{keV} \mathrm{W}^{+}$ions to a dose of (2 to 10) $\times 10^{12}$ ions $\mathrm{cm}^{-2}$ and examined by pulse field-evaporation technique at $10 . \mathrm{K}$. The quantity $v$ increased linearly with increasing projectile energy $\left(E_{1}\right)$ according to the modified Kinchin-Pease formula. However, the dimensions of the DZs did not increase with $E_{I}$ as expected from linear cascade theory and indicated a possible breakdown of this theory for dense DZs, produced by heavy ions incident on heavy targets. Evidence of the break up of DZs into subclusters at $60 \mathrm{keV}$ was obtained. The fraction of DZs that collapsed to dislocation loops increased with increasing $E_{1}$. The effect of nonlinear cascades on the damage in tungsten was determined by comparing the damage produced by $20 \mathrm{keV} \mathrm{W}^{+}$and $\mathrm{Ag}^{+}$with that produced by $40 \mathrm{keV} \mathrm{W}_{2}^{+}$and $\mathrm{Ag}_{2}^{+}$. The value of ' $v$ for the individual components of the dimer vas 1.55 times the $v$ for' the single atom ions, having the same energy. This clearly indicated the nonlinear effects associated with dense cascades. The fraction of DZs that collapsed to dislocation loops was also greater in the case of dimer irradiations of tungsten than for single atom ion irradiations.

\section{NONLINEAR EFFECTS IN IRRADIATED TUNGSTEN}

In this chapter we consider effects of bombardment on tungsten hy energetic dimers which rnnsisted of two heavy alums, with a total energy of $E_{1}$. On impact with the target's surface the dimer breaks up into two single projectile atoms of equal energy $E_{1} / 2$, which then proceed to make independent collisions with the target atoms. For a large fraction of their total path the projectile atoms will be very close to each other so that the collision cascades generated by them will to some extent overlap 
during the time period of formation of the cascades. The significance of heavy ion dimer irradiations become clear when we look at the way in which the energy may be dissipated by an energetic particle in a solid via elastic collisions. Figure 23 shows two different views, based on Sigmund's model. ${ }^{1}$ Figure $2 \dot{3}(\mathrm{a})$ shows a collision cascade and $\mathrm{fig} .23$ (b) a spike.* In both cases energy is ultimately shared by a great number of atoms. The difference between the two situations lies in the fact that while only a small fraction of all atoms within a certain cascade volume are in motion in fig. 23 (a), essentially all the atoms within a spike volume move in fig. 23(b). The picture of a cascade applies when there is a long mean free path between significant collision events--as in the case of light ion-bombardment--such that the energy is spread out over a large volume. Conversely, in a spike, energy is dissipated at a high rate, within a small volume. The difference between the two situations is characterized most illustratively when two cascades (or spikes) are generated at the same time on top of each other, as in the case of bombardment with a dimer. When two genuine cascades are superimposed, the statistical nature of the collision events will prevent a strict overlap in the two cascades. Because of the small fraction of atoms moving in either case, the two cascades superimpose so that the total number of moving atoms is twice as large as in either cascade and the energy distribution is essentially unchanged. This is to say that in each energy interval there will be twice as many atoms as there was in the case of monomer irradiation. The system is linear. When two spikes are superimposed on the other hand energy will be dissipated essentially within a single spike volume, that is the total number of atoms in motion will increase only insignificantly compared to

* The term "spike" has a long history, and it has been involved in many different concepts over the years. In this chapter, the term w1ll be used only to characterize the situation sketched in fig. 23 (b). 
a

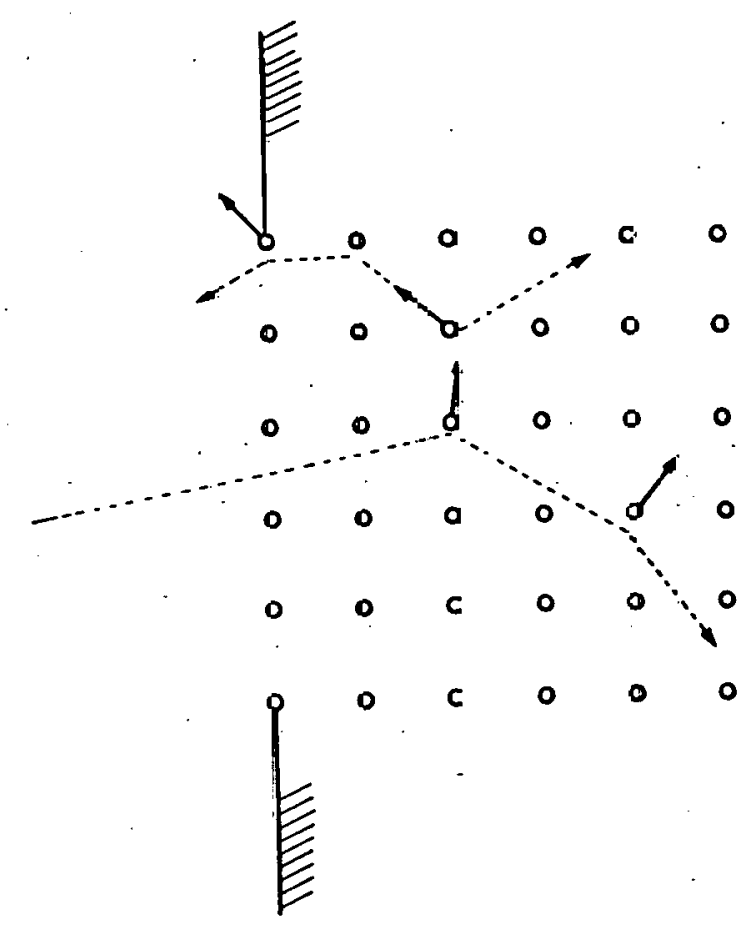

b

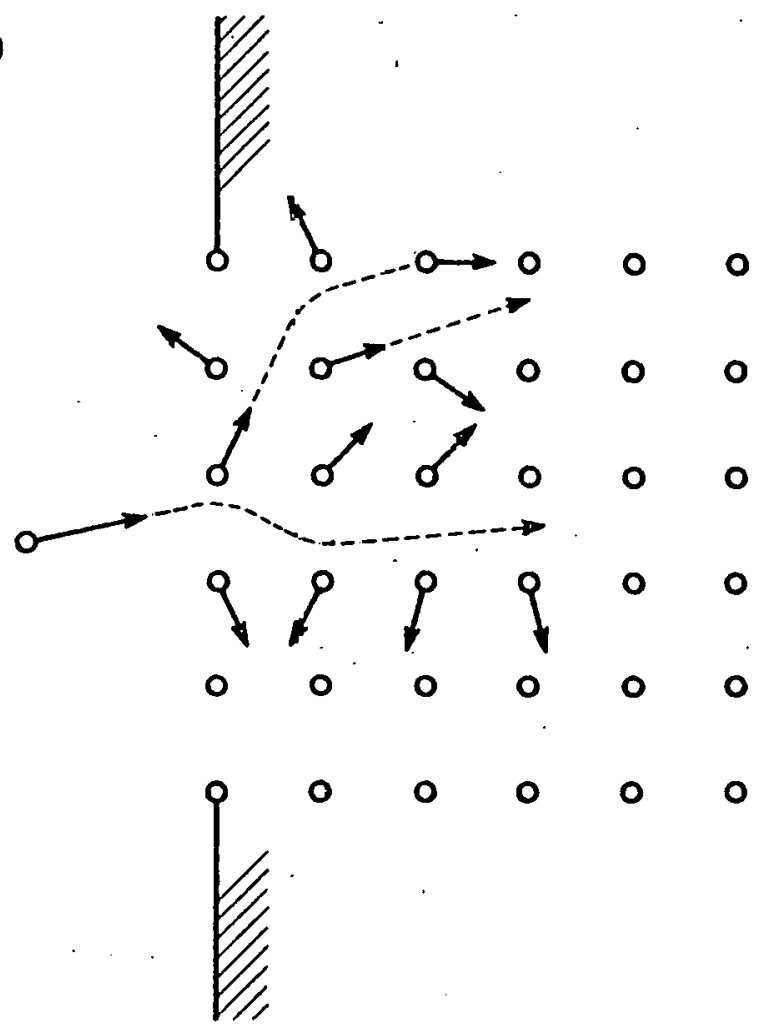

Fig. 23: (a) A linear cascade.

(b) A non-linear cascade. 
the case of monomer irradiation. Consequently, the available energy per atom must approximately double. The energy distribution will be different from that for monomer irradiation. The system is nonlinear. Since the number of vacancies produced < $v>$ depends significantly on the energy distribution of the atoms, the non-linearity should reflect itself in $\langle v\rangle$, that is, the $\langle\nu\rangle$ for a heavy ion dimer is expected to differ from the sum of the <u> of the constituents of the dimers. Moreover, the collapse of DZs to loops is dependent on the deposited energy density and hence the yield may be significantly enhanced. The sputtering yield, also is very closely tied to the energy distribution of atoms and the difference between linear and nonlinear systems should reflect itself in the sputtering yields. In a linear system, one expects the sputtering yield to be proportional to the number of impinging particles regardless of their correlation in space and time. In a nonlinear system such a simple relationship is not expected. The sputtering yield of a dimer is expected to differ from the sum of the sputtering yields of the constituents of the dimer. An illustration of these features was observed by Anderson and Bay; they compared the sputtering yields due to molecular ion bombardment with those for atomic ions at the same velocity. Approximate linearity was observed for light-ion bombardment while a drastic enhancement was observed for heavy-ion bombardment.

We have attempted to detect the effects of nonlinearity on the nature of the damage produced in tungsten by comparing the damage produced by heavy-ion dimers with that produced by atomic ions having the same velocity. FIM specimens were bombarded with $40 \mathrm{keV} \mathrm{Ag}_{2}{ }^{+}$and $\mathrm{W}_{2}^{+}$dimers and the results compared with those from the bombardment with $20 \mathrm{keV} \mathrm{Ag}^{+}$and $\mathrm{W}^{+}$ions. The nature of the $\mathrm{DZ}^{\prime}$ 's produced by $20 \mathrm{keV} \mathrm{Ag}{ }^{+}, \mathrm{W}^{+}$ions were not very different and we therefore consider the results for $\mathrm{Ag}$ and $\mathrm{W}$ together. 


\section{DEPLETED ZONES}

\section{1. $20 \mathrm{keV}$ ion irradiations}

The details of the $20 \mathrm{keV} \mathrm{W}{ }^{+}$ion irradiations were given in Chap. IV of Pramanik's Ph.D. thesis. Three tungsten specimens were irradiated. with 20 $\mathrm{keV} \mathrm{Ag}{ }^{+}$ions and three $\mathrm{DZs}$ were analyzed in detail. A vacancy count was done for another $\mathrm{DZ}$ which was not completely analyzed. Figure 24 exhibits the standard stereographic projections that show the top view of each specimen. The plane (or planes) in which a DZ was detected is indicated. The cross-sectional side views of the specimens are also shown. The vacancy count and vacancy concentrations for the DZs are given in Table 6 and the range, maximum and minimum dimengions and average dimensions in Table 6 . We obtained $\langle U\rangle_{\text {TRIM }}=143 \pm 12$. The number of vacancies observed in the experimental DZs was much greater than this and in the case of DWA5a it was significantly larger. The discrepancy is commented on later in this section.

The rangc of the cascades weite wilhin llue linics expected from the TRIM program $L=(35.3 \pm 14.84 \stackrel{\circ}{\mathrm{A}})$. From Winterbon's tables $\mathrm{L}=43 \mathrm{~A}$. The average size of the vacancy clusters on the basis of the TRIM program was

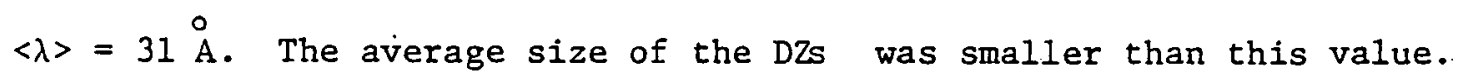
The radial distribution functions are plotted in fig. 25 and 26 . They show a sharp single peak indicating a single cluster. Though the $R(i) / Z(i)$ for the individual cascades fluctuated, the curve representing the average of the three cases is almost identical to the average for $30 \mathrm{keV} \mathrm{Mo}{ }^{+}$on $\mathrm{W}$. The atoms $\mathrm{Ag}$ and Mo have almost the same atomic number and the similarity is therefore not surprising. As mentioned before, and in $\theta O G$, the average $R(i) / \angle(i)$ curves depend on $M_{1}$ but do not appear to be particularly sensitive to $E_{1}$. In fig. 27.-28, we show the ORTEP visualizations of the 3 DZs . which indicate the compact nature of the DZ's: 


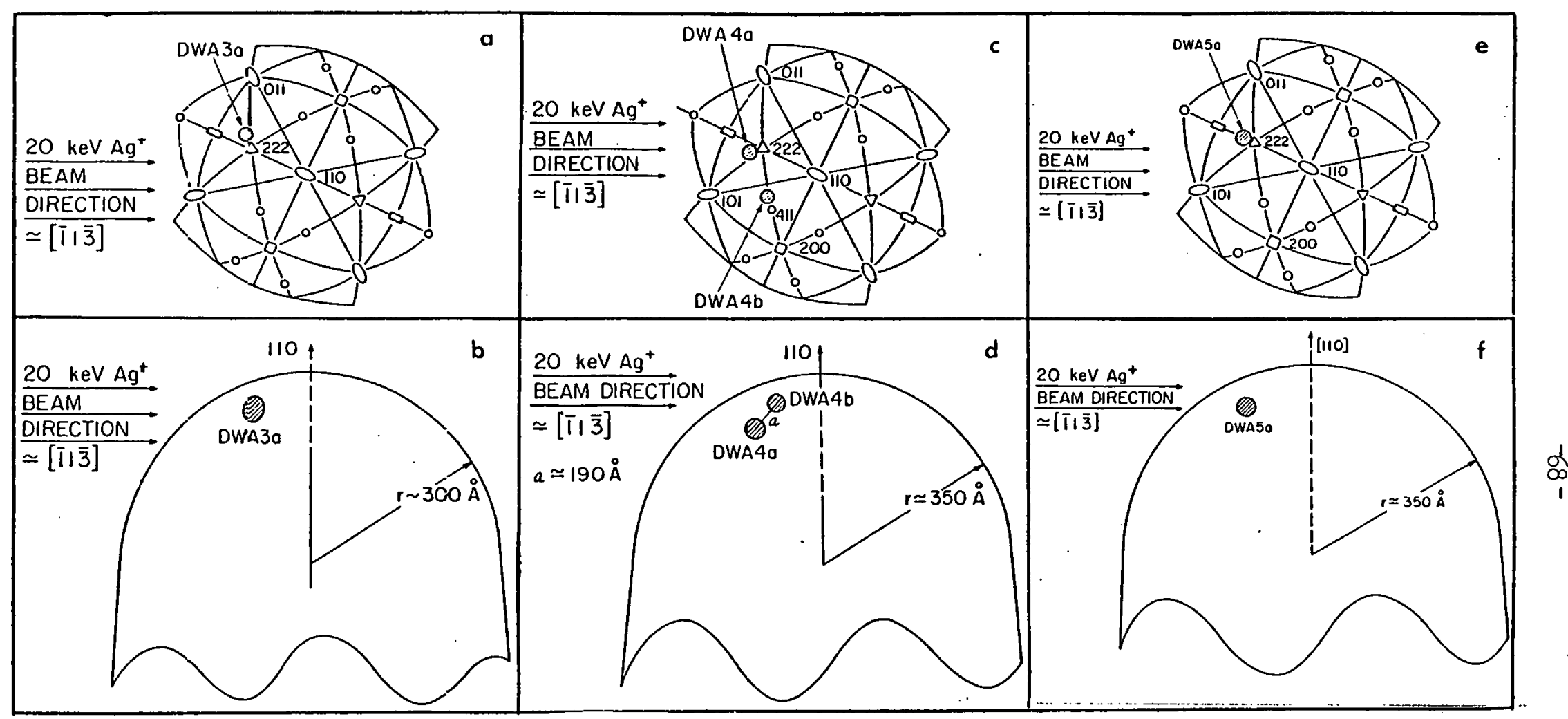

Fig. 24 : (a), (c) and (e) are partial 110 stereographic projections showing location of depleted zones produced by $20 \mathrm{keV} \mathrm{dg}^{+}$irradiation of tungsten.

(b), (d) and (f) show schematic cross-sectional views of the FIM tip specimens. 
Number of vacancies and vacancy concentration of $\mathrm{DZ}^{\prime} \mathrm{s}$ produced by $20 \mathrm{keV} \mathrm{Ag}^{+}$on $\mathrm{W}$

\begin{tabular}{|c|c|c|}
\hline $\begin{array}{c}\text { DEPLETED } \\
\text { ZONE }\end{array}$ & NO. OF VACANCIES \\
$\nu$ & $\begin{array}{c}\text { VACANCY } \\
\text { CONCENTRATION } \\
\left(c_{v}\right) \text { at } \%\end{array}$ \\
\hline DWA3a & 269 & 10.8 \\
DWA4a & 153 & 4.9 \\
DWA4b & $\because 150$ & - \\
DWA5a & 201 & 12.1 \\
\hline
\end{tabular}

*only vacancy count available. 
TABLE 7

Range and dimensions of $\mathrm{DZ}^{\prime}$ 's produced by $20 \mathrm{keV} \mathrm{Ag}{ }^{+}$on $\mathrm{W}$

\begin{tabular}{|c|c|c|c|c|c|c|}
\hline $\begin{array}{l}\text { DEPLETED } \\
\text { ZONE } \\
\text { (DZ) }\end{array}$ & $\begin{array}{l}\text { RANGE } \\
\text { (L) } \\
\dot{A}\end{array}$ & $\begin{array}{c}\text { ELONGATION } \\
\text { DIRECTION } \\
{[\mathrm{hk} 1]}\end{array}$ & $\begin{array}{c}\text { DIAMETER } \\
\lambda^{+}{ }^{+} \\
(\dot{\mathrm{A}})^{+}\end{array}$ & $\begin{array}{c}\text { DIAMETER } \\
\lambda_{2}{ }^{\dagger} \\
(\dot{\mathrm{A}})^{-1}\end{array}$ & MEAN & $\begin{array}{l}\text { DIAMETER } \\
\langle\lambda\rangle \\
(\dot{A})\end{array}$ \\
\hline DWA3a & 50 & [10̄] & 26.38 & 16.03 & & 18.9 \\
\hline DWA4a & 60 & {$[11 \overrightarrow{1}]$} & 32.45 & 21.8 & & 24.9 \\
\hline DWA $5 \mathrm{a}$ & 47 & [ī11] & 16.54 & 13.02 & & 14.1 \\
\hline
\end{tabular}

${ }^{\dagger} \lambda_{1}, \lambda_{2}$ are the maximum and minimum dimensions, respectively, of each $\mathrm{DZ}$. 


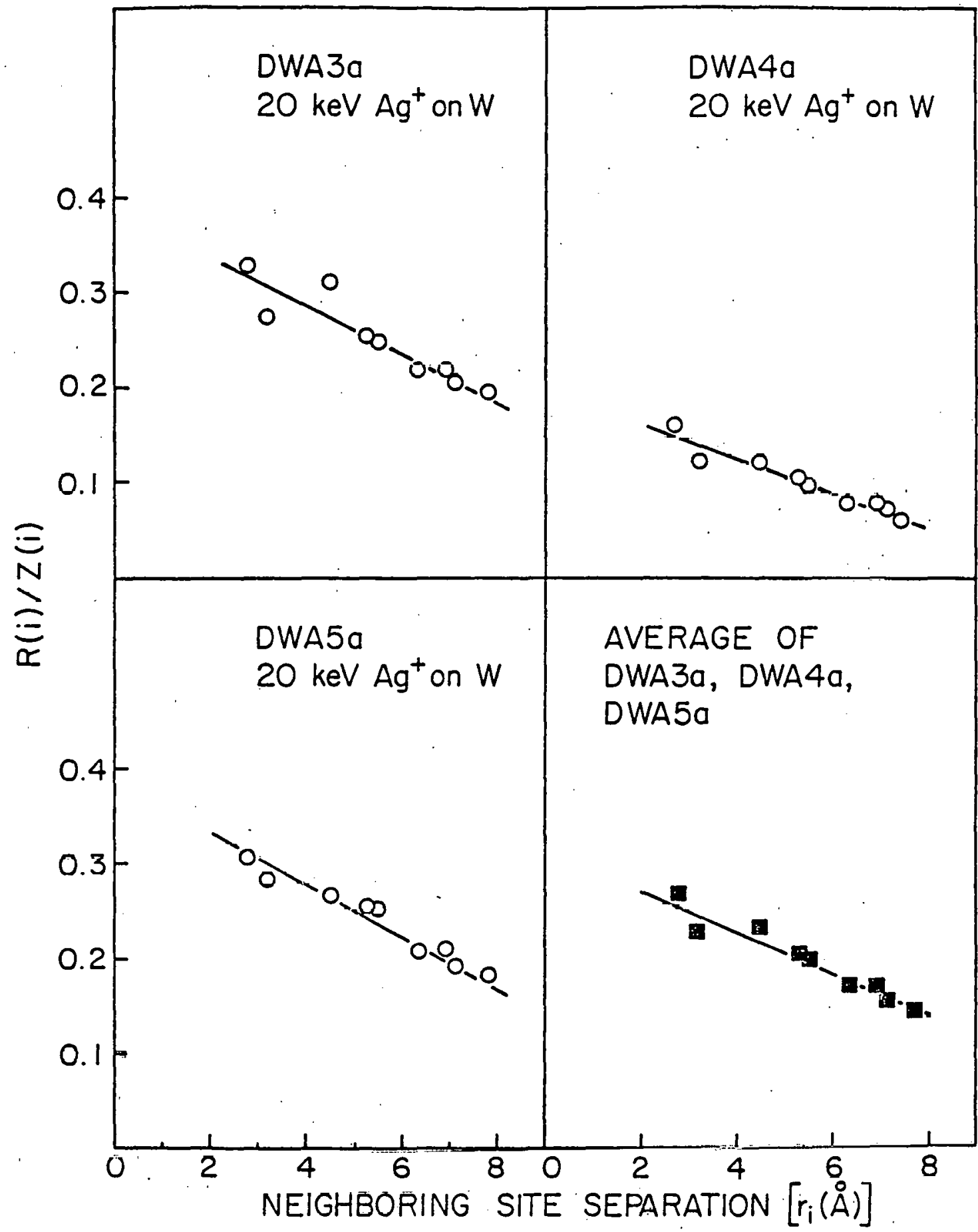

Fig. 25: The normalized radial distribution functions $[R(i) / z(i)]$ for depleted zones produced by $20 \mathrm{keV} \mathrm{Ag}^{+}$irradiation of tungsten. 


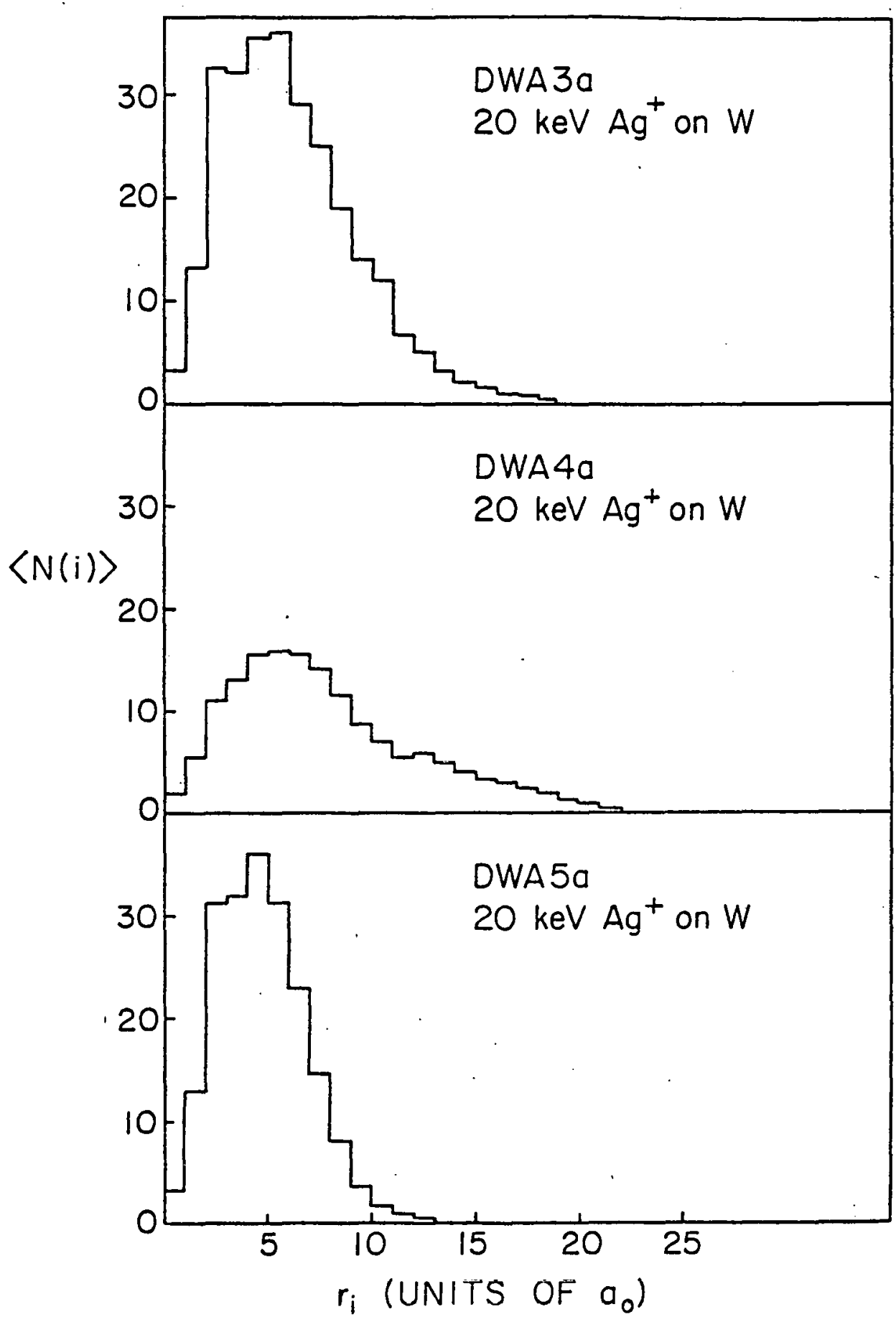

Fig. 26: The spectra of $<N(i)>s$ for depleted zones produced by $20 \mathrm{keV}$ $\mathrm{Ag}^{+}$irradiations of tungsten. 


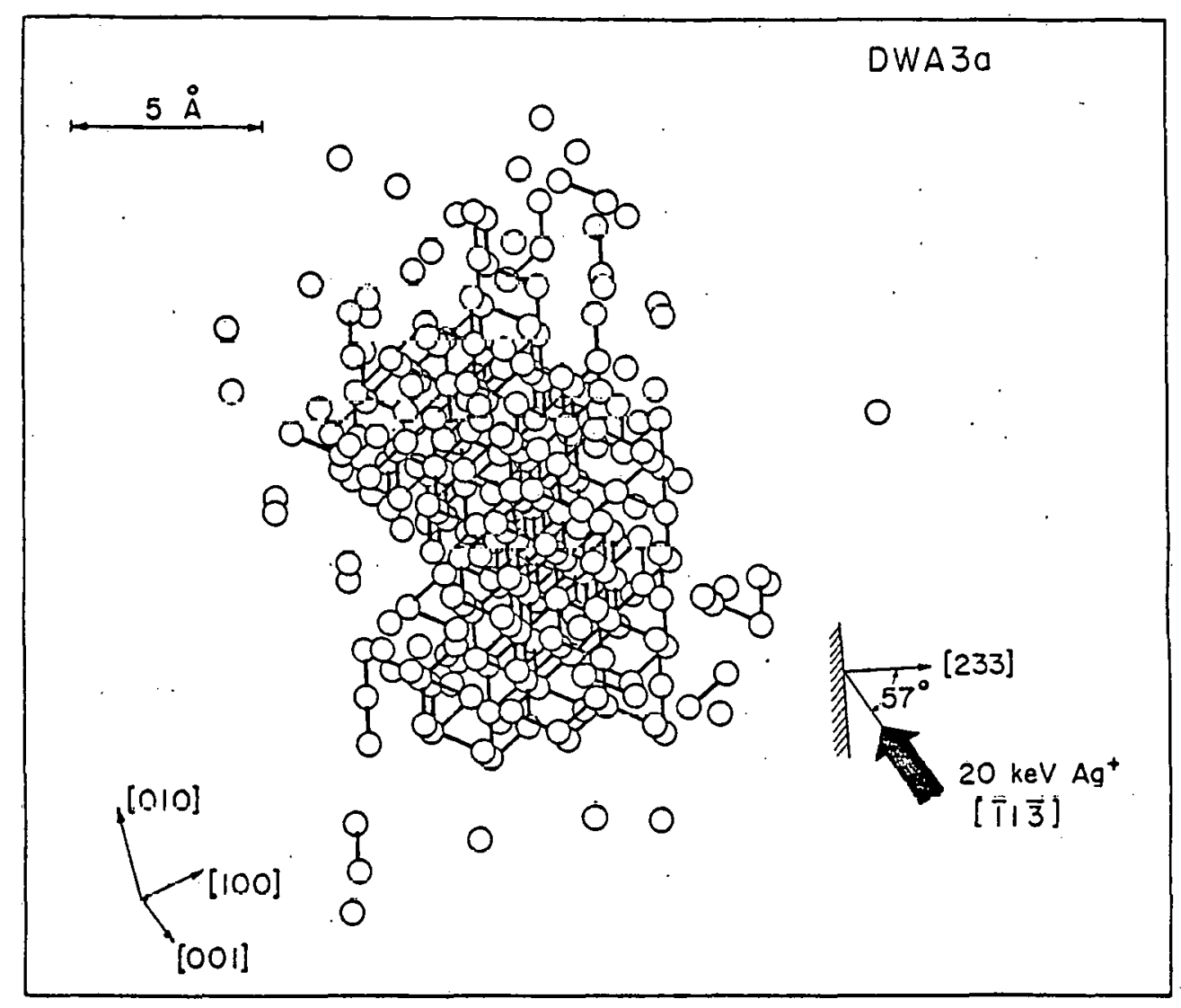

Fig. 27: An OR TEP drawing of NWA3a. 
$-74$.

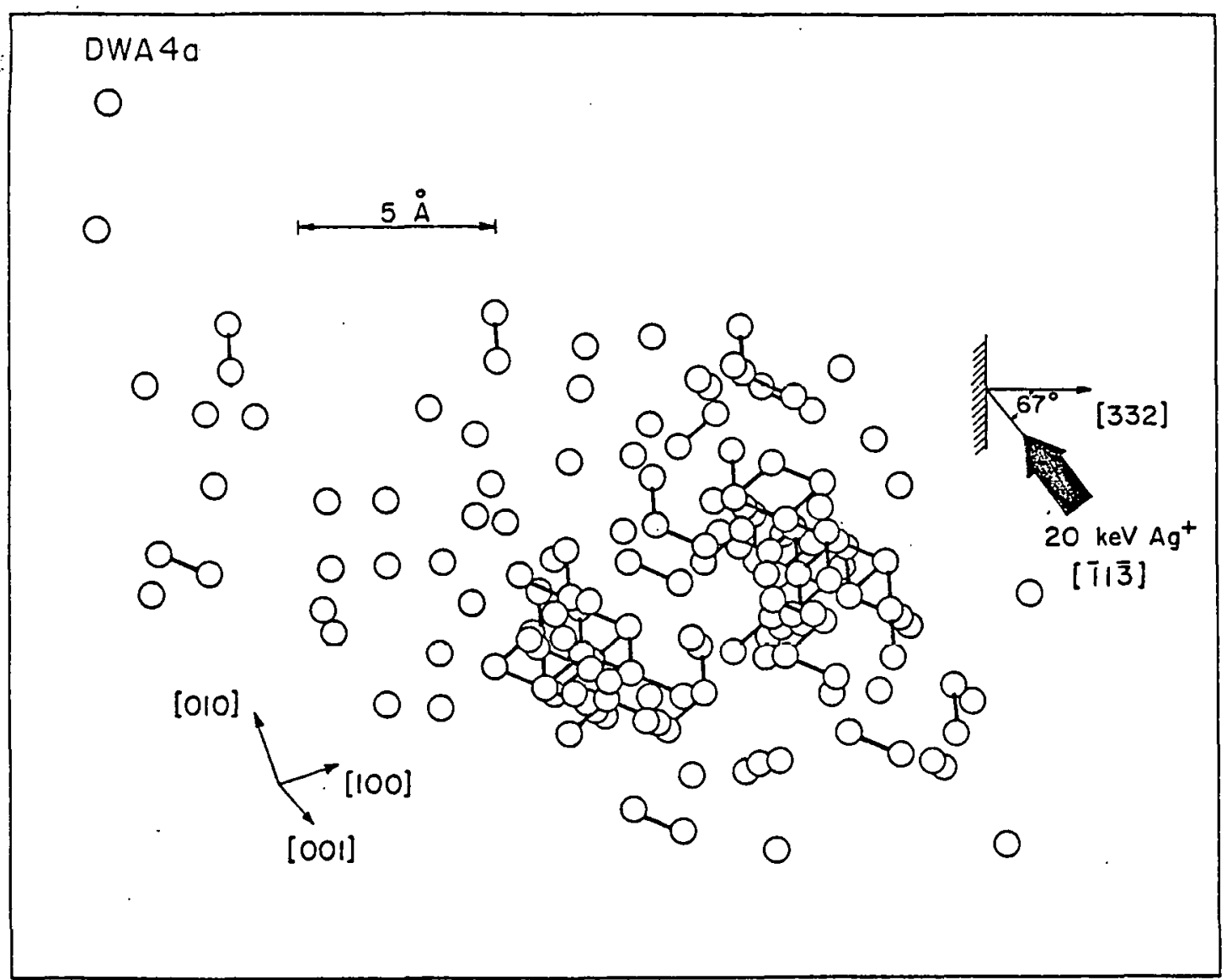

Fig. 28: An OR TEP drawing of DWA4a. 


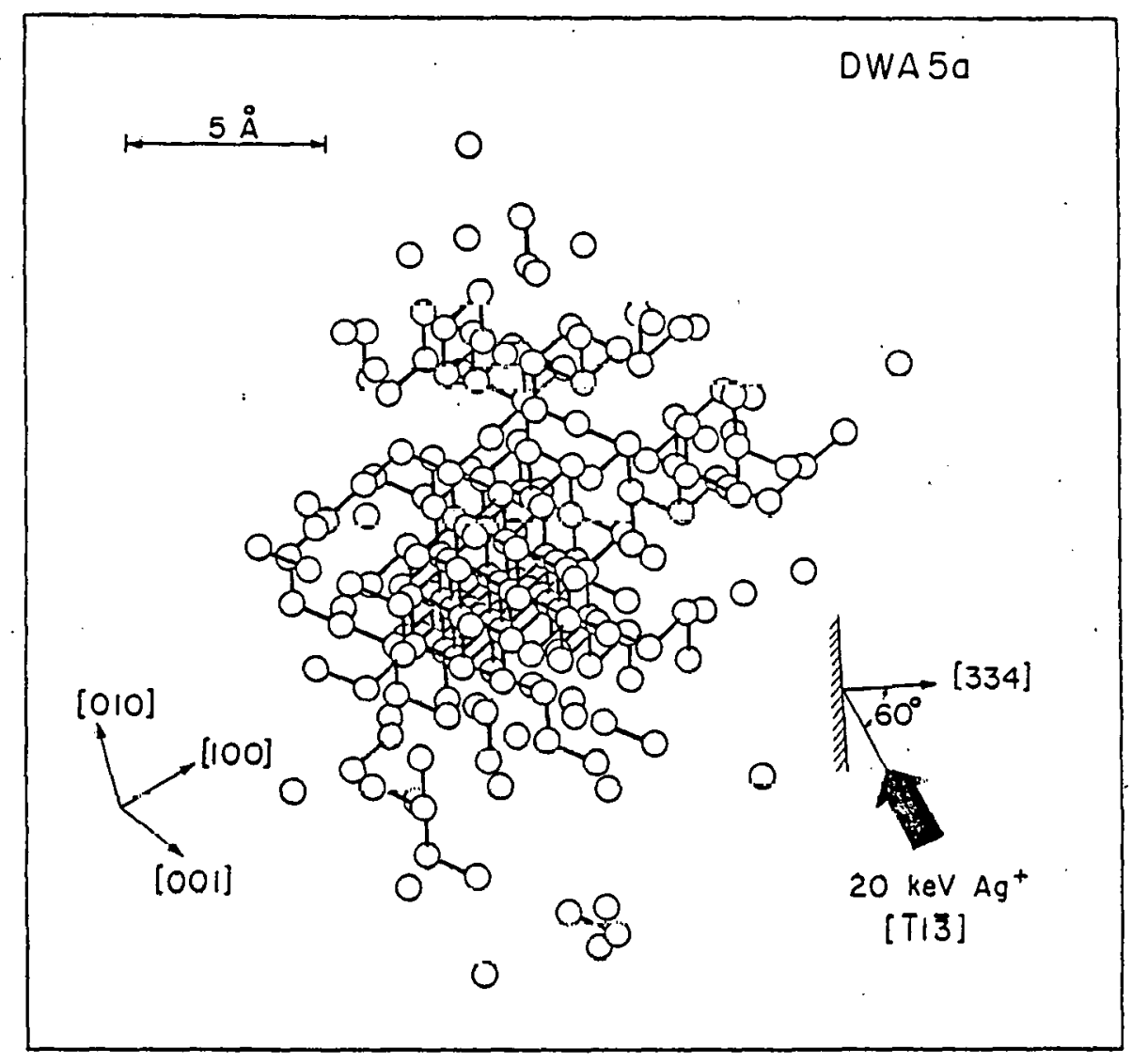

FLG. 29: An OR TEP drawing of DWA5a. 
An analysis of the degree of clustering revealed that DWA3a contained 48 monovacancies, 11 divacancies, four trivacancies, one pentavacancy, one hexavacancy, and one jumbo cluster of 176 vacancies. DWA4a had 56 monovacancies, 13 divacancies, two trivacancies, one quadravacancy, one pentavacancy, one heptavacancy, one octavacancy, one cluster of 19 and one of 24 vacancies. DWA5a has 34 monovacancies, 5 divacancies, two trivacancies, one quadravacancy, one hexavacancy and one jumbo cluster of 141 vacancies.

\subsection{Results for $40 \mathrm{keV}$ dimers}

Four sets of irradiations with dimers were carried out, two each for $\mathrm{Ag}_{2}{ }^{+}$and $\mathrm{W}_{2}{ }^{+}$. In all four $\mathrm{DZ}$ 's were analyzed, two for $\mathrm{Ag}_{2}{ }^{+}$and two for $\mathrm{W}_{2}{ }^{+}$. One of the $\mathrm{DZ}$ 's for $\mathrm{W}_{2}^{+}$was a surface cascade and contained only a small number of vacancies relative to the other three. Figures 30 and 31 show the standard stereographic projections that show the top view of each specimen. The plane (or planes) in which a DZ was detected is indicated. We have also shown in the fig. 30 and 31 the positions of DZs that were detected but not analyzed. The cross-sectional side views of the specimens are also shown.

The vacancy count and vacancy concentration for the DZ's are given in Table 8 and the range, maximum and minimum dimensions and average dimensions are given in Table 9.

The radial distribution functions $\langle N(i)\rangle$ and $R(i) / Z(i)$ are plotted in figs. 32 and 33 . The $\langle N(i)\rangle$ for DWW $3 a$ and DWW4a indicate a single cluster for these DZs while that for DWAla indicates the presence of two clusters, and that for DWA2a indicates that the DZ is somewhat diffuse. These features are also reflected in the $R(i) / Z(i)$ graphs. The $\mathrm{W}_{2}^{+} \mathrm{DZs}$ formed far tighter clusters than the $\mathrm{Ag}_{2}{ }^{+} \mathrm{DZs}$. The ORTEP visualization of the DZs shown in figs. 34 to 37 confirm the above conclusions. 


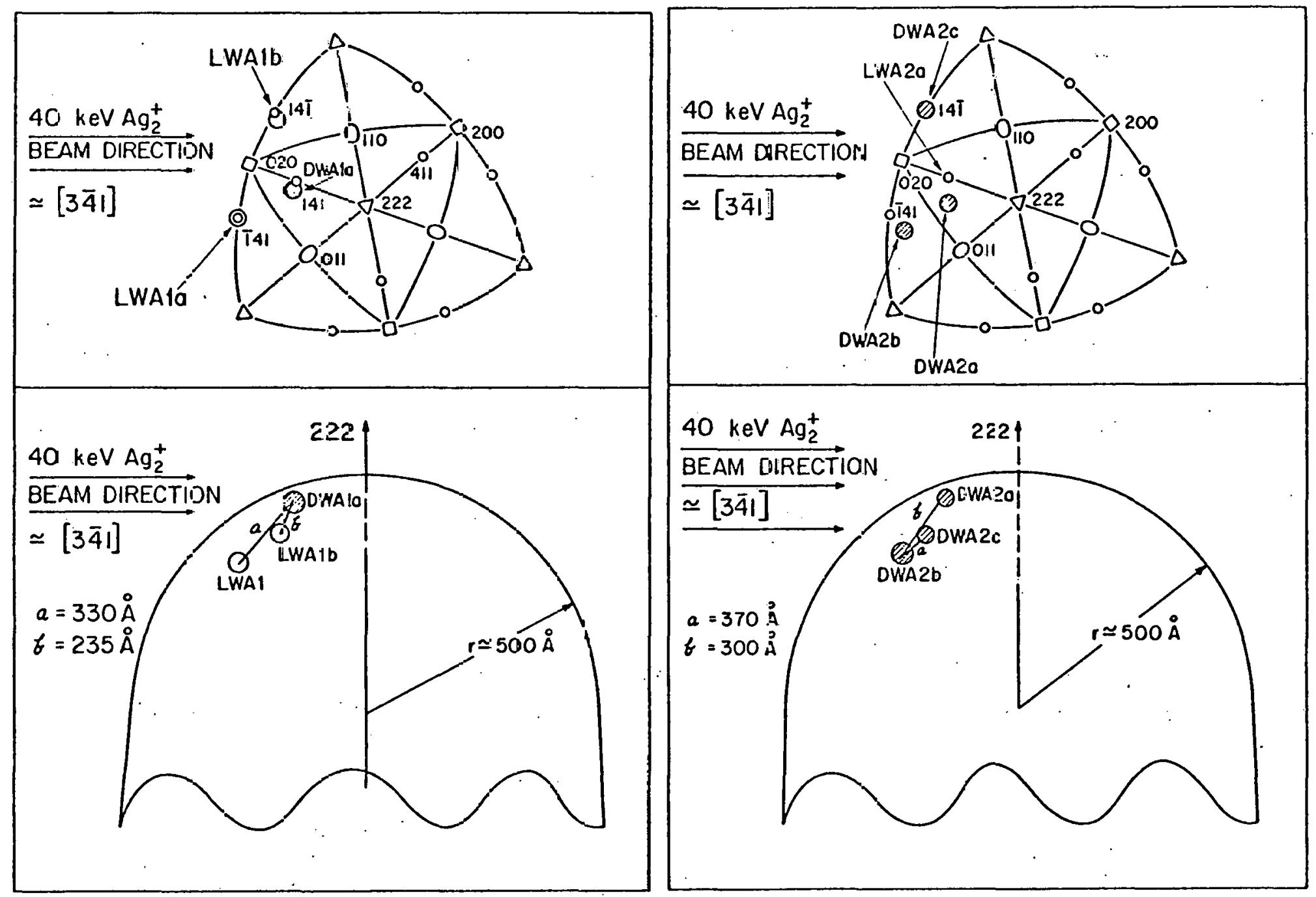

Fig. 30: (a), (t) Partial 222 stereographic projections showing location of cepleted zones produced by $40 \mathrm{keV} \mathrm{Ag}_{2}^{+}$irradiation of tungsten.

(c), (d) Schematic cross-sectional views of the FIM tip specimen. 

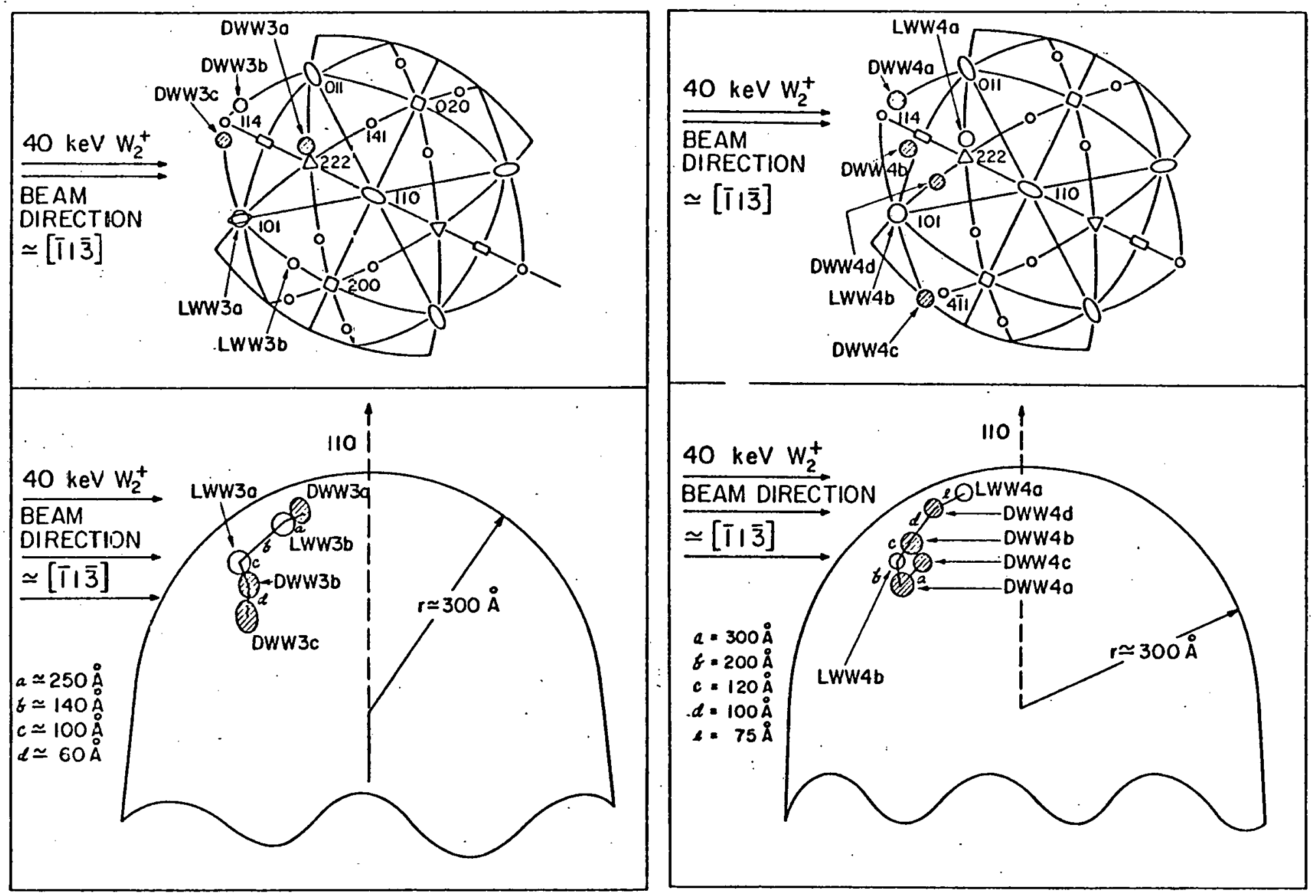

Fig. 31: (a), (b) Partial 110 stereographic projections showing location of depleted zones produced by $40 \mathrm{keV} \mathrm{W}_{2}^{+}$irradiations of tungsten.

(c), (d) Schematic cross-sectional views of the FIM tip specimens. 


\section{TABLE 8}

Number of vacancies and vacancy concentration in DZ's produced in dimer irradiations of $\mathrm{W}$

\begin{tabular}{|l|c|c|}
\hline $\begin{array}{c}\text { DEPLETED } \\
\text { ZONE3 } \\
\text { (DZ) }\end{array}$ & $\begin{array}{c}\text { NUMBER OF } \\
\text { VACANCIEE } \\
v\end{array}$ & $\begin{array}{c}\text { VACANCY } \\
\text { CONCENTRATION } \\
\left(\mathrm{c}_{\mathrm{v}}\right) \text { at \% }\end{array}$ \\
\hline DWA1a & 675 & 9 \\
DWL2a & 446 & 7.3 \\
DWA2b $^{*}$ & $\approx 650$ & -- \\
DWW3a $^{\dagger}$ & 190 & 12.2 \\
DWW4a & 593 & 8.13 \\
\hline
\end{tabular}

* Vacancy count only available.

+ Surface cascade. 
TABLE 9

Range and dimensions of DZ's produced by dimer irradiations of $W$

\begin{tabular}{|c|c|c|c|c|c|}
\hline $\begin{array}{c}\text { DEPLETED } \\
\text { ZONES } \\
(\mathrm{DZ})\end{array}$ & $\begin{array}{c}\text { RANGE } \\
(\mathrm{I}) \\
\AA\end{array}$ & $\begin{array}{c}\text { ELONGATION } \\
\text { DIRECTION } \\
{[\mathrm{hk} 1]}\end{array}$ & $\begin{array}{c}\text { DIAMETER } \\
\lambda_{1} \\
(\dot{\mathrm{A}})\end{array}$ & $\begin{array}{c}\text { DIAMETER } \\
\lambda_{2} \\
(\dot{\mathrm{A}})\end{array}$ & $\begin{array}{c}\text { MEAN DIAMETER } \\
<\lambda> \\
(\dot{\mathrm{A}})\end{array}$ \\
\hline DWAIa & 30 & {$[1 \overline{1} 1]$} & 44.52 & 27.7 & 32.4 \\
DWA2a & 36 & {$[100]$} & 31.3 & 24.28 & 26.4 \\
DWW3a & 5 & {$[10 \overline{1}]$} & 25.3 & 15.8 & 18.48 \\
DWW4a & 25 & {$[1 \overline{1} 0]$} & 33.08 & 24.06 & 26.76 \\
\hline
\end{tabular}


$-81-$

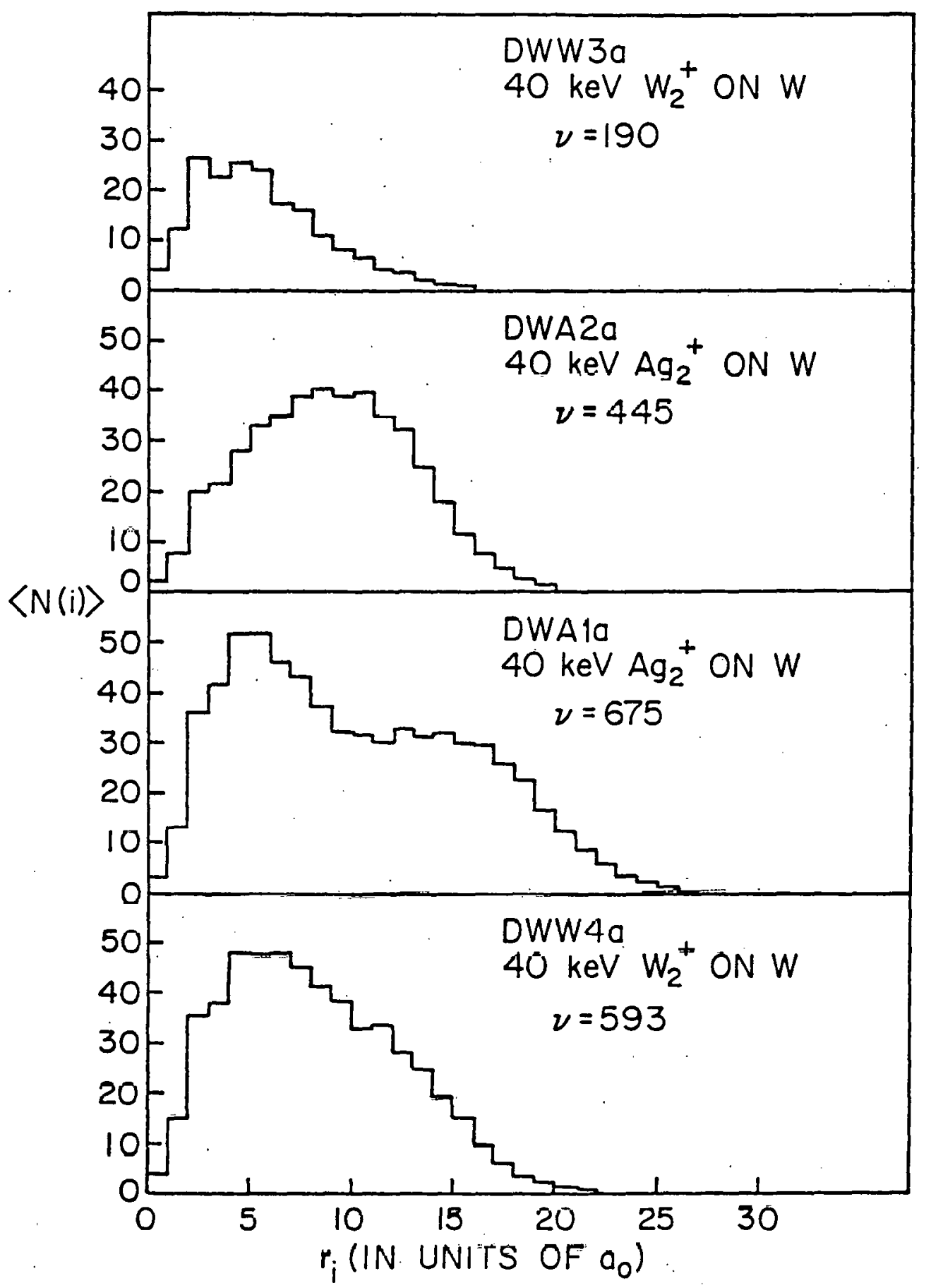

Fig. 32: The spectra of $<\mathrm{N}(\mathrm{i})>\mathrm{s}$ for depleted zones produced by $40 \mathrm{keV}$ $\mathrm{Ag}_{2}{ }^{+}$and $\mathrm{W}_{2}^{+}$irradiation of tungsten. 




Fig. 33: The normalized radial distribution functions $R(i) / Z(i)$ for depleted zones produced by $40 \mathrm{keV} \mathrm{Ag}_{2}^{+}$and $\mathrm{W}_{2}^{+}$irradiations of tungsten. 


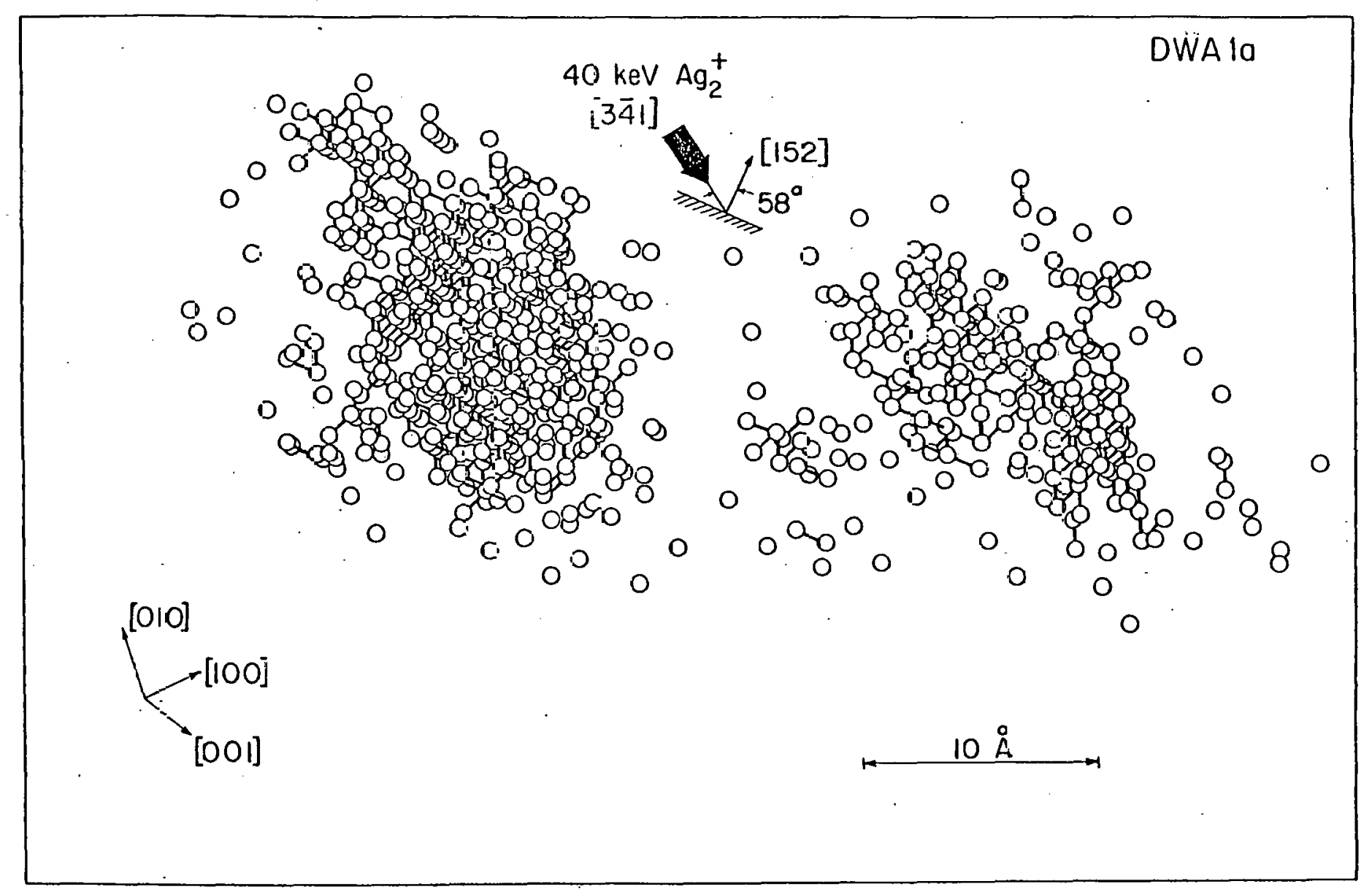

Fig. 34: An OR TEP drawing of depleted zone DWAla. 


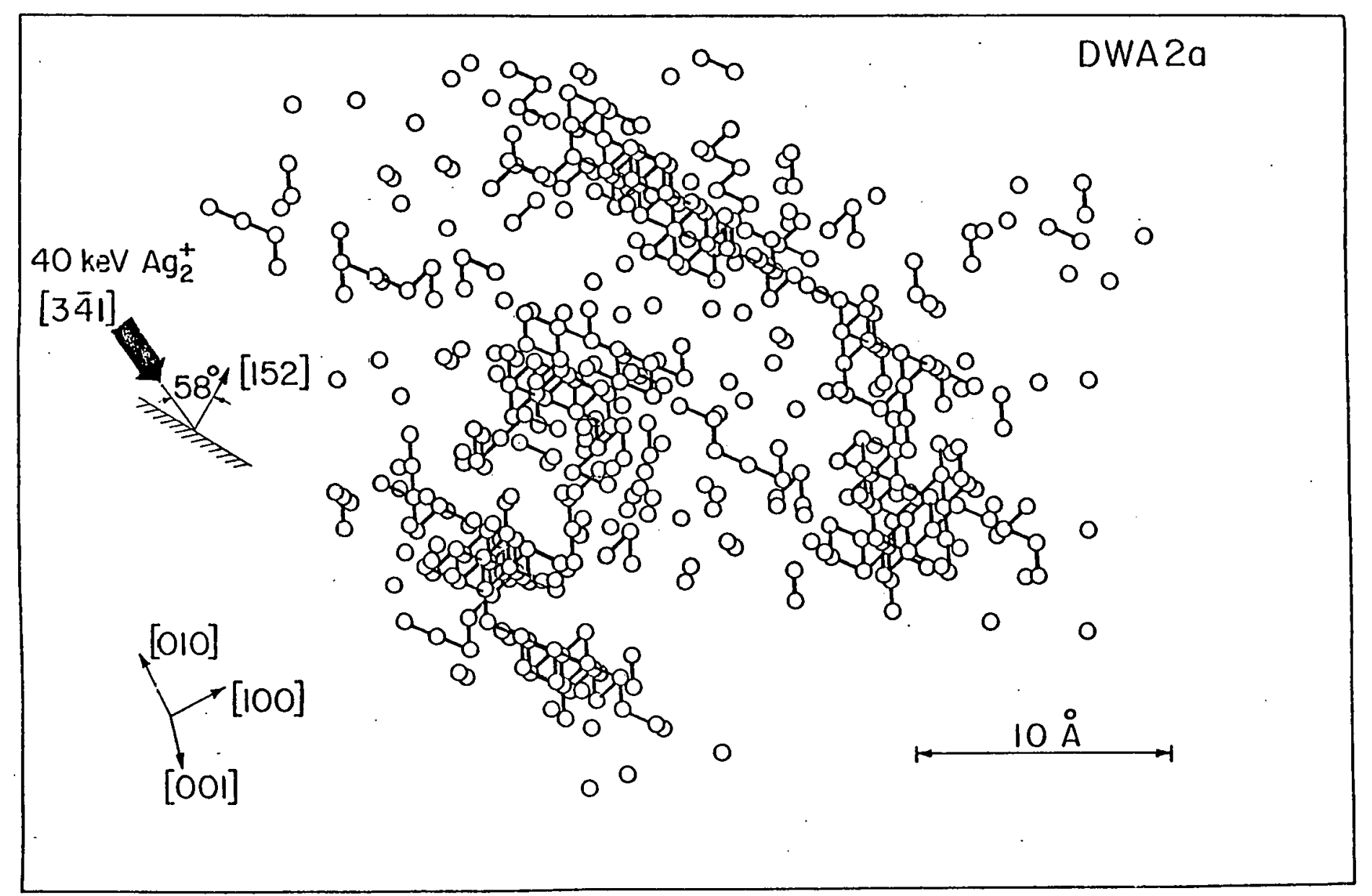

Fig. 35: An OR TEP drawing of depleted zone DWA2a. 


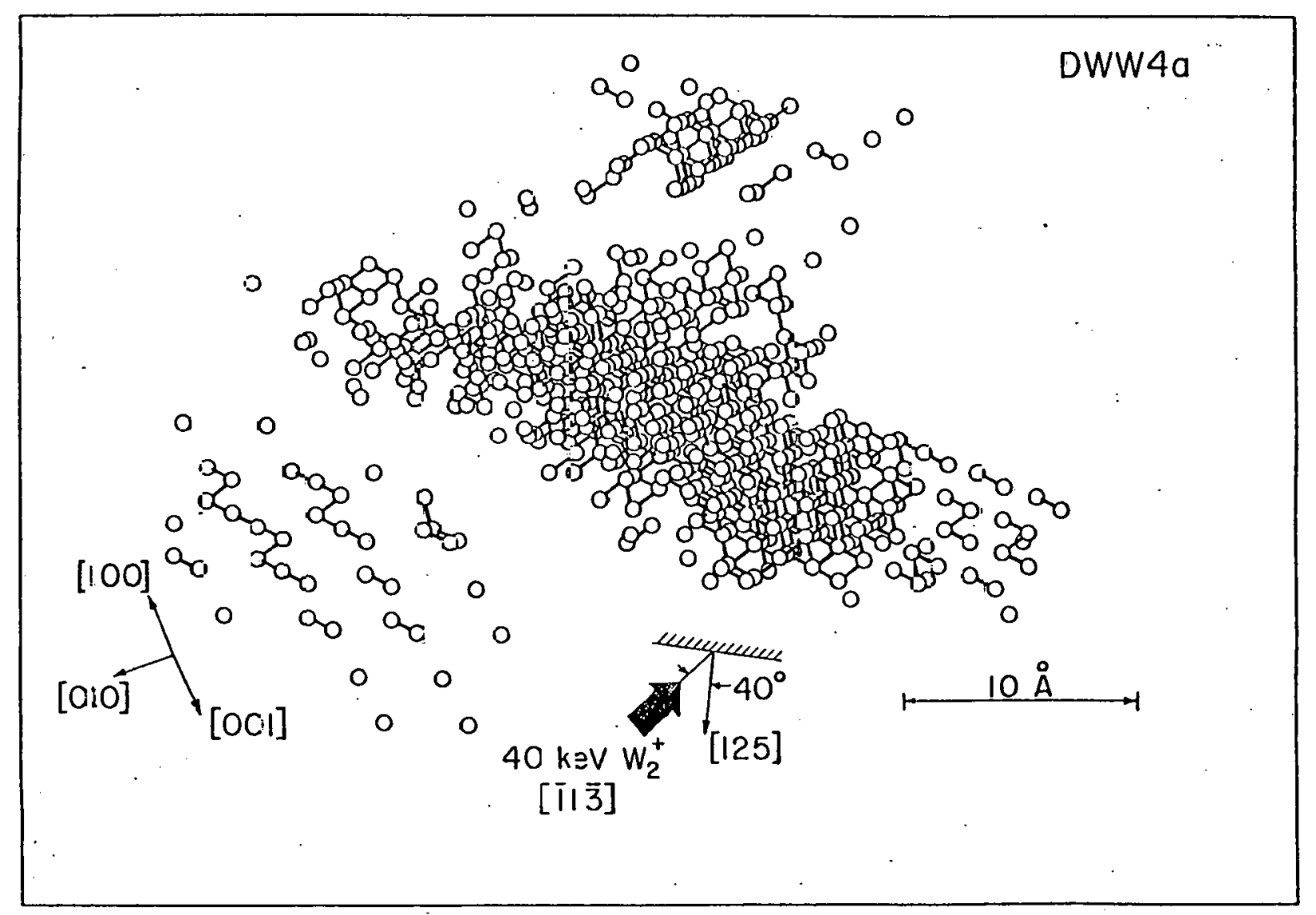

Fig. 36: An OR TEP drawing of depleted zone DWA4a. 


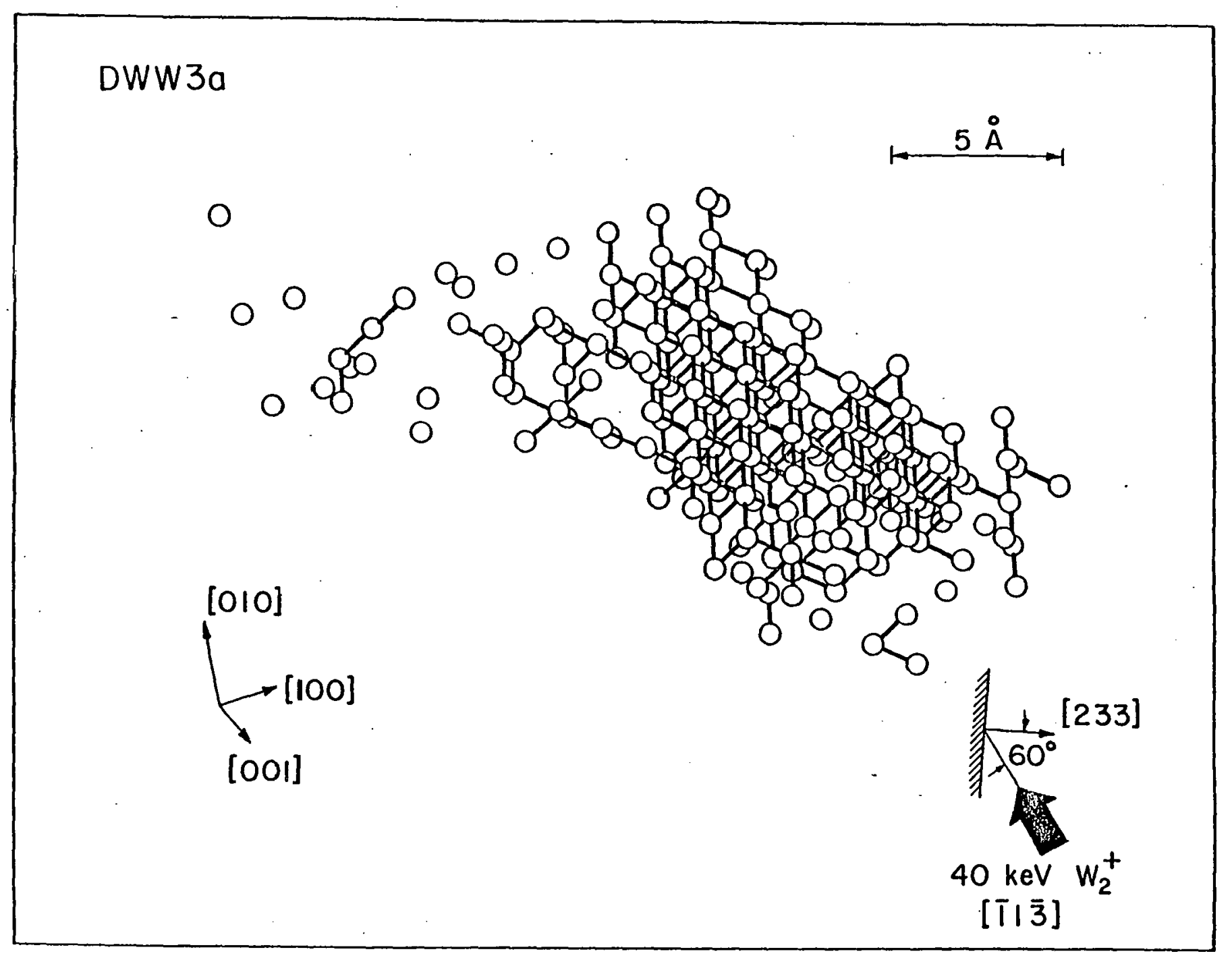

Fig. 37: An OR TEP drawing of depleted zone DWW3a. 
An analysis of the degree of clustering revealed the following:

DWAla has 155 monovacancies, 12 divacancies, four trivacancies, three quadravacancies, three pentavacancies, two clusters of 9 , one cluster of 110 and one cluster of 329. DWA2a has 111 monovacancies, 23 divacancies, four trivacancies, four quadravacancies, one pentavacancy, two hexavacancy, two heptavacancies, one octavacancy, one cluster of 15 , one cluster of 19 , one cluster of 43 , one cluster of 64 , one cluster of 80 .

DWA4a has 54 monovacancies, 17 divacancies, one trivacancy, two quadravacancies, three pentavacancies, one hexavacancy, one cluster of nine, one cluster of 36 and one jumbo cluster of 428 .

DWA3a has 19 monovacancies, one trivacancy, one peutavacancy, and one jumbo cluster of 163 . It is clear that in the $W_{2}$ irradiations the majority of the vacancies were formed in a single big cluster.

\subsection{Comparison of monomer and dimer irradiations}

Spike effects should be pronounced for heavy ions on heavy targets at not too high ion energies, no sritorion of whethel dil lun w111 produce a spike or not is given by the quantity $\theta_{0}$, the effective maximum

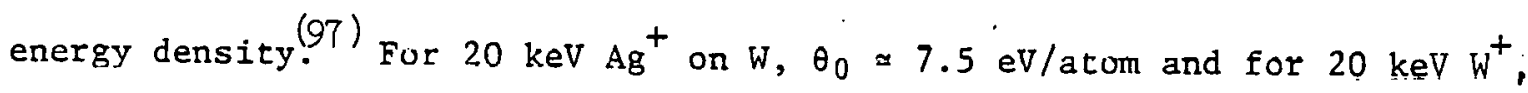
$\theta_{0} \simeq 15 \mathrm{eV} /$ atom. The sublimation energy of $\mathrm{W}$ is $8.7 \mathrm{eV}$ so that we can expect the spike effect from $\mathrm{Ag}^{+}$and $\mathrm{W}^{+}$to be quite pronounced.

In the case of $20 \mathrm{keV}$ heavy ions $\left(\mathrm{Ag}^{+}\right.$and $\mathrm{W}^{+}$) 1rradiation of $\mathrm{W}$, $\langle V\rangle=190$ for seven $\mathrm{DZ}^{\prime} \mathrm{s}$ (four $\mathrm{Ag}^{+}$. and three $\mathrm{W}^{+}$). This is somewhat greater than the expected value of $\langle\nu\rangle=145$ obtained from TRIM program or from the modified Kinchin-Pease theory using a single threshold value of $43 \mathrm{eV}$. The fluctuations were also very large with a count of 269 vacancies being madc for one of the DZ's--this value is even greater than the unmodified Kinchin-Pease estimate. If this $\mathrm{DZ}$ "is left out then $\langle v\rangle$ falls to 177 for the six remaining $\mathrm{DZ}$ 's.

The possibility of very large number of vacancies is due to the spike- 
like nature of the cascade. As a consequence of this, statistical fluctuations may lead to much higher energy densities in some individual cascades than in others. The high energy density would lead to an energy distribution that is different from that calculated assuming simple binary collisions, or to various physical processes, such as the lowering of the threshold energies within the volume of the cascade. Both of these would lead to an enhancement of point defect production. A point to note is that the spike-like nature may appear only in very few individual cascades and an average over a large number of cascades may not necessarily exhibit this behavior.

Excluding DWW3a, which was a surface cascade--and therefore not fully developed--the average number of vacancies for the $\mathrm{DZ}$ 's detected in the dimer irradiations were $\langle\nu\rangle=590$. This is far greater than twice the $\langle v\rangle$ for the monomers and clearly indicates nonlinearities in the defect production rate. If $\langle\nu\rangle_{\text {dimer }}$ is the number of defects produced per incoming ion for the dimer then

$$
\begin{aligned}
\frac{(\langle v\rangle)_{\text {dimer }}}{(\langle v\rangle)_{\text {monomer }}} & =\frac{295}{190} \\
& =1.55
\end{aligned}
$$

It is instructive to compare these results with the ratio of sputtering yields of monomers to dimers. The sputtering yield $\delta$ and the damage level < \langle\rangle are connected to the same physical process, namely the dissipation of energy of an incident projectile ion in a cascade. The sputtered atoms come from cascades close to the surface. As the properties of the cascades are independent of the depth at which they are produced, various properties of the sputtered atoms should reflect what is occurring inside the cascade. Since only those atoms that possess energy greater thän the sublimation energy $V$ (within a distance $\delta$ - $<5 \dot{A}$ - from the surface) are finally sputtered, it is clear that the energy distribution 
inside the cascade will critically affect the sputtering yield. The same is true for the damage level according to the simple threshold model, where all the atoms having energy greater than the threshold energy $\mathrm{E}_{\mathrm{d}}$ are displaced. Thus spike effects that are observable as nonlinearities in $\mathrm{S}$ should also be observable as nonlinearities in the damage level. Andersen and Bay ${ }^{(95)}$ measured the dimer to monomer yield ratios for Se and Te irradiations, where the atomic and molecular ions had the same velocity for each species. The collision cascades produced by $\mathrm{Te}$ on $\mathrm{Au}$ should be very similar to that of $\mathrm{Ag}$ on $\mathrm{W}$. Andersen and Bay measured a dimer to monomer yield ratio of $=2.2$, showing very strong nonlinearity. Our damage levels for $\mathrm{Ag}$ and $\mathrm{W}$ monomer and dimer irradiations also show strong non-linearities.

The extent to which the cascades caused by the individual atoms of the dimer superimpose should be given by a comparison of the average dimensions of the $20 \mathrm{keV}$ monomers and that of the dimers. The value of $\langle\lambda\rangle$ for the six fully developed cascades due to $20 \mathrm{keV}$ monomers ( $\mathrm{Ag}$ and $\mathrm{W}$ ) is $17.5 \dot{A}$. That for three fully developed cascades due to the $40 \mathrm{keV}$ dimers is $28.5 \dot{\mathrm{A}}$. The cascades due to the dimers are much larger than that due to the single atoms, but not twice as large, indicating that the cascades overlap to some extent. However, the degree of overlap is most likely to be a very strongly fluctuating quantity.

The average concentration of vacancies $c_{v}$ is much less for the dimer UZ's chan 1 it is for the monomer VL's. However, the $c_{v}$ 's that are calculated are not representative of the local concentrations in different regions of the cascades, which can fluctuate considerably. This is clear from an examination of the ORTEP visualizations. The formation of large clusters in DWAla and DWW4a indicates very high vacancy concentrations in certain regions of the DZ's and these may be the regions in which the cascades due to the individual atoms of the dimers overlapped. 
In fig. 38 , we have plotted $\langle R(i) / Z(i)>$ for the dimers and monomers, separately for the case of $\mathrm{Ag}$ and $\mathrm{W}$. The curve for $20 \mathrm{keV} \mathrm{Ag}$ on $\mathrm{W}$. Now $<R(i) / Z(i)>$ measures the average local environment around the vacancies in a $\mathrm{DZ}$. When an average is taken over several $\mathrm{DZ}$ 's, the averages should represent the local environment around vacancies for the cumulative damage distribution, that is, it should give an idea of the nature of the vacancy distribution when a beam of ions is impinging on the target. It was pointed out earlier that, although the deposited energy should be the same for dimers and two monomers the damage level should be higher in the first case due to nonlinear effects. As a consequence, we would expect that $R(i) / Z(i)$ should be higher in the case of dimers. The fact that this was not the case for our $\mathrm{Ag}^{+}$. results appeared to be the result of the small number of DZ's examined which may not have been enough to predict the general trend. The degree to which the cascades due to the atoms of the dimers may overlap is also subject to statistical fluctuations and this would affect the degree of non-linearity. For example, in the two experimental $\mathrm{Ag}_{2}{ }^{+} \mathrm{DZ}$ 's the difference in $v$ is very large. It was clear that in one of the DZ's with the large $v$ there were very large clusters indicating a high degree of overlap while in the other for which $\checkmark$ was not so large, the DZ was diffuse indicating possibly that there was little overlap of the individual cascades.

In the case of the $\mathrm{W}_{2}{ }^{+}$irradiations the average $\mathrm{R}(i) / Z(i)$ was much greater than the $\mathrm{W}^{+}$irradiations but in light of the above comments no definte conclusions could be reached.

In Tableiv, we have summarized the data on clustering of vacancies into nearest neighbor clusters of size $\mathrm{n}$, for the $\mathrm{DZ}$ 's that are produced by both $\mathrm{Ag}$ and $\mathrm{W}$ monomers, and by $\mathrm{Ag}$ and $\mathrm{W}$ dimers. The fraction of vacancies in the form of monovacancies, for the case of $\mathrm{Ag}$ is 0.22 and the 


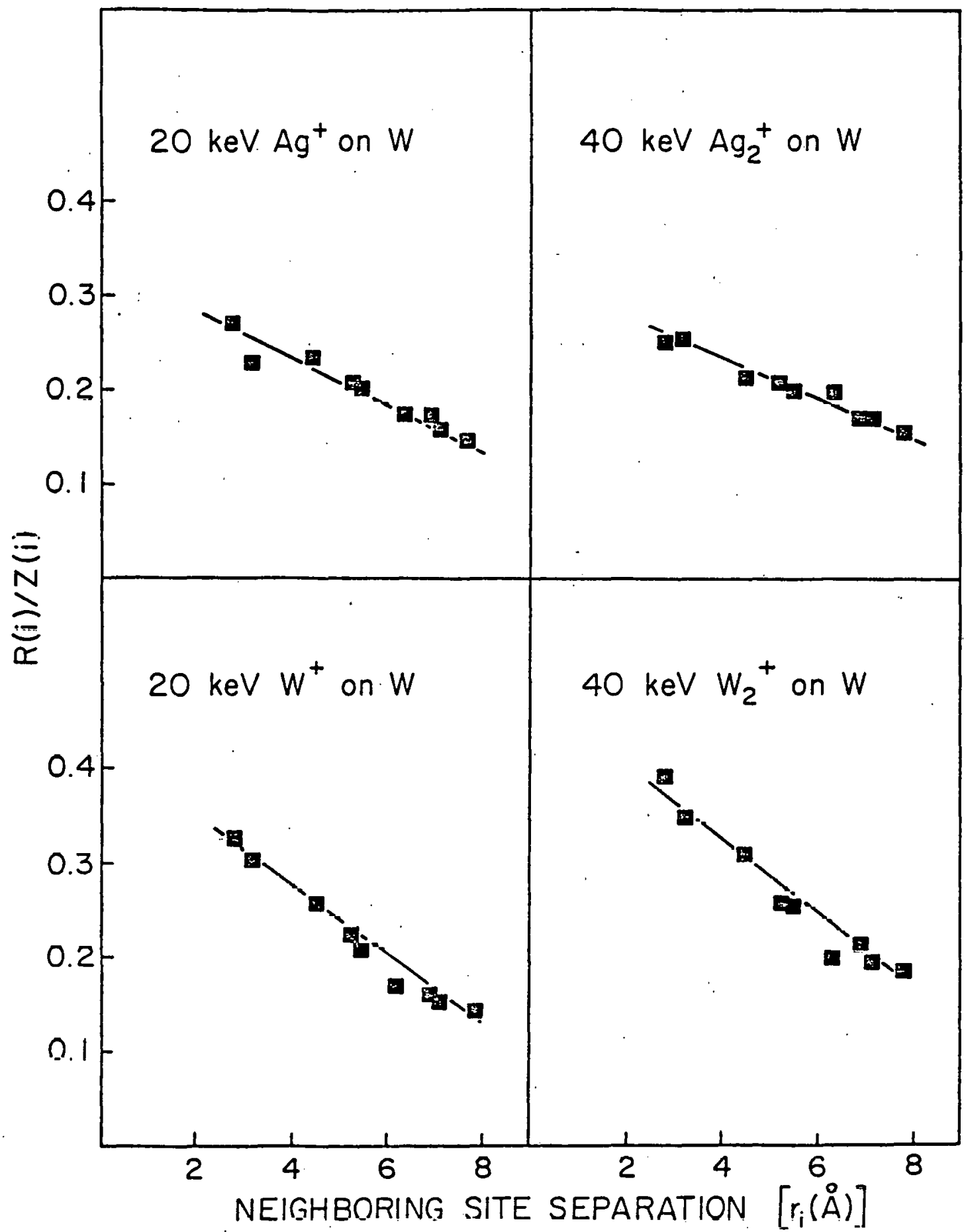

Fig. 38 : A comparison of the normalized radial distribution functions $[R(i) / Z(i)]$ for depleted zones produced by dimer and monomer irradiations of tungsten. 
TABLE 10

Fraction of vacancies in first-nearest neighbor clusters of size $\mathrm{n}$ for monomer and dimer irradiations of tungsten

\begin{tabular}{|c|c|c|c|c|c|}
\hline $\mathrm{f}=\frac{\mathrm{nN}_{\mathrm{n}}}{\nu}$ & 1 & 2 & 3 & 4 & $\geq 5$ \\
\hline $\mathrm{Ag}$ & 0.22 & 0.09 & 0.04 & 0.001 & 0.63 \\
$\mathrm{Ag} 2$ & 0.237 & 0.06 & 0.02 & 0.025 & 0.65 \\
$\mathrm{~W}$ & 0.12 & 0.023 & 0.019 & 0.019 & 0.81 \\
$\mathrm{~W}_{2}$ & 0.09 & 0.04 & 0.00 & 0.00 & 0.84 \\
$\mathrm{Mo}$ & 0.2 & 0.07 & 0.035 & 0.00 & 0.68 \\
\hline
\end{tabular}


fraction in the form of clusters having. five or greater number of vacancies is 0.63. The corresponding fractions for $\mathrm{Ag}_{2}$ are 0.24 and 0.65 , which is virtually identical to that for $\mathrm{Ag}$. Comparison of the data for $W$ and $W_{2}$ in table reveals that the degree of clustering was again identical, for $W$ and $W_{2}$. The results indicated that the degree of clustering of the vacancies was unchanged by irradiating with dimers instead of monomers, though it was sensitive to the $M_{2}$. The fraction of vacancies in the form of large clusters $(\geq 5)$ increased with $M_{2}$, while the fraction of monovacancies correspondingly decreased. The dependence of the degree of clustering on $\mathrm{M}_{2}$ was further emphasized on comparison of data for $\mathrm{Ag}$ and Mo irradiations of tungsten. The degree of clustering was almost identical, which was to be expected since $M$ is almost equal for the two elements.

I. SEMINARS AND MEETINGS

Seminars and talks were presented at the following meetings and institutions:

1. Gordon Research Conference on "Diffusion in Solids", New Hampshire, July 1980: Short Talk on "Diffusive Behavior of Helium in Tungsten."

2. Second Intemational Conference un Iun Bew Mudification of Materiala, SUNY/ALBANY, Albany, New York, July 1980. Invited lecture on the "Primary State of Damage of Ion-Irradiated Metals."

3. IBM Watson Laboratory, Yorktown Heights, New York, 27 October 1980. Invited seminar on the "Applications of Field-Ion and Atom-Hrobe Microscopy to Lon-Implantation, and Primary Stale of Ion-Damage and Semiconductors:".

4. Centre de Physique des Houches, Les Houches, France, February 18th to 28 th 1981 , invited participant in "Nucleation Workshop": Poster session entitled "On the Problem of the Collapse of a Displacement Cascade into a Dislocation Loop: A Unique "Nucleation and Growth" Problem? 
III. OTHER FINANCIAL ASSISTANCE

A total of $\$ 18,244$ will have been received, by June 30,1981 , from

the National Science Foundation through the Cornell Materials Science

Center, for the period July 1, 1980 to June 30, 1981. These research funds

will have been used to support one graduate research assistant on a project

involving the study of segregation to stacking faults in the refractory

metal alloys Co $(\mathrm{Nb})$ and $\mathrm{Co}(\mathrm{Fe})$.

IV. LIST OF DOCUMENTS GENERATED DURING THE CONTRACT PERIOD

1. "A Study of the Chemistry of the $\{111\} \mathrm{GaP}$ Planes by Atom-Probe Field-Ion Microscopy", M. Yamamoto, D.N. Seidman and S. Nakamura, DOE/ER/03518-88.

2. "The Determination of the Composition of Ordered Pt ${ }_{3}$ Co by Atom-Probe Field-Ion Microscopy: Intrinsic Problems", M. Yamamoto and D.N. Seidman, DOE/ER/03158-89.

3. "An Atom-Probe Field-Ion Microscope Study of the Stoichiometry of Ordered $\mathrm{Ni}_{4} \mathrm{MO} "$ " M. Yamamoto and D.N. Seidman, DOE/ER/03158-90.

4. "Direct Observation of the Primary State of Radiation Damage of IonIrradiated Tungsten and Platinum", D.N. Seidman, M.I. Current, D. Pramanik and C.-Y. Wei, DOE/ER/03158-9I.

5. "Direct Observation of the Primary State of Damage of Ion-Irradiated Tungsten and Platinum", D. Pramanik, Ph.D. Thesis, DOE/ER/03518-92.

6. "Experimental Determination of the Particle Reflection Coefficients of Low-Energy ( 100 to $1500 \mathrm{eV}$ ) $3_{\mathrm{He}}$ and He Atoms from the (110) Plane of Tungsten", J. Amano and D.N. Seidman, DOE/ER/03518-93.

7. "The Study of Defects, Radiation Damage and Implanted Gases in Solids by Field-Ion and Atom-Probe Microscopy", D.N. Seidman, J. Amano and A. Wagner, DOE/ER/03518-94.

8. "Interstitial Diffusion of 3 He in Tungsten: An Atomic View", J. Amano and D.N. Seidman, DOE/ER/03518-95.

9. "Defects in Metal Crystals", D.N. Seidman, DOE/ER/03518-96. 


\section{REFERENCES}

1. Y. Ohno, S. Nakamura, T. Adachi and T. Kuroda, Surface Sci. 69 (1977) 521.

2. T.M. Hall, A. Wagner and D.N. Seidman, J. Phys. E: Scient. Instrum. 10 (1977) 884.

3. A. Wagner, T.M. Hall and D.N. Seidman, J. Nuc. Mat. $69 \& 70$ (1978) 413.

4. A. Wagner and D.N. Seidman, Phys. Rev. Lett. 42 (1979) 515.

5. J. Amano, A. Wagner and D.N. Seidman, Cornell University Materials Science Center Report No. 4107 (1980); J. Amano, A. Wagner and D.N. Seidman, Cornell University Materials Science Center Report No. 4108 (1980).

6. M. Yamamoto, D.N. Seidman and S. Nakamura, Cornell Materials Science Center Report (1980).

7. A.S. Berger, Rev. Sci. Instrum. 44 (1973) 592.

8. M. Yamamoto and D.N. Seidman, "The Determination of the Composition of Ordered $\mathrm{Pt}_{3} \mathrm{Co}$ by Atom-Probe Field-Ion Microscopy: Intrinsic Problems" 27th International Field Emmission Symposium, Tokyo, Japan (1980).

9. L. Pauling, "The Nature of the Chemical Bond", (Cornell University Press, Ithaca, N.Y., 1960), p. 85.

10. H.F. Wolf, "Semiconductors", (Wiley-Interscience, New York, 1971), p. 21.

11. J. Aidelberg, Ph.D. Thesis, Cornell University (1980); J. Aidelberg, Cornell University Materials Science Center Report No. 4157 (1979); J. Aidelberg and D.N. Seidman, Nuc. Instrum. and Methods 170 (1980) 413.

12. O. Nishikawa and E.W. Mïller, J. Appl. Phys. 35, (1964) 2806.

13. D.G. Brandon, in Field-Ion Microscopy, edited by J.J. Hren and S. Ranganathan (Flenum Fress, New York, 1968, pp. 53-68.

14. D.G. Ast and D.N. Seidman, Surface Sci. 28, (1971) 19; R.S. Averback and D.N. Seidman, Surface Sci. 40, (1973) 249.

15. M. Yamamoto and D.N. Seidman, "The Determination of the Composition of Ordered $\mathrm{Pt}_{3} \mathrm{Co}$ by Atom-Probe Field-Ion Microscopy: Intrinsic Problems", 27th International Field Emmission Symposium, Tokyo, Japan (1980).

16. M. Kaminsky, Atomic and Ionic Impact Phenomena on Metal Surfaces (SpringerVerlag, Berlin, 1965), pp. $241-263$.

17. H. Verbeek, in: Radiation Effects in Solid Surfaces, ed. M. Kaminsky (American Chemical Society, Washington, D.C. 1976) p. 245.

18. O.S. Oen and M.T. Robinson, Nucl. Instrum. and Methods. I32 (1976) 647 .

19. M. Hou and M.T. Robinson, Appl. Phys. 17 (1978) 371.

20. O.S. Oen and M.T. Robinson, J. Nucl. Mater. $76 \& 77$ (1978) 370.

21. M. Hou and M.T. Robinson, Appl. Phys. 17, (1978) 295. 
22. A. A. van Gorkum and E.V. Kornelsen, submitted to Rad. Effects (1980).

23. A. Wagner, Ph.D. Thesis, Cornell University, Ithaca, New York (1978).

24. A. Wagner and D.N. Seidman, Phys. Rev. Lett. 42 (1979) 515.

25. J. Amano, A. Wagner and D.N. Seidman, Cornell Materials Science Center Report No. 4107 (1980); submitted to the Philosophical Magazine for publication.

26. J. Amano, A. Wagner and D.N. Seidman, Cornell Materials Science Center Report No. 4108 (1980); submitted to the Philosophical Magazine for publication.

27. J. Amano and D.N. Seidman, Cornell Materials Science Center Report No. 4153 (1980).

28. A. Macrander in: Defects in Metal Crystals, U.S. Dept. of Energy Report C003158-87, by D.N. Seidman, pp 86-97 (1980); A. Macrander and D.N. Seidman, Cornell Materials Science Center Report, in preparation (1980).

29. J. P. Biersack and L.G. Haggmark, Hahn-Meitner-Institut Report (Berlin, W. Germany 1980).

30. M.T. Robinson and I.M. Torrens, Phys. Rev. B 2 (1974) 5008.

31. J. Amano and D.N. Seidman, Rev. Sci. Instrum. 50 (1979) 1125.

32. K.I. Wilson and D.N. Seidman, Rad. Effects, 27 (1975) 67.

33. J.A. Panitz, Prog. in Surf. Science 8 (1978) 219.

34. S.A. Fields, J.I. Burch and W.A. Oran, Rev. Sci. Instrum. 48 (1977) 1076.

35. E.W. Müller, S.B. McLane and J.A. Panitz, Surf. Science 17 (1969) 430.

36. T.T. Tsong and E.W. Müller, J. Chem. Phys. 55 (1971) 2884.

37. E.W. Mïller, S.V. Krishnaswamy and S.B. McLane, Phys. Rev. Lett. 31 (1973) 1282.

38. S.V. Krishnaswamy, S.B. McLane and E.W. Mïller, J. Vac. Sci. Technol. 13 (1976) 665.

39. A. Macrander, M. Yamamoto and D.N. Seidman, Cornell Materials Science Center Report in preparation (1980).

40. A. Macrander, Cornell University Materials Science Center Report No. 4234 (1980).

41. J.L. Katz and H. Wiedersich, J. Chem. Phys. 25 (1971) 1414; H. Wiedersich, in: Radiation Damage in Metals (American Society for Metals, Metals Park, OH, 1976) p. 157.

42. K.C. Russe11, Acta Met. 26 (1978) 1615.

43. D.I.R. Norris, Radiation Effects 14 (197?) 1.

44. J.0. Stiegler, in: Radiation Induced Voids in Metals (Nat. Techn. Information Service, springfield, VA, 1972) p. 292.

45. A.D. Brailsford and R. Bullogh, J. Nucl. Mater. 69 \& 70 (1978) 434 .

46. L.K. Mansur, Nucl. Technol. 40 (1978) 5.

47. L.K. Mansur and W.G. Wolfer, J. Nucl. Mater. $69 \& 70$ (1978) 825.

4R. P.R. Okamoto and H. Wieders1ch, J. Nucl. Mater. 53 (1974) 336.

49. R.A. Johnson and N.Q. Lam, J. Nucl. Mater. 69 \& 70 (1978) 424. 
50. T.R. Anthony, in: Radiation Induced Voids in Metals (Nat. Techn. Information Service, Springfield, VA 1972) p. 630.

51. P.R. Okamoto and S.D. Harkness, Trans. ANS 16 (1973) 70.

52. P.R. Okamoto, A.T. Santhanam, H. Wiedersich and A. Taylor, Nucl. Technol. 22 (1974) 45 .

53. A. Barbu and A.J. Ardell, Scripta Met. 9 (1975) 1233.

54. K. Farrell, J. Bentley and D.N. Braski, Scripta Met. 11 (1977) 243.

55. E.A. Kenik, Scripta Met. 10 (1976) 733.

56. A. Wagner and D.N. Seidman, J. Nuc. Mater. 83 (1979) 48.

57. W.H. Chang and I. Perlmutter, in: High Temperature Materials II (Interscience, New York, 1963) p. 347.

58. B.L. Eyre and A.F. Bartlett, reported on by B.L. Eyre, in: Discussion Meeting on Defects in Refractory Metals (SCK/CEN, Mol, Belgium, 1972) p. 331.

59. F.W. Wiffen, in: Radiation Induced Voids in Metals (Nat. Techn. Information Service, Springfield, VA, 1972) p. 386.

60. J. Moteff, V.K. Sikka and H. Jang, in: Physics of Irradiation Produced Voids (HMSO, London 1975) p. 181.

61. R.A. Johnson and N.Q. Lam, Phys. Rev. B13 (1976) 4364.

62. R.A. Johnson and N.Q. Lam, Phys. Rev. B15 (1977) 1794.

63. W.B. Pearson, A Handbook of Lattice Spacings and the Structures of Metals and Alloys (Pergamon Press, New York, 1964) p. 763.

64. M.L. Swanson and F. Maury, Can. J. Hhyse. 53 (1979) 1117 (1975); L.M. Howe, M.L. Swanson and A.F. Quenneville, J. Nucl. Mater. $\underline{69}$ and $\underline{70}$ (1978).744.

65. R. Cauvin and G. Martin, J. Nucl. Mater. 83 (1979) 48.

66. V.K. Sikka and J. Moteff, Metals Trans. 5 (1974) 1514.

67. R.S. Wagner, In: Whisker Technology (Wiley and Sons, New York, 1970), pp 47119.

68. E.I. Givarginjov, in: Current Topics in Materials Sclence (Nurth-Holland, Ansterdam, 1978), vol. 1, pp 79-145.

69. F.C. Frank, Discussions Faraday Soc. $\underline{5}$ (1949) 48.

70. W.D. Lawson and S. Nielsen, Preparation of Single Crystals (Butterworths, London, 1958) pp 176-184.

71. G.W. Sears, Acta Metall. I (1953) 457.

72. P.B. Price, D. A. Vermilyea and M.B. Webb, Acta Metall, $\underline{6}$ (1958) 524.

73. J.M. Blakely arı K.A. Jackson, J. Chem. Phye. 37 (196?) 4 ?.

74. V. Ruth and J.P. Hirth, J. Chem. Phys. 41 (1964) 3139.

75. J.P. Hirth and.F.C. Frank, Phil. Mag. $\underline{3}$ (1958) 1110.

76. C.B. Collins, R.0. Carlson and C.J. Gallagher, Phys. Rev. 105 (1957) 1168. 
77. Y. Ohno, S. Nakamura and T. Kuroda, Japan, J. Appl. Phys: 17 (1978) 2013.

78. A.J. Melmed and R.J. Stein, Surf. Science 49 (1975) 645.

79. I. Ernst and J.H. Block, Surf. Science 49 (1975) 293.

80. Y. Ohno, S. Nakamura, T. Adachi and T. Kuroda, Surf. Science 69 (1977) 521.

81. S. Nakamura and T. Kuroda, Surf. Science 70 (1978) 452.

82. Y. Ohno, T. Kuroda and S. Nakamura, Surf. Science $\underline{75}$ (1978) 689.

83. T.T. Tsong and Y.S. $\mathrm{Ng}$, Surf. Science 77 (1978) L187.

84. Y. Ohno, S. Nakamura and T. Kuroda, Japanese J. of Appl. Phys: 17 (1978) 2013.

85. T.T. Tsong, Surf. Science 8 I (1979) 28.

86. T. Sakurai, E.W. Mïller, R.J. Culbertson and A.J. Melmed, Phys. Rev. Lett. 39 (1977) 578.

87. G. Kellogg and T.T. Tsong, J. Appl. Phys. 85 (1980) 1184.

88. T. Sakurai, T.T. Tsong and R.J. Culbertson, J. Vac. Sci. Technol. 15 (1978) 647.

89. T. Sakurai, Surf. Science, 86 (1979) 562.

90. W.R. Runyan, Silicon Semiconductor Technology (McGraw-Hill, New York, 1965) p. 168.

91. T. Sakurai, R.J. Culbertson and A.J. Melmed, Surf. Science 78 (1978) L22l.

92. D. Pramanik, Ph.D. Thesis, Cornell University (1980); U.S. Department of Energy Report No. DOE/ER/03158-92 generated under Contract No. DE-ACO2-76ERO3158 (1980).

93. D.N. Seidman, U.S. Department of Energy Report No. C00-3158-87 (1980).

94. P. Sigmund in Inelastic Ion-Surface Collisions, ed. by N.H. Tolk, J.C. Tully, W. Heiland and C.W. White, (Academic Press, Inc., New York, 1977) pp. 121-152.

95. H.H. Andersen and Bay, H.J. Appl. Phys. 45, (1974) 953; ibid. 46, (1975) 2416.

96. M.I. Current, C. - Y. Wei and D.N. Seidman, Cornell Materials Science Center Report No.4193 (1980); accepted for publication in the Philosophical Magazine.

97. P. Sigmund, Appl. Phys. Lett. 25 (1974) 169. 


\section{$\therefore$ \\ $-6 \quad 3$ \\ U.S. DEPARTMENT OF ENERGY \\ NOTICE OF ENERGY RD\&D PROJECT}

FORM DOE 53

(11/78)

PPROVED FOR USE BY

SMITHSONIAN SCIENCE INFORMATION EXCHANGE

FORM APPROVED OMB NO. 38 R-0190

1. DESCRIPTIVE TITLE OF WORK

DEFECTS IN METAL CRYSTALS

2. PERFORMING ORGANIZATION CONTROL NUMBER E74-8377 3. CONTRACT, GRANT OR PURCHASE ORDER NUMBER DE-AC02-76ER03158.

4. CONTRACTOR'S PRINCIPAL INVESTIGATOR/PROJECT MANAGER AND ADDRESS WHERE WORK IS PERFORMED

a. NAME (Last, First, MI) Seidman, David N. PHONE 256-2365

b. BUSINESS ADDRESS: STREET Bard Hall, Materials Science and Enqineering Dept. cITY Ithaca STATE New York ZIP $\quad 14853$

5. a. NAME OF PERFORMING ORGANIZATION

Cornell University (Organization)

Materials Science \& Engineering. (Department)

b. MAILING ADDRESS (If Different From $4 B$ )

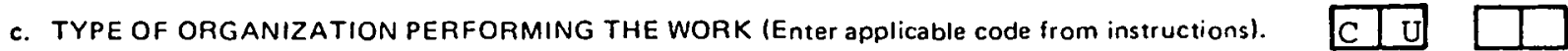

6. SUPPORTING ORGANIZATION
a. DOE PROGRAM DIVISION OR OFFICE (Full Name) Division of Materials Science, Office of Energy Research
b TECHNICAL MUNITOR (Last, First, MI) Ianniello, Louis C., Dr. $(301) 353-3428$
c. ADDRESS (If Different from DOE Hqs)
d. ADMINISTRATIVE MONITOR (Last, First, MI) Chicago operations office, Argonne,
II 60439

7. PROJECT SCHEDULE

(a) START DATE (Month) (Year)

(b) EXPECTED COMPLETION DATE N N/A (Month) TYear)

8. a. FUNDING OPERATING AND CAPITAL EQUIPMENT OBLIGATION (In Thousands of Dollars)

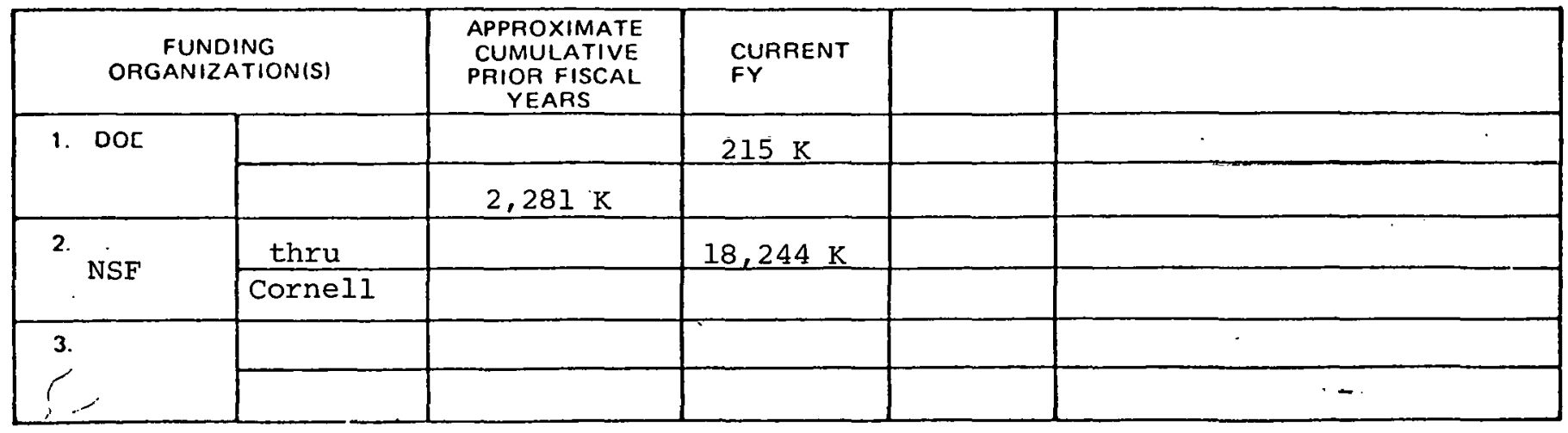

b. DOE BUDGETING AND REPORTING CLASSIFICATION CODE

9. DIRECT SCIENTIFIC AND TECHNICAL MANPOWER

\begin{tabular}{|c|c|c|c|c|}
\hline PROFESSIONAL & GRAO. STUDENTS & OTHER & TOTAL \\
\hline & 6 & 4 & 4 & 14 \\
\hline EUUMUER & 2 & 2 & 2.7 & 6.7 \\
\hline
\end{tabular}


10. SUMMARYY OF WORK ILimit to 200 words or less - include a description, objective, approach and a (inal product expected.)

SEE ATTACHED SHEET

11. PROGRESS SINCE LAST REPORT (Limit to 100 words.)

12. List publications in the last year that are available to the public which have resulted from the product. (Please give a complete bibliographic citation. Use additional sheets if necessary.)

SEE ATTACHED SHEET

13. GENERAL TECHNOLOGY CATEGORIES (Enter applicable code or codes from instructions.)

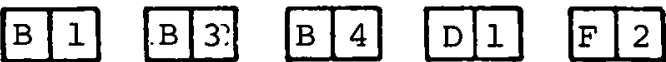

14. PHASE OF RO\&U (Enter Project Percentage! in Apviliable Buxes)

15. KEYWORDS: (Minimum of 5 )
8. $100 \%$
Basic Research
b.

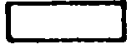
Applied Research
c
Technology Development
d. $\square$
Engineering Development
๑.
Demonstration

16. A. RESFONDENT'S NAME \& ADDRESS Prof. David N. Seidman

Cornell University, Bard Hali, MS\&E Ithaca. New York

B. PHUNE NU.

\begin{tabular}{l|l|l|l|l|l|l|l|l|l|l}
\hline 6 & 0 & 7 & $:$ & 2 & 5 & 6 & 2 & 3 & 6 & 5 \\
\hline
\end{tabular}

C. DATE 
10. $\therefore$ SUMMARY OF WORK:

The efforts of the research group are directed towards determining atomic mechanisms for: (a) radiation-induced solute segregation in binary alloys; (b) radiation induced-precipitation of second phases in subsaturated binary alloys; (c) the radiation-induced formation of second phases produced by bombarding metal-silicon sandwiches with $1 \mathrm{MeV}$ electrons, $60 \mathrm{keV}$ protons or 60 to $120 \mathrm{keV} \mathrm{He}$ ions; (d) radiationinduced segregation of solute atoms to voids in fast-neutron-irradiated refractory metals and alloys; (e) the nucleation of voids in fastneutron-irradiated metals and alloys; and ( $f$ ) the formation of metal silicides from metal-silicon sandwiches that have been thermally heated. The research topics listed above involve the use of the field-ion microscopy, atom-probe field-ion microscopy, conventional transmission electron-microscopy, high-voltage ( $1 \mathrm{MeV}$ ) electron microscopy and Rutherford backscattering techniques. The high-voltage electron microscopy is being performed at the Argonne National Laboratory (ANL) and the experiments on the irradiation of metal-silicon sandwiches is being done in very close cooperation with. Dr. R.S. Averback of the Materials Science Division of ANL; Dr. Averback is in the Kinetics Group. The Rutherford backscattering experiments are being performed at Cornell University in cooperation with Professor J.W. Mayer. The use of four different techniques to study the same problem should provide data that gives a deeper insight into the problem than any one technique. As a part of the effort on metal silicides it was found necessary to prepare our own silicon whiskers, of a given dopant level, for the field-ion and atomprobe field-ion microscope experiments. To this end a special apparatus for growing the required whiskers, by the vapor-liquid-solid (VLS) technique, was constructed. It is noted that this apparatus can also be used to grow whiskers of the III-V compound semiconductors. A study is being performed, employing the whiskers grown by the VLS technique, of the optimum doping conditions needed to obtain high-resolution stable images of silicon surfaces. It is also planned to study the very first stages of oxidation of silicon.

\section{PROGRESS SINCE LAST REPORT}

(a) Chemistry of the \{llI\} GaP planes by atom-probe field-ion microscopy; (b) determination of the composition of ordered $\mathrm{Pt}_{3} \mathrm{Co}$ by atom-probe field-ion microscopy; (c) an atom-probe field-ion microscope study of the stoichiometry of ordered NiLMo; (d) determination of the particle reflection coefficient of low-energy $3 \mathrm{He}$ and ${ }^{4} \mathrm{He}$ atoms from the (110) plane of tungsten; (e) segregation of solute atoms to voids in fast-neutron irradiated refractory metals and alloys; ( $f$ ) growth of silicon and III-V compound semiconducting whiskers for the study of metal-semiconductor-and insulator-semiconductor interfaces; (g) fieldion microscope imaging of silicon; ( $h$ ) direct observation of the primary state of damage in ion-irradiated platinum and tungsten. 


\section{PUBLICATIONS 1980-8I}

1. J. Aidelberg and D. N. Seidınan, "Direct Determination of Radiation Damage Profiles in the Order-Disorder Alloy $\mathrm{Pt}_{3} \mathrm{Co}$ Irradiated with Low-Energy (500$2500 \mathrm{eV}) \mathrm{Ne}^{+}$Ions", Nuclear Instruments and Methods 170, 413-417 (1980).

2. M. I. Current and D. N. Seidman, "Sputtering of Tungsten: A Direct View of a Near Surface Depleted Zone Created by a Single $30 \mathrm{keV} 63 \mathrm{Cu}^{+}$Projectile", Nuclear Instruments and Methods 170, 377-381 (1980).

3. M. Yamamoto and D. N. Seidman, "An Atom-Probe Field-Ion Microscope Study of the Stoichiometry of Ordered $\mathrm{Ni}_{4} \mathrm{Mo}$ ", "Proceedings of the 27 th International FieldEmission Symposium", edited by $Y$. Yashiro and N. Igata (Department of Metallurgy and Materials Science, The University of Tokyo, Tokyo, Japan, 1980), pp. 290-297.

4. M. Yamamoto and D. N. Seidman, "The Determination of the Composition of Ordered $\mathrm{Pt}_{3} \mathrm{Co}$ by Atom-Probe Field-Ion Microscopy: Intrinsic Problems", "Proceedings of the 27 th International Field-Emission Symposium", edited by Y. Yashiro and N. Igata (Department of Metallurgy and Materials Science, The University of Tokyo, Tokyo, Japan, 1980), pp. 307-312.

5. M. Yamamoto, D. N. Seidman and S. Nakamura, "A Study of the Chemistry of the \{111\} GaP Planes by Atom-Probe Field-Ion Microscopy", in "Proceedings of the 27 th International Field-Emission Symposium"., edited by Y. Yashiro and N. Igata (Department of Metallurgy and Materials Science, The University of Tokyo, Tokyo, Japan, 1980), pp. 317-323.

6. M. I. Current, C. -Y. Wei and D. N. Seidman, "Single Atom Sputtering Events: Direct Observation of Near Surface Depleted Zones in Ion-Irradiated Tungsten", Cornell Materials Science Center Report \#4193 (1980), to appear in Philosophical Magazine (1980).

7. C. -Y. Wei and D. N. Seidman, "The Spatial Distribution of Self-Interstitial Atoms Around Depleted Zones in Tungsten Ion-Irradiated at $10 \mathrm{~K}$ ", Cornell Materials Science Center Report \#4088 (1979); accepted for publication by the Philosophical Magazine (1980).

8. J. Amano, A. Wagner and D. N. Seidman, "Range Profiles of Low-Energy (100 to $1500 \mathrm{eV})$ Implanted 3He and 4He Atoms in Tungsten: I. Experimental Results", Cornell Materials Science Center Report \#4107 (1980), submitted to the Philosophical Magazine (1980).

9. J. Amano, A. Wagner and D. N. Seidman, "Range Profiles of Low-Energy (100 to $1500 \mathrm{eV}$ ) Implanted $3 \mathrm{He}$ and $4 \mathrm{He}$ Atoms in Tungsten: II. Analysis and Interpretation", Cornell Materials Science Center Report \#4109.(1980), submitted to the Philnsophical Magazinc (1.980).

10. D. N. Seidman, M. I. Current, D. Pramanik and C.-Y. Wei, "Direct Observation of the Primary State of Radiation Damage of Ion-Irradiated Tungsten and Platinum", Cornell Materials Science Center Report \#4278 (1980); to appear in Nuclear Instruments and Methods (1981). 
11. D. N. Seidman, J. Amano and A. Wagner, "The Study of Defects, Radiation Damage and Implanted Gases in Solids by Field-Ion and Atom-Probe Microscopy", to appear in Proceedings of the Workshop on the Analysis of Materials for Fusion Reactors, edited by F. W. Wiffen and J. Spitznagel (1981); Cornel1 Materials Science Center Report \#4106 (1979).

12. J. Amano and D. N. Seidman, "Experimental Determination of the Particle Reflection Coefficients of Low-Energy (100 to $1500 \mathrm{eV})$. $3 \mathrm{He}$ and $4 \mathrm{He}$ Atoms from the (110) Pladie of Tungston", Cornell Materials Science Center Report \#4310 (1980); submitted to Journal of Applied Physics.

13. G. Ayrault and D. N. Seidman, "The Transmission Sputtering of Gold Thin Films by Low-Energy $(<1 \mathrm{keV})$ Xenon Ions: . I. The System and the Measurement", Cornell Materials Science Center Report \#2944 (1978); submitted for publication to the Journal of Applied Physics. (1981).

14. G. Ayrault and D. N. Seidman, "The Transmission Sputtering of Gold Thin Films by Low-Energy $(<1 \mathrm{keV})$ Xenon Ions: II. Results and Discussion", Cornell Materials Science Center Report \#2945 (1978); submitted for publication to the Journal of Applied Physics (1981).

15. C.-Y. Wei, M. I. Current and D. N. Seidman, "Direct Observation of the Primary State of Damage of Ion-Irradiated Tungsten: I. Three-Dimensional Spatial Distributions of Vacancies", Corne11. Materials Science Center Report \#4235 (1980); submitted to Philosophical Magazine.

16. M. I. Current, C. $-Y$. Wei and D. N. Seidman, "Direct Observation of the Primary State of Damage of Ion-Irradiated Tungslen: II. Dcfinitions and Results", Cornell Materials Science Center Report \#4309 (1980); submitted to Philosophical Magazine. 